\title{
DASERSTE.IARRZETN
}
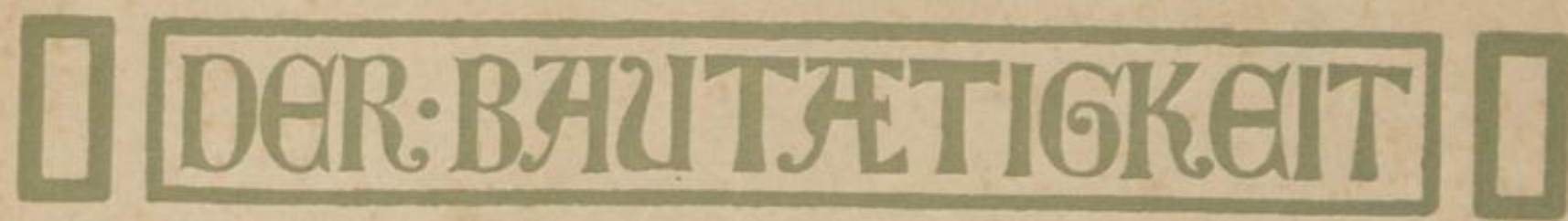

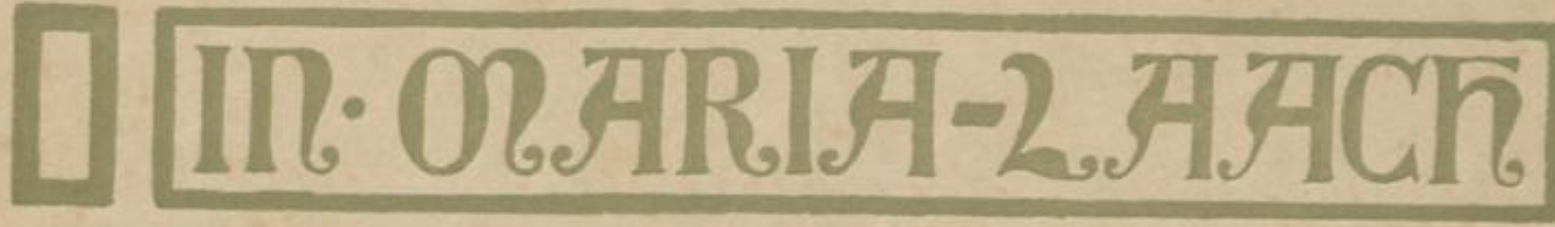

VONPP. HDAIBERT:SCEIPPERS.0.S.B.

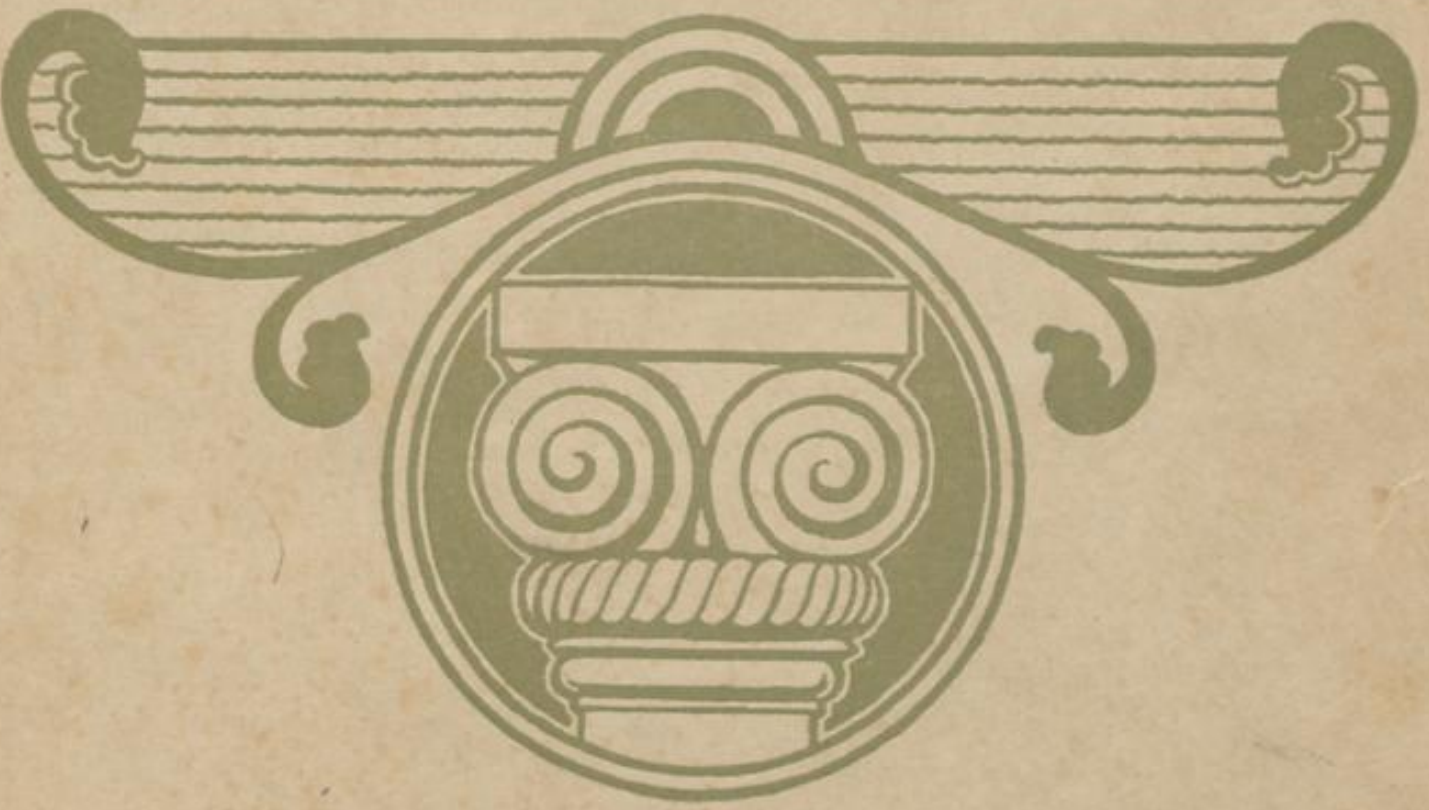

$89 \mathrm{~A}$

112 RUCK.U.VERJAG:VOR:GEORG REIMER

BERLI: 1917 


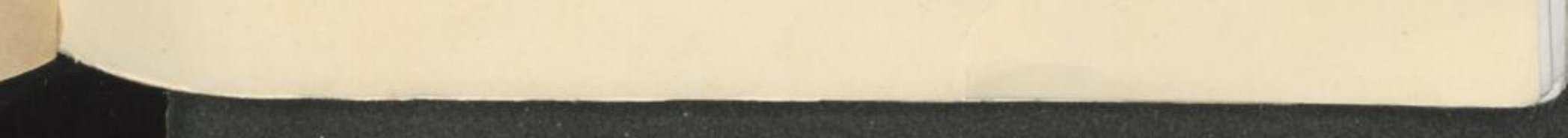




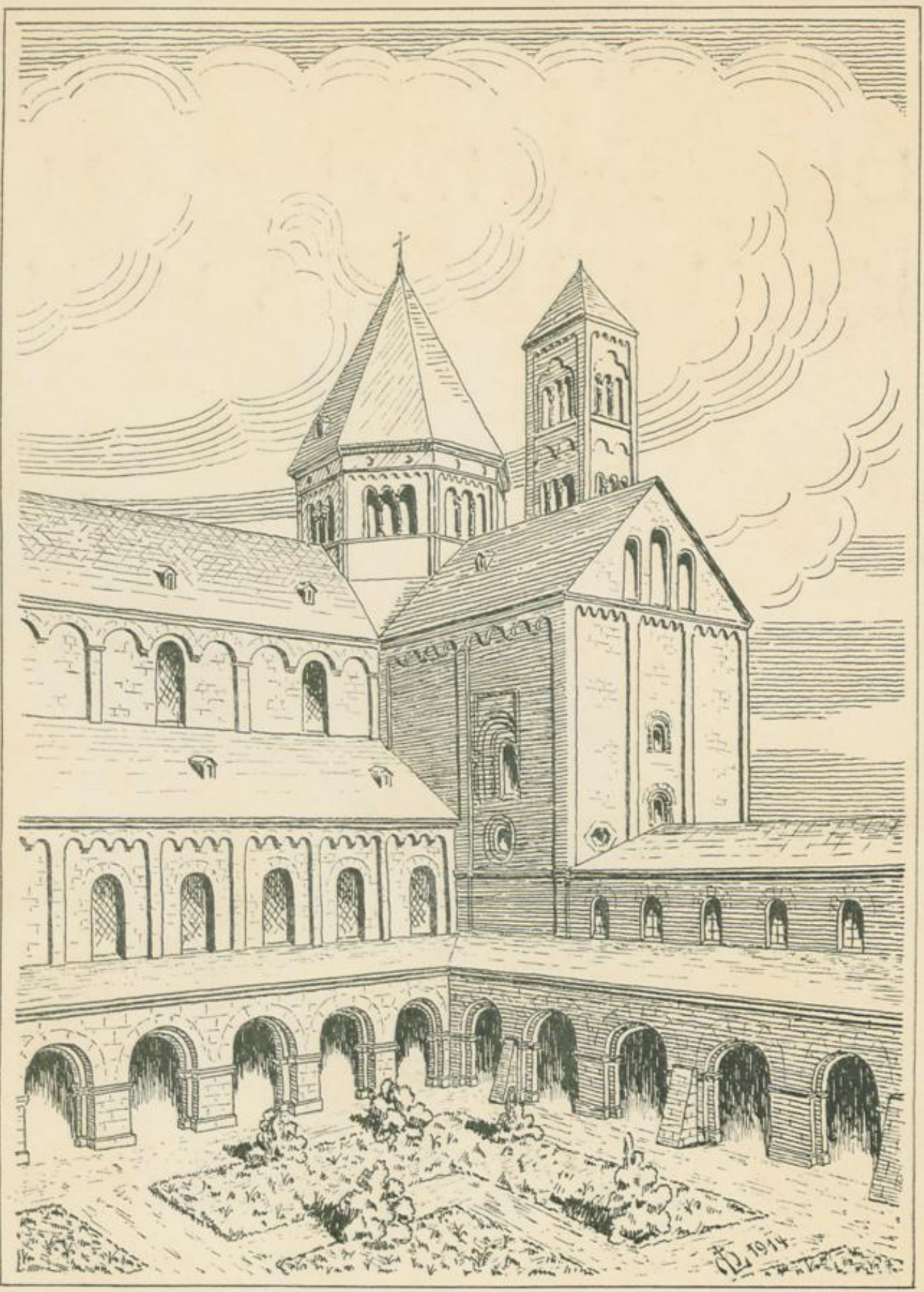

MARIA.LAACH.DER.KREUZGARTEN.IM.MITTELALTER· 


\section{DAS ERSTE JAHRZEHNT DER BAUTÄTIGKEIT IN MARIA LAACH}

\section{VON P. ADALBERT SCHIPPERS O.S.B.}

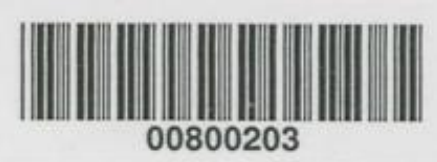

MIT 38 ABBILDUNGEN

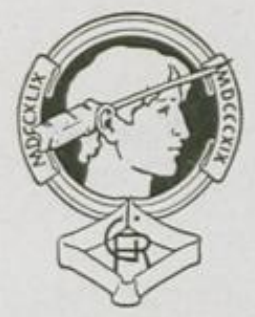

B E R L I N 1917

DRUCK UND VERLAG VON GEORG REIMER 


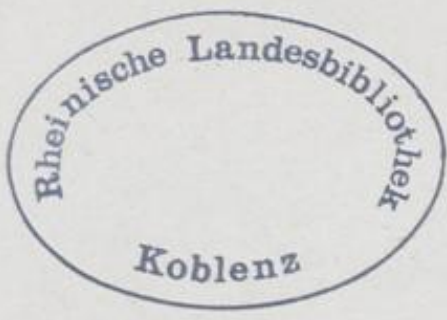

\section{Erläuterung zum Initial.}

Der Mönch des Initials mit dem Reiß-oder Schreibzeug in der Rechten ist der Laacher Benediktiner Lambert, Schreiber des Homeliarius Lacensis (12. Jahrh.). Der Drache findet sich in ganz verwandter Darstellung auch an einem Kapitell der Kirche. Siehe die Beschreibung Seite 33 dieses Werkes. 


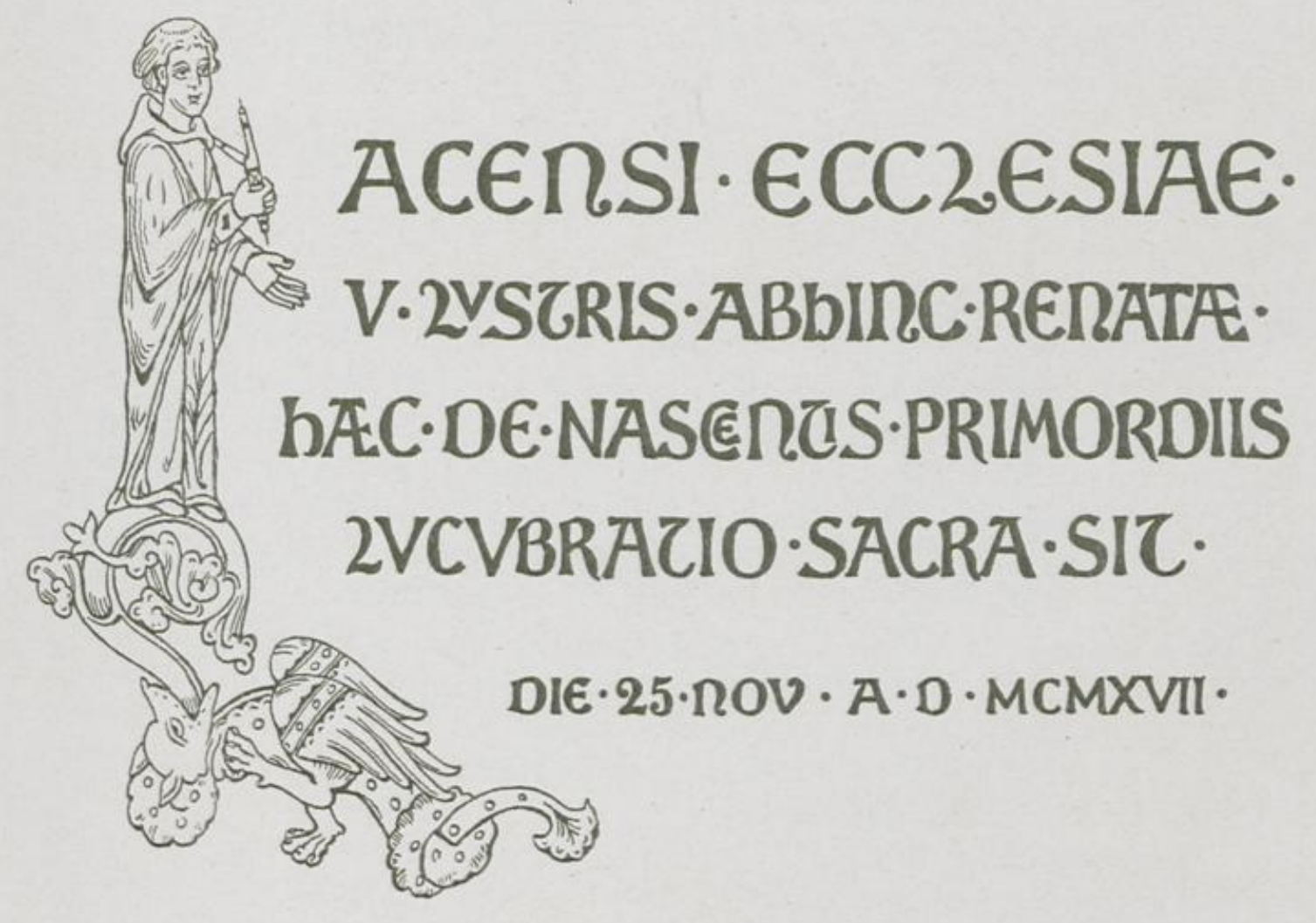




\section{GRÜNDUNG.}

$\mathrm{E}$ in peinliches Dunkel war bisher über die ersten Jahrzehnte derLaacher Klostergeschichte nach der Gründung im Jahre 1093 ausgebreitet. Erst mit der kurz vor II I 3 angefertigten Stiftungsurkunde des Pfalzgrafen Siegfried schien das Tageslicht der Geschichte über dem neuen Laach aufzugehen, in dem die Benediktinermönche das Erbe der rheinischen Pfalzgrafen angetreten hatten. Wir wußten zwar aus der eben genannten Urkunde, daß der Vollzug der Gründung »durch den Bann mehrerer Bischöfe und angesehener Geistlichen " bekräftigt worden war ${ }^{x}$ ), kannten aber, mangels eines Dokumentes hierüber, nicht die wesentlichen Rechtsbestimmungen des Stiftungsaktes. Ebensowenig war bekannt, welchem Kloster Pfalzgraf Heinrich die Neugründung zur Besiedelung übergeben hatte und was aus dem ganzen Unternehmen nach dem frühen Ableben des Stifters geworden war. Und dennoch enthielten die Quellen die Antwort auf diese, besonders den Kunsthistoriker so interessierenden Fragen. Aber weil die Urkunde Siegfrieds diese wichtigen Punkte nicht berührte, gab man die Hoffnung auf, anderswo die gewünschte Aufklärung zu finden.

Das Diplom König Konrads III. vom Jahre 1138 , wodurch den Laacher Mönchen der Bendorfer Hof zurückerstattet wird, gründet seine rechtliche Entscheidung auf eine klare Darlegung aller wesentlichen Momente des Stiftungsaktes. "Wir tun kund», so heißt es dort, sallen Christgläubigen und unseren Untertanen der Gegenwart und Zukunft, daß Pfalzgraf Heinrich, gesegneten Andenkens, von der Liebe Gottes entflammt, eine Kirche zu Ehren der gottseligen Jungfrau Maria auf seinem Erbgut am See erbauen ließ. Unter Mitwirkung und Zustimmung seiner ehrwürdigen Gemahlin Adelheid hat er die Stiftung mit seinen Gütern reichlich und rechtlich ausgestattet und fromme Männer, die das Mönchsleben nach der Regel des hl. Benedikt führen, an dieser Kirche bestellt, um Gott zu dienen. Eilbert, der damalige Erzbischof von Trier, bestätigte die genannte Stiftung samt allem, was der Kirche rechtmäßigerweise vermacht worden war, mit seinem bischöflichen Bann

${ }^{x}$ ) Vgl, den Wortlaut im Anhang des ersten Abschnittes Nr. I S. 8 . 
und Ansehen. Nach dem Ableben des Pfalzgrafen Heinrich erneuerte seine Gemahlin Adelheid die fromme Stiftung ihres Mannes vor vielen Zeugen nochmals, um ihrem Fortbestande noch größere Sicherheit zu verleihen. Einige Zeit darauf gab Pfalzgraf Siegfried, der dem mehrfach erwähnten Grafen Heinrich im Palatinat gefolgt war, meinem Großvater Kaiser Heinrich, glorreichen Andenkens, unter billigen Bedingungen einige seiner väterlichen Güter zu eigen. Da aber sein Besitztum nicht ausreichte, entriß er der Laacher Kirche gewaltsam in Bendorf einen Hof mit allem Zubehör, trotz des beständigen Widerspruches dieser Kirche, und schenkte ihn mit den andern Gütern dem Kaiser, als wenn er sein Eigentum gewesen wäre \& 2).

Diese Königsworte sind der wahre, bisher verkannte Grundstein der Laacher Klostergeschichte. Sie verbürgen die Richtigkeit von dem, was jeder im stillen ahnte. Pfalzgraf Heinrich hat von Anfang an seine Stiftung mit Mönchen, und zwar mit Benediktinern, besiedelt. Ein anderer Weg, seine Absicht zu verwirklichen, war in damaliger Zeit überhaupt kaum denkbar. Das gilt noch besonders in unserem Falle. Der Laacher Stifter trug sich offenbar mit großen Plänen. Er wollte das schönste seiner Erbgüter, wonach er sich in Urkunden mit Vorliebe nannte 3), nicht nur in eine Gott und der allerseligsten Jungfrau geweihte Stätte umwandeln und hier in einem stolzen Münster mit den Seinigen die letzte Ruhe finden. Die Zeitumstände lassen uns noch andere Beweggründe vermuten. Seit dem Jahre roso unternahm bekanntlich Kaiser Heinrich IV. unter der Bewunderung seiner Zeitgenossen einen umfassenden Umbau des Speierer Domes, der auf die Einwölbung des Mittelschiffes im Langhause abzielte. Mußte dieses Beispiel seines kaiserlichen Herrn den reichen und angesehenen Pfalzgrafen, dem es nicht vergönnt war, im politischen Leben eine Rolle zu spielen 4), nicht dazu anspornen, in der von ihm geplanten Abteikirche einen ähnlichen Bau als krönendes Lebenswerk hinzustellen? Die großartige Anlage des Grundplanes, dessen Ausführung der Stifter in den Anfängen noch vor Augen sah, die verschiedenartigen, fremden Baustoffe, die er aus beträchtlicher Entfernung herbeischaffen ließ trotz der Fülle des einheimischen gediegenen Materials, beweisen,

2) Dr. A. Huppertz hat in seiner Schrift: Die Abteikirche zu Laach und der Ausgang des gebundenen romanischen Systems in den Rheinlanden, Straßburg 1913, S. 26 einige Bruchstücke aus dem angeführten Diplom nitgeteilt, die Bedeutung desselben aber irrig ausgelegt. Das zeigt die Art und Weise, wie der Verfasser mit dem Inhalt S. 84 argumentiert. Er läft hier die Urkunde König Konrads sagen, daß Siegfried squedam patrimenia sua e cinige seiner Erbgüter dem Kloster zu eigen gegeben habe. In Wirklichkeit hat er das Gegenteil getan, indem er den Mönchen den Bendorfer Hof entriß, dessen Rückerstattung gerade der Zweck des ganzen Diploms ist. Die fraglichen Erbgüter samt dem genannten Hofgute hat Siegfried, wie die Urkunde klar und deutlich meldet, Kaiser Heinrich IV. geschenkt. Im Texte ist statt revocavit, wie Huppertz schreibt, renovavit zu lesen. Siehe Anhang Nr. 2.

3) Vgi. hierzu meine Abhandlung: Die Stiftungsurkunde Pfalzgraf Heinrichs II. für Laach (ro93) in: Trierisches Archiv Heft XV (1909), S. 53-75, mit 4 Abb.

4) M. Schmitz, Die Geschichte der lothringischen Pfalzgrafen bis auf Konrad von Staufen. (Bonner Dissertation.) Oberhausen 1878 , S. $34-4$ o. 
daß diesem Werke seine ganze Liebe gehörte. Die Kunstgeschichte hat denn auch sowohl am Ostchor als am Westchor unverkennbare Verwandtschaftszüge zwischen den mittelrheinischen Domen in Speier und Mainz und dem Laacher Münster längst festgestellt und räumt ihm aus mehreren Gründen nach diesen den ersten Platz in der deutschen Architekturgeschichte ein. So rücken die beiden Heinriche, die durch ihre politische Stellung und Freundschaft schon eng miteinander verbunden waren, durch ihre Kunstschöpfungen noch näher zusammen. Die Wissenschaft bestätigt demnach unsere Vermutung, daß der Laacher Pfalzgraf in seinem Bauunternehmen unter dem Einflusse der künstlerischen Bestrebungen des Kaisers stand.

Um solche Pläne verwirklichen zu können, mußte Pfalzgraf Heinrich sich vor allem nach geeigneten Männern umsehen. Diese konnte er nirgendwo besser finden als in St. Maximin bei Trier. Diese Abtei war im II. Jahrhundert, besonders unter der Oberleitung des angesehenen Abtes Poppo von Malmedy-Stablo (gest. 1048), gewissermaßen der geistige Mittelpunkt des deutschen Klosterlebens geworden. Sie sandte ihre Mönche als Äbte nach Echternach, Limburg a. d. Haardt, Hersfeld, Weißenburg, M.-Gladbach, St. Peter in Magdeburg, St. Emmeran in Regensburg, ja bis nach St. Gallen. Gerade diese Klöster waren aber auch zugleich die vorzüglichsten Pflegestätten der kirchlichen Baukunst. Die der ersten Hälfte des II. Jahrhunderts angehörenden Münster von Limburg, Echternach und Hersfeld sind dafür beredte Zeugen. Gleichzeitig erhielt der Trierer Dom durch Erzbischof Poppo (IoI6-47) und seinen Nachfolger nach Westen einen großartigen Anbau, der weithin vorbildlich wirkte.

Tatsächlich ist denn auch die berühmteste der Trierer Abteien das Mutterkloster von Maria Laach geworden, wie der bekannte Laacher Prior Johannes Butzbach bezeugt. In seinem oft genannten Schriftstellerlexikon (Auctarium) erwähnt Butzbach auch die wissenschaftliche Tätigkeit des Afflighemer Mönches Osto, der eine Zeitlang in Maria Laach weilte. "Er lebte«, so schreibt Butzbach, "zur Zeit des Mönches Alger, bevor Laach zur Abtei erhoben war, als nämlich der erste Eifer unter den von St. Maximin hierher verpflanzten Brüdern noch blühte und sie nicht unter einem Abte, sondern unter einem Prior standen *5). Näheres über die Persönlichkeit der ersten Laacher Mönche enthielten ohne Zweifel die verschollenen Laacher Geschichtswerke, die Annalen und die Chronik Butzbachs.

Leider war es dem hochsinnigen Stifter nicht vergönnt, die Vollendung des großen Werkes zu sehen. Schon zwei Jahre nach der Gründung starb er unerwartet

5) Claruit tempore Algeri monachi predicti, ante abbatiam Lacensem, quum scilicet primus adhuc sanctitatis fervor in fratribus de sancto Maximino huc locatis, non sub abbate sed priore aliquo optime viguit. Auctarium de Scriptoribus ecclesiasticis, Hdschr. 356 Fol. 138, Bonn, Univ. Bibl. Vgl. auch Gieseler, Symbolae ad historiam monasterii Lacensis. Bonnae 1826. Der Corveyer Mönch Alger starb um das Jahr ${ }_{11} 30$. 
schnell dahin am 23. Oktober 1095. Die Totenbücher von St. Maximin und Maria Laach erwähnen übereinstimmend sein Gedächtnis an diesem Tage. Keiner der bedeutenderen zeitgenössischen Geschichtschreiber unterließ es, das Ereignis in

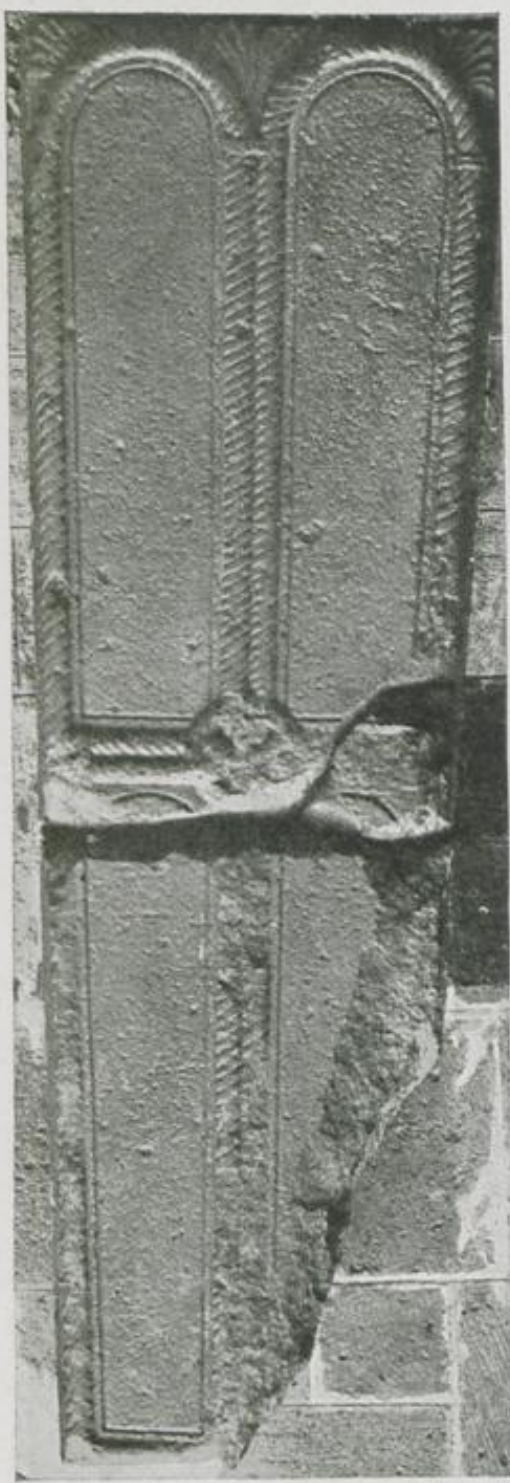

Abb, 2. Grabstein aus Maria Laach. seine Annalen aufzunehmen. Der Laacher Stifter fand seine Begräbnisstätte, wie aus einem Schriftstück aus der Mitte des I3. Jahrhunderts hervorgeht, im Kreuzgang vor dem Portal des Kapitels ${ }^{6}$ ). Für diese Tatsache liefert uns selbst noch am Ende des 17. Jahrhunderts der pfälzische Historiker Tolner eine interessante Bestätigung. . Er besuchte im Jahre I699 zu Studienzwecken für seine pfälzische Geschichte die Stiftung der Pfalzgrafen am See. und besichtigte unter Führung des Priors Klemens Aach das Kloster und die Überreste der Laacher Burg. "Der Stifter", so berichtet er, "wurde begraben in dem von ihm gegründeten Kloster, und zwar zuerst im Kreuzgang vor dem Kapitel, wo heute noch ein mächtiger Stein zu sehen ist 47 ).

Dieser "mächtige Stein «, den Tolner gesehen hat, ist uns vielleicht noch erhalten in der Grabplatte, die Abb. 2 vorführt. Ich schließe das aus der Größe, aus dem Mangel einer Inschrift, die der Geschichtsforscher ohne Zweifel aufgezeichnet haben würde, und aus der reichen Verwendung des Tauwerkes, das, wie wir sehen werden, die Ornamentik der Laacher Frühzeit bevorzugt. Selbst die Querbändchen am Seilgewinde sprechen dafür. Palmetten, wie die am Haupte des Steines, erfreuen sich am Rheine bereits seit dem 10. Jahrhundert auf Grabsteinen

6) Ossa fundatoris Henrici comitis palatini ex ambitu (stehende Bezeichnung für Kreuzgang) ante fores capituli anno 1255 ad medium navis ecclesiae translata ... fuerunt. Westdeutsche Zeitschrift XVII (I893), S. 107.

7) L. C. Tolner, Historia palatina c. XI, S. $279 \ldots$... In castro et sede sua ad Lacum cuius rudera in colle in aquas prominente hoc anno 1699 4. Kal. Oct. duce Clemente Aach eiusdem monasterii priore inspexi. Sepultus in eodem Monasterio a se condito et quidam 1 . in ambitu ante locum capitularem, ubi hodieque ingens lapis conspicitur, 2, in media ecclesia, 3. sub organo in mausoleo. 
ausgesprochener Beliebtheit ${ }^{8}$ ). Die Grabplatte ist $2 \mathrm{~m}$ lang, unten 50 , oben $68 \mathrm{~cm}$ breit. Der Umstand, daß sie wenig ausgetreten ist, dürfte darin seine Erklärung finden, daß sie soviel über den Bodenbelag hervorragte, als das aus einem Viertelkreis be. stehende Profil der Langseiten andeutet. Unter den wenigen Grabsteinen, die uns aus dem II. Jahrhundert im Rheinland erhalten sind, ist er ohne Zweifel einer der bemerkenswertesten.

Auf dem Sterbebette hatte Pfalzgraf Heinrich seinen Stiefsohn Siegfried zu seinem Erben eingesetzt und ihm die Pflicht auferlegt, die begonnene Stiftung zu vollenden. "Als junger Mann k kümmerte er sich anfangs längere Zeit nicht um die Erfüllung der übernommenen Verpflichtung. Da griff seine Mutter Adelheid ein. Ihr verdankte die fromme Stiftung nicht nur, wie die Urkunde Siegfrieds uns verrät, die erste Anregung 9). Nach dem Diplom Konrads III, vollzog sich auch die Dotierung und die nähere Bestimmung über die Bewohner unter der Mitwirkung und Einwilligung der Pfalzgräfin ${ }^{10}$ ). Eine solche Erwähnung ihrer Person bei diesem Rechtsgeschäfte würde aber keinen Sinn haben, wenn sie zur Gründung aus ihren Erbgütern nicht mit beigesteuert hätte. Dem entspricht auch ihr weiteres Verhalten. "Nach dem Tode ihres Gemahls ließ sie in Gegenwart vieler Zeugen die fromme Stiftung noch einmal wiederholen, um dadurch ihrem Fortbestande größere Sicherheit zu verleihen ${ }^{\prime I}$ ). In welcher Weise sie die damit bekundete Gesinnung gegen das Laacher Gotteshaus durch tatkräftige Förderung des Weiterbaues der Kirche an den Tag legte, wird die Baugeschichte lehren. Auf einer Romreise begriffen, starb Adelheid im Jahre $I_{100}{ }^{12}$ ). Ich möchte die Vermutung aussprechen, daß die Pfalzgräfin sich auch deshalb zur Reise in die ewige Stadt entschloß, um durch die Erwirkung einer päpstlichen Bulle ihre Stiftung vor den unter Heinrich IV. nicht seltenen Entfremdungen kirchlicher Güter zu schützen. Diese Vermutung steigert sich zur Wahrscheinlichkeit, wenn Adelheid eine Ahnung davon hatte, was ihr Sohn nachher wirklich ausführte.

Siegfried schenkte Kaiser Heinrich IV. unter billigen Bedingungen einige seiner Güter, und da diese nicht ausreichten, fügte er den Klosterhof in Bendorf hinzu. Im selben Augenblicke hören wir nun auch die Stimme der Laacher Benediktiner, die gegen diesen Gewaltakt des Pfalzgrafen protestiert; semper ecclesia reclamante. Als Apposition zu necclesie b. Marie apud Lacum»lassen diese Worte

8) Drei Beispiele aus Bonn siehe bei Clemen, Die Kunstdenkm. d. Stadt u. d. Kr. Bonn, 1915, S. 106, Abb. 54-56. Zwei weitere Beispiele aus romanischer Zeit finden sich in Maria Laach.

9) Exhortante uxore sua Athelheide videlicet matre mea. S. Anhang Nr. 1.

to) Astipulante et assentiente honorabili coniuge sua Adelheide. Vgl. Anhang Nr. 2.

ir) S. Anhang Nr. 2.

${ }^{12}$ ) Adela sive Adelheit palatina Romam pergens defuncta est. Annalista Saxo, ad annum 1100. Mon. Germ. SS. VI, S. 733. Romreisen orationis causa waren im 11. und 12. Jahrhundert nichts Ungewŏhnliches. S. Hauck, Kirchengeschichte Deutschlands 3 (1896), S. 485 , Anm. I. 
deutlich den Nachdruck herausfühlen, den man in sie legen wollte ${ }^{13}$ ). Die Mönche haben von Anfang an und bei jeder günstigen Gelegenheit ihren Einspruch erneuert. Das zeigt uns, daß das Maximiner Priorat am See ununterbrochen fortbestanden hat. Hierfür legt Siegfried selber einige Jahre später in seiner Stiftungsurkunde einen neuen Beweis nieder. "Was ich zuerst in jugendlichem Leichtsinne vernachlässigte, habe ich später, von Reue ergriffen, aufs beste gutzumachen gesucht. So ließ ich die der Kirche benachbarte Burg mit Rücksicht auf die Ruhe der Brüder niederlegen, und habe die bis dahin dazugehörigen Güter den Brüdern, die dort Gott und der allerseligsten Jungfrau dienen, übergeben\&. Die Präsensform sfratribus ibi Deo et b. Marie famulantibus " kann unmöglich anders verstanden werden als von Mönchen, die zur selben Zeit in Maria Laach wohnten, als die Urkunde abgefaßt wurde. Diese Mönche waren keine anderen als die von St. Maximin gekommenen Gründer, die Siegfried nun aber dem Abte von Afflighem unterstellte, aus dem Grunde, weil beide Klöster auf seinem Eigentum lagen. Wir dürfen daraus entnehmen, daß der Pfalzgraf, nach Zerstörung seiner Laacher Burg, keine Hoffnung mehr hegte, sich fernerhin noch der Stiftung seiner Eltern annehmen zu können ${ }^{14}$ ). Unter diesen Umständen glaubte er dadurch am besten für ihr Fortkommen zu sorgen, daß er sie der seit $\mathrm{IO}_{3}$ neugegründeten, frisch aufblühenden Brabanter Abtei unterstellte, die ihm ja auch als Patron verpflichtet war ${ }^{15}$ ).

Abt Fulgentius entsandte nun den Laacher Brüdern eine Verstärkung aus seinen Mönchen. Soweit die Quellen uns einen Einblick gestatten, waren es Schreiber und Schriftsteller, wie der oben genannte Osto. Baukünstler unter ihnen zu suchen, haben wir um so weniger Grund, als erst der II 20 gewählte zweite Abt Franko den Bau der Afflighemer Basilika unternahm ${ }^{16}$ ).

x3) Vgl. den Urkundentext Anhang Nr. 2.

x4) Über die Zerstörung der Laacher Pfalz vgl. I. Herwegen, O. S. B., Die lothringischen Pfalzgrafen und die niederrheinischen Benediktinerklöster. Annalen d. Hist. Vereins f. d. Niederrhein Heft 89 (1910), S. $46 \mathrm{ff}$.

15) Pfalzgraf Siegfried starb an den Wunden, die er im Gefechte bei Warnstedt gegen Hoier von Mansfeld erhielt, am 9. März $\mathrm{II}_{3}$. Seine letzte Ruhestätte fand er in der benachbarten, von ihm gestifteten Klosterkirche Herrenbreitungen an der Werra. Erzbischof Adalbert von Mainz verlieh dieser Kirche im Jahre 1112 auf Bitten Siegfrieds das Tauf- und Begräbnisrecht. Nach der Ausdrucksweise der Urkunde darf mit Sicherheit angenommen werden, daß die Abteikirche in dem genannten Jahre vollendet war. (Concessimus baptismale Sacramentum et christianam sepuituram ..... ecclesiae in Breitingen sitae, scilicet ut omnis populus ..... ad ecclesiam beati Michaelis matrem et parochiam Deo canonice dedicatam..... recurrant.) Die Gründung dürfte daher wohl noch zu Lebzeiten Adelheids, vor Inoo, erfolgt sein, was auch die Formensprache des Baues bestätigt. Diese Tatsache läßt uns die Vernachlässigung der Laacher Stiftung durch Siegfried etwas milder beurteilen. Seine Grabschrift lautet nach Crollius (Erläuterte Reihe der Pfalzgrafen zu Aachen, 1762, S. 280-28I): Septima idus martii aõ. MCXXIV (statt XIII) obiit Sigfrid. palatinus comes de Orlamunde fundator istius ecclesiae. Cuius anima requiescat in pace. Der unzweifelhafte Irrtum im Datum dieser Inschrift ist P. Weber entgangen in seiner Abhandlung: Die Ausgrabungen im Kloster Herrenbreitungen an der Werra, mit $6 \mathrm{Abb}$. auf 4 Taf. und $\mathrm{II}$ Textbildern, in: Monatshefte für Kunstwissenschaft, 5. Jahrg. (1912), 5. Heft, S. $177-184$.

16) Ao. I 120 obiit domnus Fulgentius abbas primus Affligemensis..... Succedit dominus Franco..... 
Mit der Unterordnung des Laacher Priorates unter das Brabanter Kloster, die übrigens nur I4 Jahre bis zur Wahl des ersten Laacher Abtes Gilbert, II27, dauerte, waren die Beziehungen zum Trierer Mutterkloster nicht unterbrochen. Das Totenbuch von St. Maximin enthält die Namen der beiden Pfalzgrafen, Heinrich und Siegfried, und fast aller Laacher Äbte bis auf Kuno (gest. I326).

\section{ANHANG.}

I. Pfalzgraf Siegfried erneuert die Stiftung der Abtei Maria Laach.

I. n. s, e. i. tr. Ego Sifridus gratia dei comes palatinus, notum esse volo fidelibus, qualiter et a quibus ecclesia que vocatur Lacus constructa sit et libertati tradita. Predecessor et dominus meus Heinricus comes palatinus exhortante uxore sua Athelheide videlicet matre mea predictam ecclesiam edificare cupiens, fundamentum eius tantummodo posuit et iam morte imminente, sicut bonorum suorum ita huius quoque laboris ecclesie scilicet perficiende heredem me instituit. Quod primum quidem utpoteiuvenis negglexi, postmodum vero penitentia ductus, quod negglexeram devotissime corrigere studui. Itaque castellum ecclesie vicinum quieti fratrum prospiciens destruxi, et bona ad ipsum prius pertinentia fratribus ibi deo et b. Marie famulantibus tradidi, ipsumque locum cum omnibus appenditiis suis haffligeniensis cenobii abbati et successoribus suis perpetuo regendum tradidi, ea videlicet consideratione, ut quia uterque locus in allodio meo situs erat, unius eiusdemque abbatis gubernaretur providentia.

Nun folgen Bestimmungen über die gemeinsame Abtswahl beider Klöster. Hieran schließt sich das Vogteirecht über die fratres und familia von Maria Laach.

Advocatum vero non alium quam me ipsum quamdiu vixero ecclesie constituo. $\mathrm{Me}$ autem defuncto cuicumque filiorum meorum vel in posterum cuicumque heredum. meorum bona mea lacum circumiacentia obvenerint hunc advocatum sibi fratres assumant, si tamen decretum a me constitutum et hic subscriptum observaturum se esse promiserit, si bona ecclesie viriliter tueri et familiam eius clementer et humane tractare voluerit. Noverit itaque omnimodo sibi observandum, ne advocatiam vel coniugi sue in dotem vel alicui in beneficium dare praesumat, ne alium pro se substituat, ne aliquando in bonis ecclesie hospitando ecclesiam vel familiam eius gravet, ne servitia ab ea, ne iniustas exactiones quas precarias vocant aliquando exigat. De placitis autem ad advocatum iure pertinentibus, ubi abbas duos nummos acceperit, tercius eius erit. In quo tamen suscipiendo vel in alio quolibet negocio cum familia ecclesie peragendo, nullus alius minister advocati, neque vicarius neque subadvocatus preerit, nisi ille solummodo, qui villicus abbatis fuerit. Ad pla-

Basilicam Affligemensem fundavit, libris et ornamentis eam decoravit ..... Sigeberti auctarium Affligemense, Mon. Germ. SS. VI, S. 400 . 
citum autem nunquam veniet nunquam consedebit nisi a fratribus sires ita poposcerit invitatus fuerit. Cum vero invitatus venerit subscriptum tantum servitium a fratribus habebit. Duo maldre ad panem vespere, unum mane; ad pabulum equorum $\mathrm{X}$ maldre hieme, $\mathrm{V}$ estate; duos porcos, $\mathrm{V}$ solidorum vespere, unum $\mathrm{XXX}$ denariorum mane; hamam vini vespere, dimidiam mane. Ita autem agat et tam pium, tam modestum, tamque benignum fratribus et familie se exhibeat ut et honore nominis sui dignus existat et pro officio fideliter amministrato eternam a Christo remunerationem b. Maria interveniente suscipiat. Quod si timoris dei oblitus quos fovere debuerat violenter oppresserit et ammonitus infra VI ebdomadas non satisfecerit, tandem apostolico anathemate percussus, advocatiam amittat et de propinquis eius idoneum sibi fratres eligant qui sub predicta conditione eam amministraturus suscipiat.

Preterea desidero et quantum de mortuo vivens possum firmiter statuo, ut ubicumque in provincia vita excessero, nusquam nisi in eadem ecclesia sepeliar. Idem de uxore mea et filiis nostris et de advocatis omnibus et advocatorum proximis fieri maxime volo et constituo.

$\mathrm{Ne}$ autem quisquam heredum vel successorum meorum aliquam iniuriam domino deo et $\mathrm{b}$. Marie quandoque inferre intendat de bonis a domino meo Heinrico palatino comite et a me quoque sibi collatis ea nominatim supponi placuit. Ipse quidem tradidit et episcoporum atque electorum sacerdotum banno confirmari fecit Croth cum ecclesia, Bella, Reyde, Alkene, Willeberch ${ }^{77}$ ). Ego vero donationem eius confirmando renovavi et insuper quatuor mansus de Croth, Hoverhof et Meylem de Brabant addidi atque banno similiter et probatis testibus confirmavi. Haec inquam b. Marie tradidimus cum omnibus appenditiis suis .....

Mittelrhein. Urkundenbuch I., S. $487-488$.

2. König Konrad III. stattet der Abtei Maria Laach den Hof zu Bendorf zurück. II 38 .

I. n. s. c. i. tr. Cunradus divina favente clementia Romanorum rex secundus. Ad hoc dei ordinatione constitutos credimus principes seculi tanquam cedros libani ut sub eorum defensione nidificent id est quiete conversentur pauperes Christi. Ad muniendam igitur quietem humilium spiritu notum facimus cunctis Christi nostrique fidelibus, tam futuris quam presentibus, qualiter bone memorie Heinricus Palatinus comes, divino amore illustratus, ecclesiam unam in honore b. Marie perpetue virginis apud lacum in predio suo a fundamentis erexit, quam, astipulante et assentiente honorabili coniuge sua Adelheide, de suo patrimonio large et legitime dotavit et viros religiosos monachicam vitam et regulam s. Benedicti sequentes ad serviendum deo in ea ordinavit. Huius ergo tam piam largitatem Eilbertus eo tempore Trevirorum archiepiscopus cum merito approbasset, omnia que eidem ecclesie iuste erant tradita, banno et episcopali auctoritate confirmavit. Post mortem quoque predicti palatini comitis Heinrici, iam nominata coniunx sua Adel-

17) In der Güterliste fehit Bendorf aus dem oben angeführten Grunde. 
hedis pium factum mariti sui ad maioris stabilitatis augmentum, coram multis iterum renovavit. Deinde aliquanto tempore elapso, Sigefridus palatinus, qui prefato comiti in palatii comitatu successit, quedam patrimonia sua, per quasdam condictiones equas, avo nostro Heinrico, dive recordationis imperatori augusto, in proprium tradidit, et cum sua predia non sufficerent, unam curtim, que est in Bettendorph, ecclesie b. Marie apud Lacum, semper ecclesia reclamante, cum omnibus appendiciis suis violenter abstulit et imperatori, tamquam sua esset, inter cetera donavit. Postquam ergo divina dignatio nos ad regni solium provexit, superna illustratione commoniti veritatem cognoscentes, iniuriam illatam prefate ecclesie Dei genitricis Marie recognovimus et prenominatam curtim in Betthendorph b. Marie iniuste ablatam cum omnibus appendiciis ..... in presentia principum resignavimus et in perpetuum sine contradictione cuiusquam transfudimus.

Mittelrhein. Urkdbch. I., S. $55 \mathrm{I}-55^{2}$.

\section{BAU DES KLOSTERS UND DER KIRCHE BIS ZUM TODE PFALZGRAF HEINRICHS (1095).}

Die bisherigen Ausführungen haben die ersten Jahrzehnte der Laacher Klostergeschichte klargestellt. Pfalzgraf Heinrich legte die Ausführung des großen, von ihm geplanten Unternehmens von Anfang an in die sachkundigen Hände der Mönche von St. Maximin. Das erste, womit begonnen werden mußte, war selbstverständlich die Errichtung des Klosters, das zugleich als Bauhütte dienen sollte. Wie wir später sehen werden, wurde die $68 \mathrm{~m}$ lange Kirche nicht etwa vorläufig teilweise, sondern von vornherein in ihrem ganzen Umfange in Angriff genommen. Daraus ergab sich ein großer Baubetrieb, der viele Hände beschäftigte. Die Schar der Bauleute gehörte hauptsächlich drei Gruppen an. Es waren die Mönche als Künstler und Steinmetze mit dem Baumeister an der Spitze; dann die von auswärts herbeigezogenen, freien Handwerker und endlich die umwohnenden Untertanen des Pfalzgrafen, welche Handlanger- und Spanndienste leisteten. Die letzteren waren durch die Klosterstiftung vielfach Gotteshausleute geworden und bildeten die familia, wovon in der Stiftungsurkunde Pfalzgraf Siegfrieds wiederholt die Rede ist ${ }^{18}$ ). Da das Kloster außer den Mönchen auch den Handwerkern Obdach bieten mußte, so dürfen wir uns seinen ersten Umfang nicht gering vorstellen. Auf Grund der Nachricht über das Grab des Stifters und der erhaltenen Bauüberreste müssen wir annehmen, daß die älteste Anlage wenigstens die Gebäude umfaßte, welche sich nach drei Seiten an den Kreuzgang anschlossen.

Pfalzgraf Heinrich wurde, wie wir gehört haben, im Jahre 1095 vor dem Portal des Kapitels im Kreuzgange begraben ${ }^{19}$ ). Der Kapitelsaal hatte in den mittel-

\footnotetext{
$\left.{ }^{18}\right) \mathrm{Vgl}$. den Anhang des I. Teiles Nr. I, S. $7-8$.

x) Siehe oben S. 4 .
}

Schippers, Maria Laach. 
alterlichen Benediktinerklöstern seinen unabänderlichen Platz im Ostflügel. Im Obergeschoß desselben wurde stets das Dormitorium eingerichtet. Aus dem im ersten Teile S. 4 angeführten Berichte Tolners über die Grabstätte des Stifters geht hervor, daß dieser Ostflügel noch bis zum Jahre 1699 seine ursprüngliche Einrichtung in wichtigen Punkten bewahrt hatte. Leider ist dieselbe in den umfangreichen Neubauten des I8. Jahrhunderts fast vollständig untergegangen.

Dagegen sind uns vom Süd- und Westflügel bedeutende Teile des Urbaues erhalten geblieben $\left.{ }^{20}\right)$. Bei der Restauration des Refektoriums und des Kreuzganges im Südflügel traten an der Zwischenmauer oben sieben romanische Fenster zutage, welche ehemals den Speisesaal von Norden her erleuchteten. Unten fand sich der Anschnitt der fünf rechteckigen Gewölbe des Kreuzganges. Die Mauer

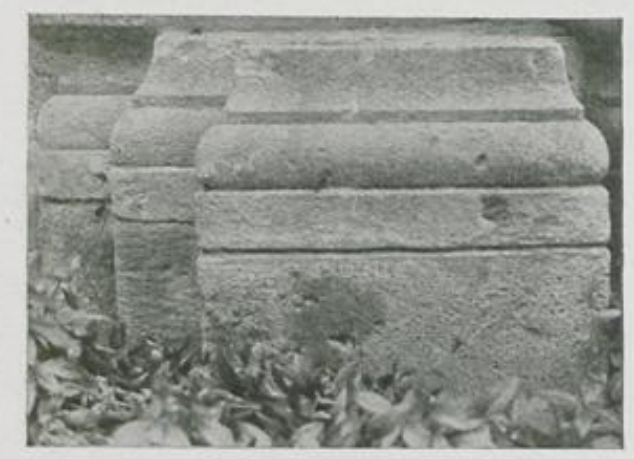

Abb. 3. Pfeilerbasis des Kreuzganges.

selber zeigte einen sorgfältigen Quaderbau aus dem gelben Laacher Tuff ohne Beimischung eines andersfarbigen Tuffes. Wir werden sehen, daß die aus. schließliche Verwendung des gelben Tuffes überall an den ältesten Teilen des Klosters und der Kirche wiederkehrt. Die drei östlichen Joche des Kreuzganges vor dem Refektorium begleitete der Waschraum. Glücklicherweise sind von demselben noch so viele Überreste vorhanden, daß die von mir versuchte Rekonstruktion seiner originellen Anlage in allen wesentlichen Punkten das Richtige treffen dürfte $\left.{ }^{2 r}\right)$. Die erhaltene Pfeilerbasis zeigt dasselbe Profil wie der Sockel an der Ostfassade der Kirche: Viertelkreis, Plättchen, Pfühl, Plättchen, Platte. Nur ist die Umrißlinie im Kreuzgang steiler. (Abb. 3 u. 5.)

Die beiden westlichen Joche vor dem Refektorium sind an der Außenseite durch einen abgeböschten Strebepfeiler verstärkt. (Abb. 4.) Er ist in der fein-

to) Vgl. hierzu meine Schrift: Maria Laach und die Kunst im 12. und 13. Jahrh., mit über 50 Abb. Trier, Mosella-Verlag, 19II, Die romanische Klosteranlage, S. 70 ff. und die Abb. 26-29.

21) A. a. O., Abb. 29, 2. Ähnliche Lavatorien aus spätgotischer Zeit gibt es heute noch in England, z. B. am Kreuzgange der Kathedrale von Gloucester. 
körnigen Niedermendiger Lava ausgeführt, die neben der grobkörnigen des Laacher Veitskopfes an den frühesten Bauteilen auftritt. Die Höhe beträgt $1,83 \mathrm{~m}$, die Breite $0,54 \mathrm{~m}$ und die Tiefe über dem Sockel $0,70 \mathrm{~m}$. Genau dieselben Vorlagen zeigt der westliche Flügel des Kreuzganges an den vier Pfeilern, die den fünf rechteckigen Gewölben als Stützpunkt dienen. Die Ähnlichkeit erstreckt sich bis aufs Kleinste, und es besteht kein Zweifel, daß sie alle gleichzeitig und nach demselben Entwurf hergestellt wurden. Alle ruhen auf demselben, rundum gleichmäßig vorspringenden Sockel. Der Rücken wird unten und oben überall durch einen einzigen Quader abgeschlossen. Dazwischen liegen drei oder vier Schichten von je zwei Werkstücken. Die Breite der Fugen beträgt meistens nur $\mathrm{I}-2 \mathrm{~mm}$.

Ähnliche Strebepfeiler wie unser Kreuzgang weist bekanntlich der des Bonner Münsters auf. Sie gehören dem Baue Gerhards von Are (vor II69) an. Da sie bisher zu den ältesten Beispielen ihrer Art zählten 22), möchte ich besonderen Nachdruck auf den Beweis legen, daß unsere Strebepfeiler mit dem Kreuzgang gleichzeitig sind und aus dem Ende des II. Jahrhunderts stammen. Die fünf Widerlager stehen überall und in der gleichen Weise mit der Mauer in sehr sorgfältigem Verbande, so daß der Gedanke an eine spätere Zutat ausgeschlossen ist. Ihre Basaltquadern lassen vielfach noch deutlich den Randschlag erkennen, der

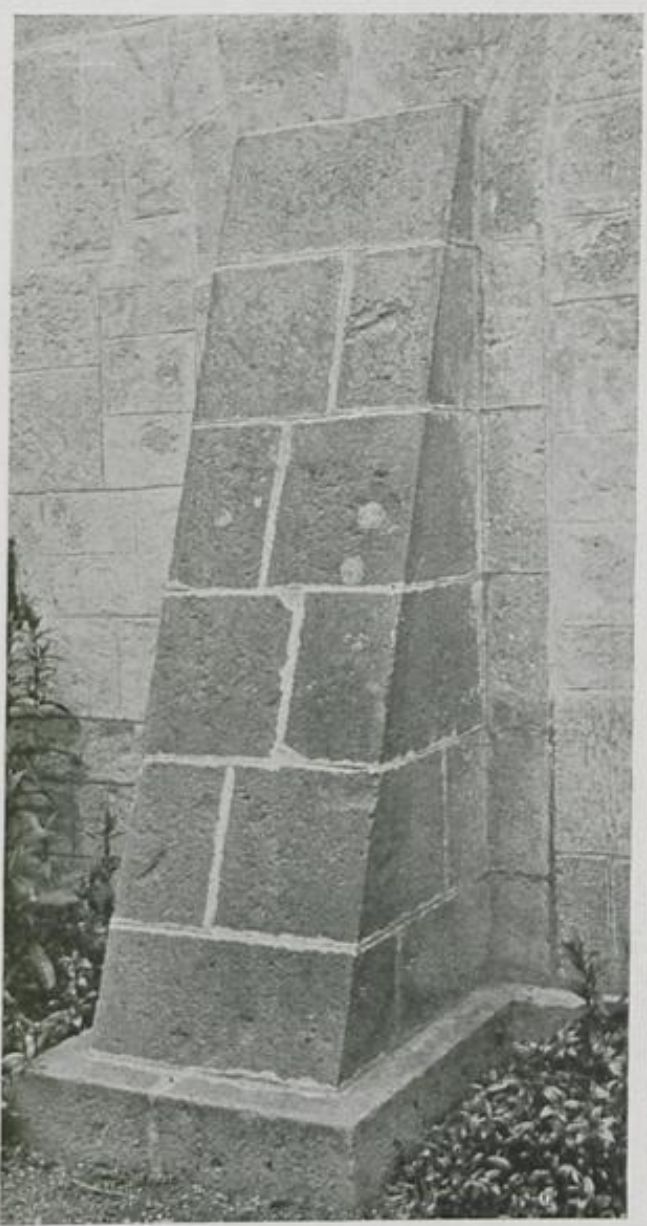

Abb. 4. Strebepfeiler des Kreuzganges. auch sonst die Werksteine der ältesten Bauteile auszeichnet. (Siehe Abb. 4.) Die Pfeiler ohne Streben, die mit den anderen die zehn Arkaden bildeten, wodurch das klösterliche Atrium sich auf allen vier Seiten nach dem inneren Lichthof öfnete, zeigen als Sockel-

2z) Vgl. Effimann, Der Kreuzgang an der Münsterkirche zu Bonn, Deutsche Bauzeitung, 1890, Nr. 40, S. 237. Clemen, Die Kunstdenkm. d. Stadt u. d. Kr. Bonn, 1905, S. 98 ff. C. Hauptmann hält die Strebepfeiler des Bonner Kreuzganges für eine spätere Zutat. Die Münsterkirche in Bonn und ihr Kreuzgang, mit 90 Abb. Bonn (1915), Verlag der Rhenania-Druckerei. 
profil die einfache Schräge. Die Reste der beim Umbau abgeschlagenen Kämpfer sind sowohl am West-als am Südflügel des Kreuzganges an ihrer ursprünglichen Stelle noch zu erkennen. Sie waren in einem grünen Phonolith ausgeführt, dessen Verwendung nur am Kreuzgang bekannt ist. Dieser Stein kommt in der Laacher Umgegend nur in losen Blöcken am Schorenberg bei Rieden vor. Wieder Umstände, die auf die früheste Bauzeit hinweisen, die sich durch die Vorliebe für ver-

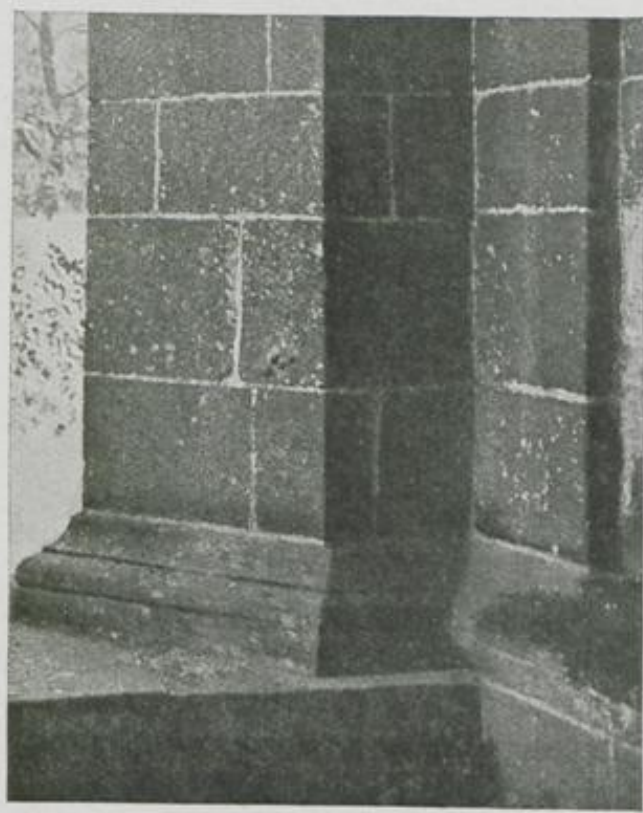

Abb. 5. Strebepfeiler am Ostchor der Kirche. schiedenfarbiges und fremdes Material auszeichnet. Auch die Schichten aus gelbem Laacher Tuff, die über den erwähnten Kämpfern sämtlicher Pfeiler lagern, bekräftigen das Gesagte.

Sehr lehrreich ist endlich ein Vergleich der Vorlagen des Kreuzganges mit den Strebepfeilern unseres Ostchores, die wir bis zur Höhe von $3 \mathrm{~m}$ vor 1095 ansetzen müssen. (Abb. 5.). Diese Stützen übertreffen die anderen Widerlager bedeutend sowohl in technischer Hinsicht als in bezug auf die künstlerische Form. Die letztere trägt in der fünfteiligen Anlage schon etwas von gotischer Eleganz an sich. Beide Ausbildungen des Strebepfeilers, womit Maria Laach allen deutschen Bauten vorauseilt, offenbaren schon den Geist des großen Meisters, der den Plan des Laacher Münsters entworfen hat.

An der Nordseite ist das Kloster aufs innigste mit der Kirche verwachsen. $\mathrm{Da}$ die Trennungsmauer zwischen beiden schon bei der Errichtung des Klosters dem Plane der Kirche angepaßt werden mußte, so enthält ihre Anlage über die erste Gestaltung dieses Planes die wertvollsten Aufschlüsse. Sie hat sich naturgemäB auch am besten erhalten. So ist die Rekonstruktion des alten Klosters dort am leichtesten, wo sie für uns mit Rücksicht auf die Erkenntnis des ursprünglichen Kirchenplanes die größte Bedeutung hat.

An der Außenwand des südlichen Seitenschiffes zeigen die Lisenen noch heute die Gewölbekämpfer des alten Kreuzganges, Abb. ${ }^{23}$ ). Sie weisen vier verschiedene Profile auf. Am häufigsten kehrt die Umstellung der attischen Folge wieder, der Wulst zwischen zwei Kehlen, Abb. 6, Nr.,3. Das erste Profil auf Abb. 6 hat ein Gegenstück am Westchor, Abb. I2 Nr. 6. Das zweite mit der einfachen Schräge und dem

5) Vgl. hierzu auch die Aufnahmen der Meßbildanstalt. 
Wulst darunter kommt nur einmal vor. Bezeichnend für die Frühzeit ist der Um. stand, daß die Umrißlinie bei allen sehr steil verläuft. Das erkennt man am besten, wenn man die Zeichnung auf den Kopf stellt. Zwischen den Kämpfern wurde der Anschnitt der zehn quadratischen Gewölbe gefunden, welche hier mit Rücksicht auf die Fenster des Seitenschiffes an die Stellè der fünf rechteckigen im übrigen Kreuzgang treten mußten.

Das Gurtgesimse an der Westwand des südlichen Querschiffes setzte sich ursprünglich in gerader Linie am Ostflügel des Klosters als Dachgesimse fort. Dort wo das Gurtgesimse jetzt aufhört, sieht man an den Quadern der Kirche noch die $4 \mathrm{~cm}$ breite Fase, welche vom Querschiff zum Klosterbau überleitete. Dem Dache des Ostflügels war an der Kirchenwand wenig Spielraum gelassen. Es mußte sich unter den drei kleinen Fenstern halten, die im Innern der Kirche von den
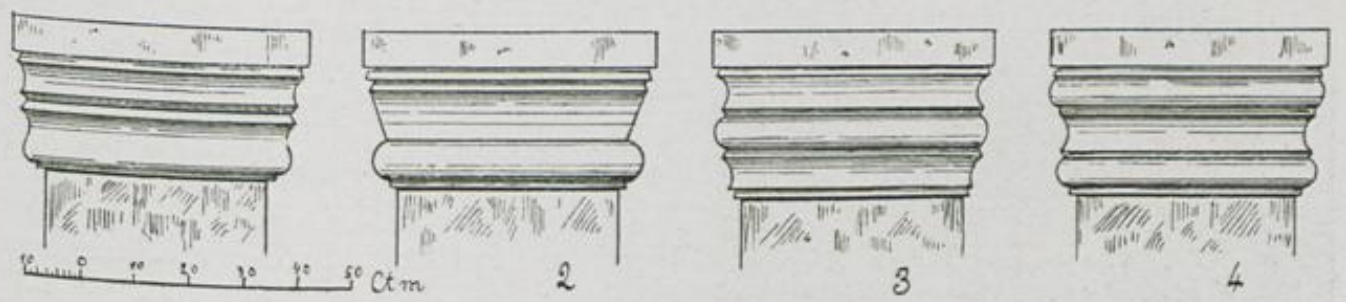

Abb. 6. Gewölbekảmpfer des Kreuzganges lāngs der Kirche.

Wandarkaden umrahmt, das Querschiff von Süden her beleuchteten Abb.8. Darum steht das Mittlere etwas über der Achse der seitlichen Fenster. Unter dem Dachgesimse des Ostflügels zogen sich die Fenster des Dormitoriums hin. Sie waren von gleicher Größe wie die früher erwähnten Fenster des Refektoriums und bildeten mit ihnen eine Reihe. Darunter wölbte sich der Kreuzgang in seiner schlichten monumentalen Art. So der Laacher Kreuzgarten im Mittelalter (Titelbild). Die Haltung seiner klösterlichen Bauten legt ebenso sehr Zeugnis ab von der strengen Lebensweise der ersten Laacher Benediktiner als von ihrem architektonischen Taktgefühl gegenüber dem formenreichen Münster.

Wenden wir jetzt unsere Aufmerksamkeit der Kirche zu. Zunächst gilt es genauer festzustellen, wie weit durch den Bau des Klosters die Südseite der Kirche gefördert wurde. Das schöne, mit Karniesprofil und einem Zahnschnitt zwischen zwei Rundstäben umrahmte Rundfenster über dem Gurtgesimse der Westwand des Querschiffes zeigt an seinen ziegelförmig hergerichteten Stücken roten Sandstein und weißen Kalkstein in regelmäßiger Abwechselung (Abb. 24). Da die gleichzeitige Anwendung dieser beiden fremden Steinarten nur am Westchor begegnet, so wird auch die Herstellung beider Teile nahe zusammenfallen. Die West- und Südwand des Querschiffes dürfte daher zum Teil mit Rücksicht auf das Dach des östlichen Klosterflügels anfangs bis über das beschriebene Rundfenster emporgeführt 
worden sein. Diese Höhe (Io m) trifft gerade den Kämpferpunkt der Gewölbe des Querschiffes.

Mit dem Nordflügel des Kreuzganges erhob sich die Seitenschiffsmauer bis zur Sohlbank der Fenster und der südliche Rundturm in gleicher Linie $5 \mathrm{~m}$ hoch bis dort, wo an den Wänden der gelbe Laacher Tuff, und an den Lisenen der rote Sandstein aufhören.

Der südliche Rundturm zog nun alsbald den übrigen Westbau bis zur gleichen Linie von $5 \mathrm{~m}$ nach sich. Aus dem hier verwendeten, und darüber nicht mehr

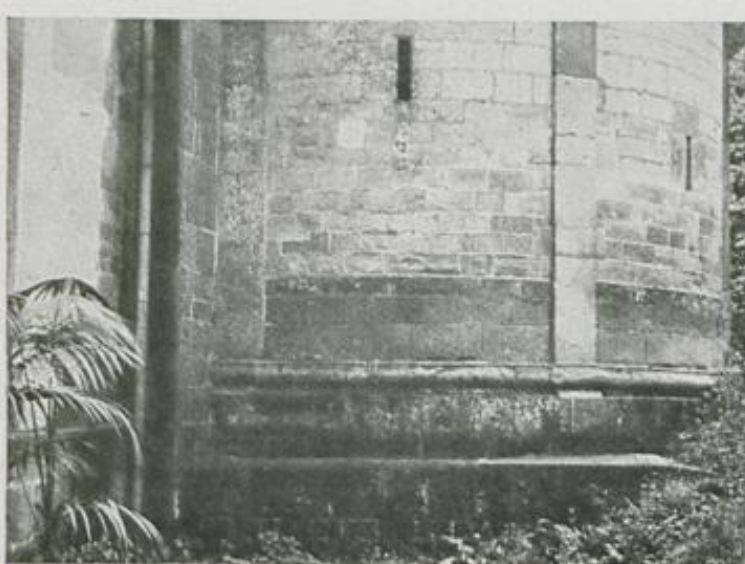

Abb. 7. Verwitterung der ersten Tuffschichten tiber dem Lavasockel am nördlichen Rundturm. auftretenden roten Sandstein und weißen Kalkstein geht das klar hervor. Der Fortgang des Kirchenbaues an der Nordseite läßt sich am sichersten durch die Verwitterung des gelben Tuffes feststellen. Der Baustoff, der anfangs aus den Brüchen an den Abhängen des Seebeckens gewonnen wurde, war vielfach mit Sand und Steinchen durchsetzt, weil er aus den oberen Schichten stammte. Diese $\mathrm{Zu}$ sammensetzung vermindert die Festigkeit des Steines, Die Außenseite der Quadern sind infolgedessen durch die Verwitterung vielfach abgerieselt oder abgeblättert. Diese Zerstörung zeigt sich an der Westwand des südlichen Querschiffes, besonders aber in gleichmäßiger Weise an den vier bis sechs ersten Schichten über dem Lavasockel der Westtürme, der nördlichen Seitenschiffsmauer, des nördlichen Querhauses und in der ganzen Krypta (Abb. 7). Darüber hingegen sind die Quadern unverletzt. Soweit sie dem gelben Laacher Tuff angehören, stammen sie aus den besseren Lagen derselben Grube, deren Stoff regelmäßig in der Tiefe an Güte zunimmt.

$\mathrm{Da}$ auch die übrigen Baustoffe an den genannten Teilen einheitlich auftreten, so ergibt sich aus der erwähnten Beobachtung, daß, wie an der Südseite, so auch an der Nordseite die Kirche von vornherein ganz in Angriff genommen wurde. Man beabsichtigte sie in allen Teilen gleichzeitig hochzuführen - ein Beweis wie umfassend die erste Bautätigkeit ans Werk ging. Von diesem Vorhaben ist man nach einiger Zeit abgegangen. Mit Sicherheit dürfen wir annehmen, daß der Tod Pfalzgraf Heinrichs im Jahre I095 diesen Umschwung herbeiführte.

Man entschloß sich jetzt, zuerst das Querschiff fertigzustellen und im Anschluß daran den Ausbau des Ostchores und des Langhauses mit dem Westchore nach Maßgabe der Mittel und Kräfte allmählich folgen zu lassen. Die Wahl des 
Querschiffes als vorläufiges Gotteshaus empfahl sich aus mehreren Gründen. Durch die Errichtung des anstoßenden Klosters war der Südfügel am weitesten vorangeschritten. Vor allem aber gewährte dieser Bauteil einen stattlichen einheitlichen Raum für den Gottesdienst. Stellte man den Hauptaltar an der Nordwand auf, so hatte man eine Kirche von $30 \mathrm{~m}$ Länge mit dem Sängerchore unter der Vierung in der Mitte und dem Haupteingang in bequemer Nähe des Kapitels und des Kreuzganges.

Die Frage, wie weit der mit dem Kloster nicht zusammenhängende Kirchenbau im Jahre 1095 gelangt war, läßt sich wegen der sofortigen Weiterführung desselben durch Adelheid natürlich nicht genau beantworten. Doch ist eine annähernde Schätzung aus folgenden Gründen wohl möglich. Einerseits müssen wir die gleichzeitige Inangriffnahme des ganzen Baues, die sich in der Verwitterung der ersten 4-6 Tuffschichten über dem Lavasockel zeigt, auf Pfalzgraf Heinrich zurückführen. Andererseits konnte die Pause, die in der Bautätigkeit nach der Hochfüh. rung des Querhauses eintreten mußte, wie sich zeigen wird, am geeignetsten nach der Fertigstellung der Sohlbank in den Abseiten stattfinden. Da nun zu Lebzeiten Pfalzgraf Heinrichs das Westchor sicher nicht höher als bis zur Sohlbank der Apsisfenster $(3 \mathrm{~m})$ gelangte und wie hier so auch an den beiden Strebepfeilern des Ostchores in der Höhe von $3,80 \mathrm{~m}$ der Übergang von der grobkörnigen zur feinen Lava sich zeigt, so dürfen wir annehmen, daß, bei gleichmäßigem Baubetriebe, ebenfalls die zwischen beiden Chören auf der Nordseite der Kirche liegenden Teile nicht über $3 \mathrm{~m}$ hinaufstiegen ${ }^{24}$ ). Diese Höhe bildet die mutmaßliche Baulinie Heinrichs an der Kirche, soweit sie nicht mit dem Kloster zusammenhängt. Die Baulinie Adelheids zu bestimmen, ist der Gegenstand des dritten Teiles.

\section{AUSBAU DES QUERSCHIFFES.}

Im ersten Teile habe ich die Mitwirkung der Pfalzgräfin Adelheid bei der Laacher Gründung dargelegt. Zu diesem Werke gab sie als »exhortans * vermutlich die erste

21) Die Gründe, die Huppertz anführt, um zu beweisen, da $B$ das Bauwerk damals uberall genau $4-5 \mathrm{~m}$ hoch gewesen sei (a. a. O. Taf. IV-VI, Text S. $63-64$ und S. 95), sind, abgesehen von der Südseite, auch für die Nordseite nicht stichhaltig, weil sie vom wahren Sachverhalte abweichen. Der Ubergang von der gröberen zur feineren Lava an den Strebepfeilern des Ostchores liegt nicht auf ziemlich gleicher Linie wie der Abschluß sdes bräunlichene (gelben) Laacher Tuffes, sondern $1,45 \mathrm{~m}$ darunter, bei einem Baukörper von 4-5 m ein nennenswerter Unterschied. Der weiße Kalkstein an den beiden östlichen Vierungspfeilern reicht genau bis zum Beginn der Apsisbogen des Querschiffes, welche $6 \mathrm{~m}$ über dem Boden der Kirche ansetzen. Dieses Material ubersteigt somit erheblich beide am Ostchor angegebenen Punkte. Die Basaltquaderschicht, die sich nur an der AuBenseite der West- und Nordwand des nördlichen Querschiffes findet, deckt nicht iden verwitterten Tuff $a$ ab, denn unter ihr lagern an der Nordseite sechs, an der Westseite vier unverletzte Tuffschichten. Auch hat Siegfried nach dem Tode seines Stiefvaters nicht den Kirchenbau kurze Zeit fortgesetzt, wie Huppertz meint. Dieser Annahme widerspricht der Pfalagraf in seiner Urkunde selbst, indem er sagt, daß er anfangs, als er noch jung war, seine Pflicht vernachlasssigt habe, 
Anregung. Bei dem rechtlichen Vollzuge der Stiftung, d. h. bei der Dotierung und bei der Bestimmung der Laacher Bewohner, nennt sie das Diplom Konrads III. vastipulans « und »assentiens «. Nach dem Tode ihres Gemahls tritt sie auf, "renovans pium factum mariti sui coram multis «. Ja die Bestätigungsbullen der Päpste Innozenz' II. (II 39) und Eugens III. (II47), deren ortsgeschichtliche und ortsrechtliche Mitteilungen unzweifelhaft wörtlich aus der Eingabe der Laacher Mönche entnommen sind, berichten geradezu, "daß das Kloster bekanntlich von Pfalzgraf Heinrich und seiner Gemahlin Adelheid in der Hauptsache erbaut worden sei«25). Demnach dürfen wir der Pfalzgräfin den Ehrentitel einer wirklichen Mitgründerin von Maria Laach im vollen Sinne des Wortes nicht versagen. Er berechtigt uns aber auch zu der Annahme, daß sie das mit so großem Eifer begonnene Werk nach dem Ableben ihres Gemahls fortsetzen ließ.

Hiergegen könnten aus dem Stiftungsbriefe Siegfrieds Einwände erhoben werden. Diese undatierte Urkunde, deren Abfassung wir nach der Entlassung des Pfalzgrafen aus seiner Würzburger Haft am I5. August IIII und vor seinem Tode am 9. März III 3 anzusetzen haben, berichtet nämlich, daß Pfalzgraf Heinrich snur das Fundament der Kirche gelegt habe«. Die von mir angenommene Weiterführung des Baues durch Adelheid übergeht er mit Stillschweigen.

Um die erste Schwierigkeit zu lősen, genügt es, den Sinn der Worte richtig zu verstehen. Der Ausdruck »ecclesia " wird in dem Schriftstück stets nur gebraucht, um damit das ganze Kloster zu bezeichnen, niemals die Basilika allein. Das gilt besonders von der in Rede stehenden Stelle: "fundamentum eius tantummodo posuit ". Diese Worte beziehen sich auf jene "predicta ecclesia ", von der die Urkunde unmittelbar vorher sagt, daß sie "Lacus " genannt werde ${ }^{26}$ ). Unter dem Namen Laach ohne Zusatz wird aber niemand die Basilika allein verstehen. Wären die technischen Fundamente der letzteren gemeint, dann hätte die Urkunde ohne Zweifel den Plural sfundamenta " gebraucht, wie es in Gründungs- und Weihinschriften geschieht. Der fragliche Ausdruck ist demnach nur eine Formel und bedeutet, Heinrich hat den Grund zum Kloster gelegt, sowohl durch den Beginn des Baues als durch die Einführung der Mönche 27).

25) In primis ipsum locum qui Lacus vocatur, in quo idem cenobium a prefato Henrico nobili palatino comite et Athelheide uxore sua praecipue constat esse constructum liberum ab omni iure et potestate seculari. Mittelrhein. Urkdbch. I, S. 561 u. S. 602 . Görz, Mittelrhein. Regesten S. 529 f.

26) Vgl, den Urkundentext Anhang Nr, I.

77) Liest man die Urkunde 425 des Mittelrhein. Urkdbuches aufmerksam durch, so erkennt man sofort, daß ecclesia durchgängig nicht den Sinn von Kirche im engeren Sinne d. h, von Basilika hat, sondern die gesamte Klosteranlage, natürlich mit Einschluß der Basilika und nach dieser als dem hervorstechendsten Teil benannt, bezeichnet. Das entspricht dem Sprachgebrauch jener Zeit. Du Cange gibt in seinem Glossar Beispiele dafür, daß ecclesia für monasterium, ja sogar für prioratus steht. Noch mehr Beispiele bieten die Urkunden im Mittelrhein. Urkdbch. Es wird dabei auch die Bezeichnung der an einem Orte versammelten Gläubigen als ecclesia, wie sie schon im Neuen Testament vorkommt, mitspielen. Es liegt gar kein Grund vor, diese Bedeutung im zweiten Satze der Urkunde nicht anzunehmen. 
Mit der gegebenen Erklärung des Wortes »ecclesia « stimmt die Auffassung überein, die Siegfried von seiner Aufgabe die Stiftung zu vollenden, »labor ecclesie perficiende im weiteren Verlaufe der Urkunde an den Tag legt. Die Weiterführung des Baues erwähnt er mit keinem Wort. Dafür beschäftigen ihn ausschließlich die rechtlichen Verhältnisse des Klosters. Er unterstellt es auf immer der Abtei Afflighem in Brabant, „weil beide auf seinem Grundeigentum liegen «. Er trifft eingehende Bestimmungen über die gemeinsame Abtswahl beider Klöster, über die Rechte und Pflichten der Vögte, über das Begräbnis der letzteren und seiner Familie und schließt mit der Aufzählung der Güterliste. Damit hat er die Stiftung der ecclesia lacensis rechtlich vollendet, sie ist nun selbständig, "libertati tradita ", auch dem Rechte ihrer Stifter entzogen.

Das Stillschweigen Siegfrieds über die Weiterführung der Bautätigkeit durch seine Mutter braucht nicht zu befremden, da er auch ihre feierliche Erneuerung der Stiftung vor vielen Zeugen nicht erwähnt. Überhaupt ist die historische Einleitung seiner Urkunde im Vergleich zum Diplom Konrads III. sehr lückenhaft, obschon er mitzuteilen verspricht, "qualiter et a quibus ecclesia quae vocatur Lacus constructa sit «.

Mit der Erneuerung der Laacher Stiftung durch Siegfried hat man allgemein einen Wiederbeginn der Bautätigkeit in Verbindung gebracht. Wie wenig diese Annahme, wie gut hingegen die Fortsetzung des Baues durch Adelheid begründet ist, zeigt ein Blick in die gleichzeitige wirtschaftliche Entwicklung des Klosters, die doch naturgemäß eine wichtige Grundlage für jede größere Entfaltung der Baukunst bildet. Nun hat aber Siegfried, vermutlich nach dem Tode seiner Mutter, die wirtschaftliche Lage der Mönche nicht unbedeutend verschlechtert, indem er ihnen den großen Bendorfer Hof mit allem Zubehör entriß. Was er dafür dem Kloster bei der Erneuerung der Stiftung gewissermaßen als Entschädigung zurückgab, „vier Mansus in Kruft, Hoverhof und Meylem in Brabant «, konnte den Verlust bei weitem nicht aufwiegen. Die beiden letztgenannten Güter waren wegen ihrer großen Entfernung von geringem Werte und gingen deshalb bald in den Besitz von Afflighem über. Aus demselben Grunde konnte aber auch dieses für sein neues Tochterkloster wenig tun.

Die Erträgnisse der übrigen Stiftungsgüter reichten nur notdürftig aus, um den Lebensunterhalt der Mönche zu bestreiten. Ihre wiederholt erwähnte große Predecessor et dominus meus Heinricus comes palatinus exhortante uxore sua Athelheide uidelicet matre mea predictam ecclesiam edificare cupiens fundamentum cius tantummodo posuit. Heinrich wollte natürlich das Kloster Laach (ecclesia que uocatur lacus) gründen, kam aber nicht dazu, die Gründung selber ganz durchzuführen. Das ist der Sinn des Satzes. Wir sind keineswegs gezwungen, das Bild vom Fundament wörtlich zu nehmen, so daß Heinrich nur die Fundamente des materiellen Baues errichtet hätte. Aber selbst wenn wir das zugeben wollten, müBten wir daran festhalten, daB Heinrich die Fundamente des gesamten Klosterbaues, nicht der Basilika allein gelegt hat. Wahrscheinlich will die Urkunde aber sagen, daß Heinrich die von ihm geplante Klostergründung nur in ihren Anfingen gesehen hat. So erklärt es sich auch leicht, daß Siegfried im Folgenden gar nichts von dem Weiterbau sagt, sondern nur von der Sicherstellung und Dotierung des Klosters spricht. (Anmerkung von P. Odo Casel O.S. B.) Schippers, Maria Laach. 
Armut im I2. Jahrhundert läßt uns darüber nicht im Zweifel $\left.{ }^{28}\right)$. Eine bescheidene Bautätigkeit war unter diesen Verhältnissen nur so weit möglich, als man über eigenes Material und eigene Kräfte verfügte. So blieb es volle drei Jahrzehnte. Bis I I 30 fand, nach Ausweis der erhaltenen Urkunden, merkwürdigerweise keine einzige größere Schenkung an das Kloster statt. Von anderen Bauherren aus dieser Zeit ist nichts bekannt. Erst in dem genannten Jahre vermachte das ritterliche Ehepaar Johann und Mechtilde von Ebernach an der Mosel der jungen Abtei ihre dortigen Besitzungen, woraus sich die Propstei gleichen Namens entwickelte 29). Darauf folgten bis zur Mitte des Jahrhunderts viele weitere Zuwendungen größeren und kleineren Umfanges. Die Bullen Innozenz' II. und Eugens III. geben uns hiervon eine ziemlich vollständige und im ganzen chronologische Übersicht.

Mit dieser Erstarkung des Klostervermögens seit II 30 geht der-Ausbau des Vierungsturmes, des Langhauses und des Westchores bis zur Weihe der Kirche, I156, gut zusammen. Die Teile des Klosters und des Gotteshauses, die vorher fertiggestellt wurden, lassen sich nicht minder passend auf Heinrich und Adelheid zurückführen. Damit scheidet Siegfried als Bauherr aus. Das stimmt nicht nur mit seinem reichbewegten politischen Leben, seiner Sorge für das Kloster Herrenbreitungen und mit dem Tiefstand des klösterlichen Wirtschaftsbetriebes, sondern auch mit den ausdrücklichen Worten der Bulle Innozenz' II. überein, die im Jahre II 39 den Kloster- und Kirchenbau, soweit er damals fertig war, min der Hauptsache " Heinrich und Adelheid, zuschreiben. Hätte Siegfried für den Bau etwas Nennenswertes getan, so sieht man nicht ein, warum er hier nicht nach seinen Eltern als Bauherr aufgeführt worden wäre.

Es ist nun meine Aufgabe, zu zeigen, wie die bisherigen Ausführungen durch die Verwitterung, das Material und die Formensprache des Baues bestätigt werden. Als das Innere der Kirche vom Verputz befreit wurde, traten im Langhause, vor allem an den sechs ersten Schichten über dem Sockel, dieselben Verwitterungen zutage, wie ich sie oben am Außenbau geschildert habe. Auch war die Sohlbank der Fenster an der Nordseite stark zerstört. Die nämlichen Wetterschäden sind heute noch in der Krypta zu sehen. Hier zeigen besonders die in weichem, grauem Sandstein hergestellten Halbsäulen der Westwand tiefe, vom abströmenden Regen gegrabene Furchen. Ein Hinweis auf die hohe Mauer, die das Querschiff nach Osten hin während der Bauunterbrechung vorläufig abschloß. Dagegen wurden diese Schäden im Querschiff nicht beobachtet. Als kürzlich die Nebenapsiden an der Ostseite des Querschiffes vom alten Verputz entkleidet wurden, konnte nirgendwo eine Spur von Verwitterung entdeckt werden.

${ }^{28}$ ) So berichtet der Laacher Mönch Heinrich von Münstereifel (c. 1214) in seiner Schrift: Liber de ortu charitatis, Westdeutsche Zeitschr. f. Geschichte u. Kunst XVI, (1893), S. roo. Ebenso Abt Joh. Augustin (gest. 1568), De paupertate priscorum monachorum lacensium, Rituale, Bonn, Univ.-Bibl. Hs. 354, fol. 65 .

29) Mittelrhein. Urkdbch. I, S. 529. 
Weist diese Tatsache schon deutlich auf die Fortsetzung des Baues am Querhause hin, so läßt uns der gelbe Laacher Tuff noch erkennen, wie der Ausbau sich im einzelnen vollzog.

Man führte die Querschiffsmauern rundum zunächst bis zur Schließung der tiefer sitzenden Vierungsbogen und der obersten Fenster des Querhauses auf (Abb. 8). Das können wir am Außenbau leicht erkennen. Bis zur genannten Höhe steigt der gelbe Tuff in unvermischter Schichtung empor, wie an den untersten Teilen. Nun wurden die tiefer stehenden Vierungsbogen im gelben Tuff übermauert bis zur Schließung der beiden andern Vierungsbogen, deren Scheitel die Höhe des Mittelschiffes bildet. Dieser weitere Aufbau der Vierung erreicht bis zum Dache eine Höhe von $3 \mathrm{~m}$. Er forderte als Widerlager naturgemä $\beta$ auch eine Höherführung des Querschiffes. Dieselbe geschah in folgender Weise. Der Südflügel des Querhauses wurde bis zum Dache ausgebaut. Er zeigt an diesem Teil einen bemerkenswerten, regelmäßigen Wechsel der Schichtung zwischen dem bisher verwendeten gelben und einem andern dunkelgrauen Tuff. An der West- und Südwand wechseln zwei graue Schichten mit einer gelben, an der Ostwand umgekehrt eine gelbe mit zwei grauen. Hier erstreckt sich der Schichtenwechsel auch auf den anstoßenden Flankenturm. Der Nordflügel des Querhauses erhielt den vollen Ausbau bis zum Dache nur teilweise. Die Ost- und Westwand wurden in der Höhe des

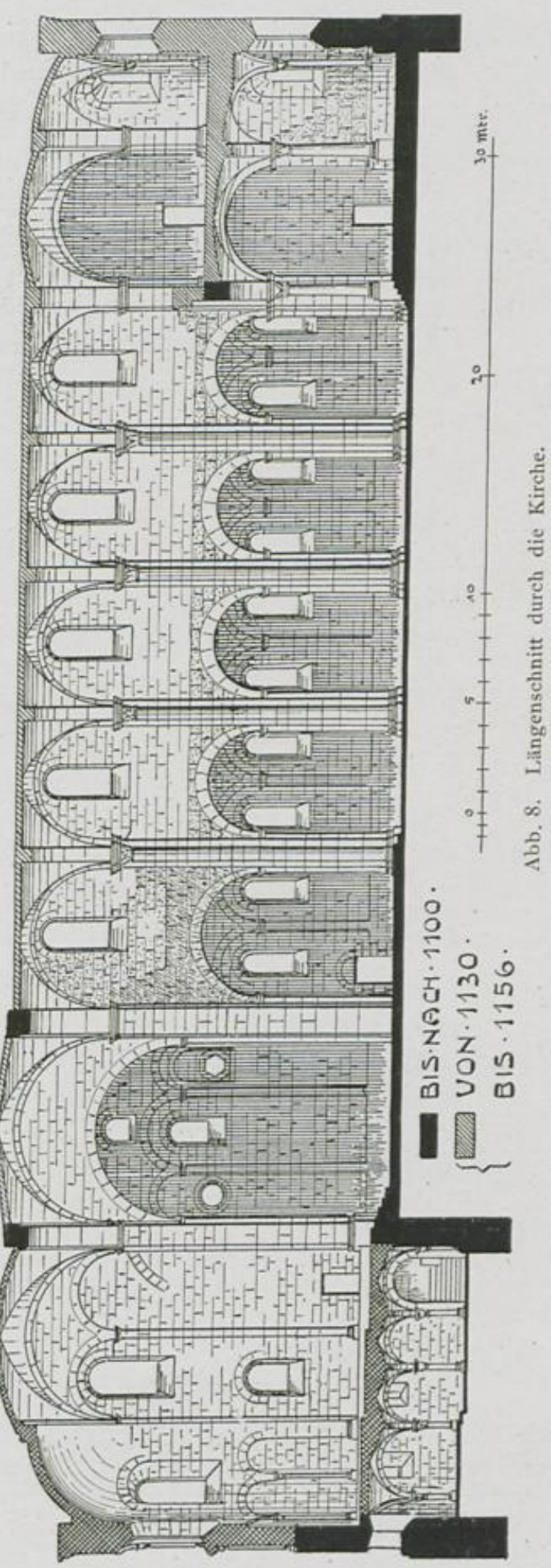

$3^{*}$ 
Daches nur bis zur Mitte notdürftig als Widerlager ausgeführt und endigten hier in einer laufenden Verzahnung. Diese ist an beiden Wänden heute noch ganz deutlich zu erkennen. An der Turmwand auf der Ostseite hebt sie sich in gelbem Tuff über dem Gewölbe von der späteren Fortsetzung in grauem Tuff ab. An der Westwand endigt die Verzahnung außen vor der Mittellisene. Hier zeigt sich auch wieder der Schichtenwechsel wie an der Westwand des Südflügels. Auf zwei graue Tuffschichten folgt eine gelbe. Während endlich die Freilisenen der Nordwand drei Blendbogen tragen, stützen sie an der Südseite das Gurtgesimse.

Wie bewerkstelligte nun unser Baumeister die Sicherung der Vierung nach Osten und Westen? Im Chore kamen die Flankentürme seinem Zwecke vortrefflich entgegen. Mit dem Bau aufs innigste verwachsen, mußten sie ohnehin bis zum Dache der anstoßenden Schiffe mitaufgeführt werden, was der gelbe Tuff auch bestätigt. Um die Drucklinie der Obermauer aber noch sicherer in die Turmwand zu bannen, die vermutlich vor den Fenstern des Chores in einer stehenden Verzahnung abschloß, brachte er in den Chorwänden noch Strebebogen an (Abb. 8).

Nicht so einfach gestaltete sich die Sicherung der Vierung nach dem Lang. hause hin. Unser Architekt wählte das natürlichste und zuverlässigste Mittel. Mit der Vierung ließ er gleichzeitig alle Scheidbogen des Mittelschiffes und die Bogen des Westchores bis zur Apsis mitaufführen. Die Entfernung des Verputzes versetzt uns in die glückliche Lage, diese Tatsache unzweifelhaft zu erkennen. Der gelbe Laacher Tuff ist auch hier wieder zunächst unser Führer. Im ersten Joch vor der Vierung steigt er mit der östlichen Leibung des Fensters zu dessen Bank, dann in schräger Linie zu dem hier angebrachten Basaltwiderlager herab. In den folgenden vier Jochen füllt er die Zwickel der Bogen bis zur Scheitelhöhe aus. Beim Übergang vom Mittelschiff zum Westchor erhebt er sich bis zum Gesimse der Emporenbrüstung, fällt über den Bogen, die den Eintritt in das Westchor vermitteln, auf zwei Schichten herunter (Abb. 34) und steigt dann im Westchor vom Kämpfer der Eckpfeiler in laufender Verzahnung einerseits zu den Portalbogen, anderseits zur Sohlbank der Apsis herab. Die beschriebene Linie zeigt sich gleichmäßig auf beiden Seiten des Langhauses (Abb. 8) 30).

Es ist nicht zu verkennen, daß der Baumeister auf diese Weise das einfachste und sicherste Mittel wählte, um eine Ausweichung oder eine Verschiebung des Baues zwischen den fünf mächtigen Scheidbogen zu verhüten, die wohl sicher eingetreten wäre, wenn er mit dem ersten oder dem zweiten Bogen vor der Vierung einstweilen abgeschlossen hätte.

War damit für die Verbindung des Querschiffes mit dem Langhause aufs beste gesorgt, so wandte unser Architekt dem unmittelbar unter dem Drucke der Obermauer stehenden Unterbau noch seine besondere Aufmerksamkeit zu. Der $3 \mathrm{~m}$ tiefere

$\left.3^{\circ}\right)$ Auf dem Laingenschnitt ist der gelbe Tuff im Langhause punktiert, das gleich zu erwähnende Basaltwiderlager im ersten Joch schraffiert. 
Ansatz der Gewölbe in den Querhausflügeln war schon von Anfang an auf eine bessere Sicherung dieser größten Steindecken der ganzen Kirche sowohl als des Vierungsturmes berechnet. Jetzt aber, wo die Vierung ausgebaut werden sollte, bevor das Langhaus ganz fertiggestellt werden konnte, galt es noch besondere Maßregeln zu treffen. Nun wurden die Bogen im ersten Joche des Langhauses bis zur Kämpferhöhe der Vierung noch mit der harten Basaltlava übermauert und aus demselben Material, entsprechend den Strebebogen auf der Ostseite, noch schräg aufsteigende Widerlager aufgeführt, um dem Seitenschub der Vierungsbogen und zugleich dem Drucke der Obermauer noch besser zu begegnen. Nur in dem beschriebenen, vorläufigen Bauabschluß findet diese ganze Versicherung der Vierung nach Osten und Westen hin ihre volle befriedigende Erklärung.

Der tiefere Ansatz der Gewölbe in den Querhausflügeln erzielt jedoch nicht nur den eben erwähnten praktischen $Z$ weck. Er bringt auch einen doppelten ästhetischen Vorteil mit sich. Die Arme des Querschiffes erhalten dadurch den Charakter selbständiger, gut proportionierter Seitenräume, deren Mittelpunkt die Nebenapsiden mit ebenfalls gut abgewogenen Verhältnissen bilden. Seitdem die südliche Apsis mit Mosaiken ausgestattet ist, kommt dieser Vorzug erst ganz zur Geltung. Dabei verliert das Querhaus nichts von seiner Mitwirkung am Gesamtraum des Inneren. Ich kenne keine gleichzeitige romanische Kirche, deren Querhausflügel einen so bedeutenden, geschlossenen Raumeindruck hervorrufen.

Im Langhause vermittelt das Querschiff eine doppelte, gleichmäßige Höhensteigerung der Bogen, zunächst vom Mittelschiff zur Vierung, dann von der Vierung zum Presbyterium.

Nicht nur das Mittelschiff, auch das erste Joch der beiden Seitenschiffe wurde bis zum Dachgesimse, einschließlich des Rundbogenfrieses, gleichzeitig mit dem Querhause aufgeführt. Das ergibt sich aus folgenden Beobachtungen. Die Wände derAbseiten sind bis hinter der zweiten Doppellisene ganz in gelbem Laacher Tuff hergestellt. Hier steigt er in stehender Verzahnung an der östlichen Leibung des dritten Fensters zur Sohlbank herab. Die übrigen Teile der Seitenschiffe über der Fenstersohle sind später in hellem Tuff ausgebaut worden. Die kleinen Bogen des Rundbogenfrieses wurden über den beiden ersten Fenstern nicht so gleichmäßig im Halbkreis gebildet wie über den folgenden, sondern etwas überhöht und in der Linie etwas freier gehalten, was ihnen ein viel eigenartigeres Gepräge verleiht. Die Überhöhung der Bogen hat ihren Hauptgrund darin, daß die in Lava hergestellten Konsolen bereits die Ansätze zu den Bogen besitzen, wie eine ältere und eine neuere Konsole nebeneinander unter dem ersten Bogen hinter der zweiten Freilisene auf Abb. 9 besonders anschaulich beweisen. Zeigt sich hier nicht ein Gegenstück zu den Plättchen, die wir in der Einzahl oder verdoppelt auf dem oberen Pfühl der frühromanischen Säulen- und Pfeilersockel sowohl in unserer Kirche als anderswo finden? Endlich sind die älteren Konsolen mit geometrischen und anderen Figuren geschmückt. So ergibt sich 


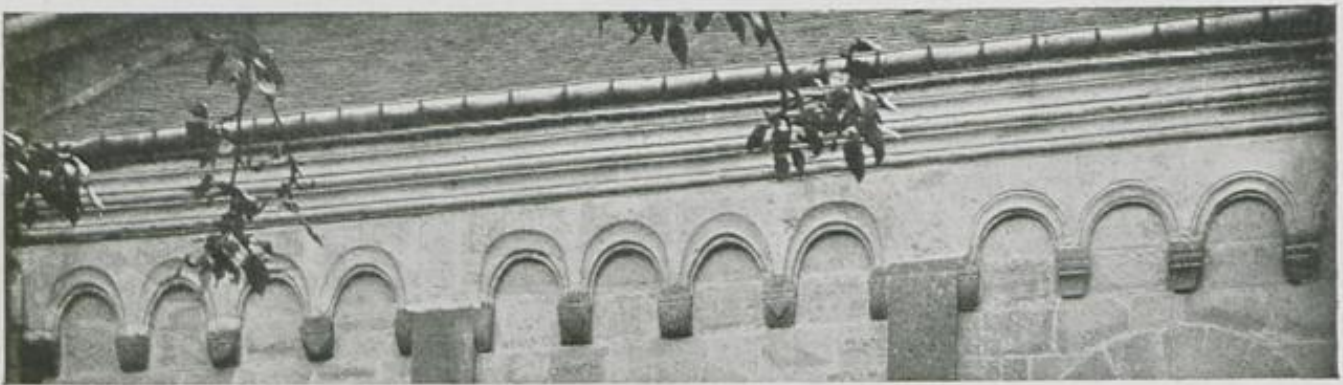

Abb. 9. Rundbogenfries am nördlichen Seitenschiff vor dem Querhause.

ein dreifacher Unterschied zwischen dem älteren und späteren Rundbogenfries, der beiden einen ganz anderen Formcharakter aufprägt. Derselbe hat seinen Grund in der großen Bauunterbrechung, die ich rund zwischen IIOO und II 30 annehme. Nach diesem Zeitpunkt kann ein längerer Stillstand der Bauführung bis zur Weihe der Kirche im Jahre II 56 nicht mehr stattgefunden haben.

Hier drängt sich ein Vergleich mit dem Rundbogenfries an den Nebenapsiden des Querhauses auf (Abb. IO). Derselbe besteht aus regelmäßig gebildeten Doppelbogen, die untereinander geradlinig abgestuft sind. Obgleich schon an den fein scharrierten Tuffplatten überhöht, setzen diese Bogen sich auch noch an den aus Lava hergestellten Konsolen fort und bestimmen konsequent die ganze Gliederung der Konsolenverzierung. Die senkrechte Teilung besteht aus einem erhöhten Mittelstück und zwei tieferen Seitenstücken; das Profil bilden Platte, Wulst und Karnies, natürlich im Kleinen. Die Überführung der Bogen in das Profil der Konsolen verleiht den letzteren etwas Leichtes und Feines, was man bei den später üblich gewordenen Konsolenformen vermißt. Diese wollen lediglich Stützpunkte sein, hemmen aber dadurch den Fluß der Bogenlinie. Dagegen wirkt der Rundbogenfries der Seitenapsiden unter dem breiten Karnies des Dachgesimses wie ein leichter, festlicher Fransenbehang.

Bisher haben wir den Ausbau des Querhauses fast nur an der Hand des Laacher Tuffes verfolgt. Mit ihm verbindet sich aber noch anderes Material, wodurch das Querschiff sich als der älteste hochgeführte Teil der Kirche zu erkennen gibt. Der weiße Kalkstein, der neben dem roten und grauen Sandstein die ältesten Teile der Kirche kennzeichnet, ist am Querschiff am ausgiebigsten verwendet. An den östlichen Vierungspfeilern steigt er $6 \mathrm{~m}$ hoch hinauf. Von da springt er zu den Stirnbogen der Seitenapsiden über, die er in malerischem Wechsel mit der blauen Lava belebt. Dasselbe Spiel mit dem roten Sandstein wurde schon früher (S. I3) am Rundfenster in der Westwand des südlichen Querhausflügels erwähnt. Die letzten Stücke des weißen Kalksteins finden wir endlich an den Kapitellen und Basen der Fenster, derèn reiche Umrahmungen er wie mit lichten Punkten schmückt. 


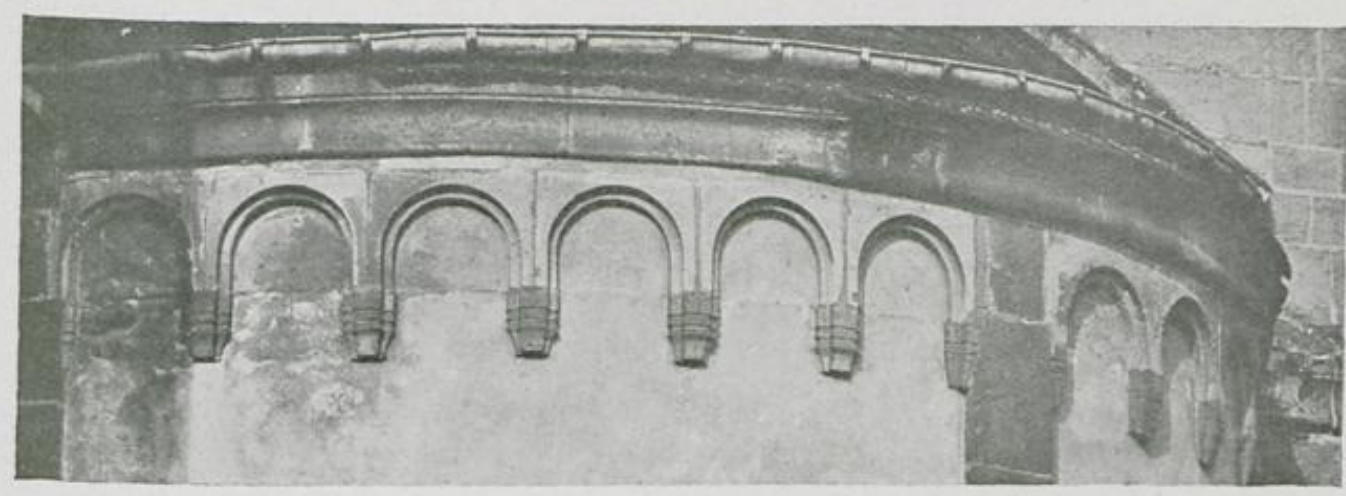

Abb. ro. Rundbogenfries an der nördlichen Nebenapsis.

Ist es auch im allgemeinen unzulässig, aus dem regelmäßigen Farbwechsel der Quadern, wie er eben beschrieben wurde, sichere chronologische Schlüsse zu ziehen, weil er vereinzelt noch das ganze I2. Jahrhundert hindurch vorkommt, so steht doch fest, daß er sich im II. Jahrhundert besonderer Beliebtheit erfreute. Das bestätigen auch die Laacher Bauten. Obschon hier die blaue Lava und der Tuff beständig nebeneinander verwendet wurden, die erste an den konstruktiven Teilen, der andere an den Wänden, so finden wir den Schichtenwechsel doch nur an den Teilen der Kirche, die wir der Wende des II. Jahrhunderts zuweisen müssen. Der Wechsel zwischen weißem Kalkstein und blauer Lava begegnet uns dreimal; an dem Bogen über der Türe, die vor dem Querschiff vom Kreuzgang in die Kirche führt, und an den Stirnbogen der beiden Nebenapsiden. Roter Sandstein und weißer Kalkstein wechseln regelmäßig an der Stromschicht des Rundfensters in der Westwand des südlichen Kreuzarmes und an einem später zu erwähnenden Schachbrettmosaik im Bogenfelde des nördlichen Portals der Westfront. Selbst der Wechsel zwischen gelbem und grauem Tuff wurde nicht verschmäht, wie wir eben gesehen haben, sobald beide gleichzeitig in Anwendung kamen. Zusammen bilden diese Beispiele eines farbenfrohen Geschmackes ein sehr ausgeprägtes Merkmal jener Zeit, die es sich so viel kosten ließ, roten Sandstein und weißen Kalkstein aus fernen Gegenden an die Ufer des Laacher Sees schaffen zu lassen. Das ist die Bauperiode Heinrichs und Adelheids.

Überblicken wir den vorhin beschriebenen Bauabschluß noch einmal als Ganzes, so läßt er deutlich die Absicht erkennen, nach Hochführung des Querschiffes die anderen Teile bald folgen zu lassen. Man rechnete offenbar damit, daß Pfalzgraf Siegfried wenigstens nach dem Tode seiner Mutter Adelheid sich seiner Verpflichtung erinnern und das Werk fortsetzen würde. In dieser Erwartung wurden aber die Mönche bitter getäuscht. Statt zu helfen, schädigte er sie durch die Entziehung des Bendorfer Hofes. Diese schmerzlichen Ereignisse haben gewissermaßen einen symbolischen Ausdruck gefunden in der jähen Unterbrechung, die der beschriebene Bau- 


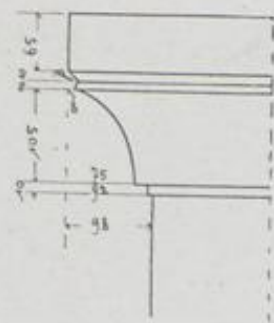

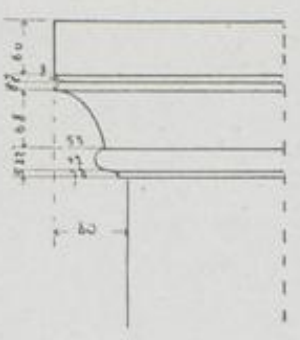

2

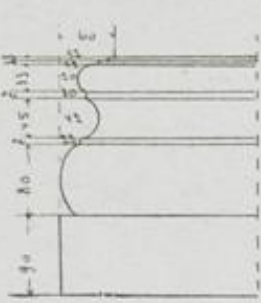

3

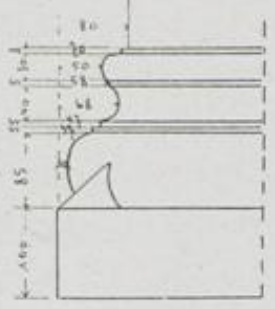

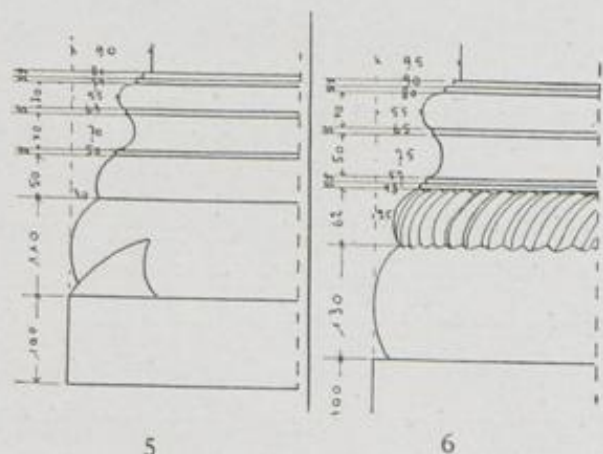

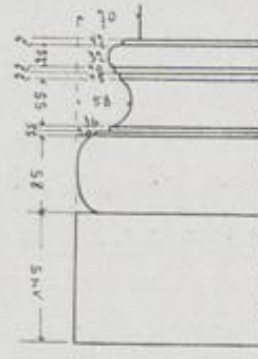

7

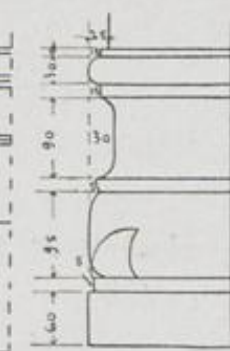

8

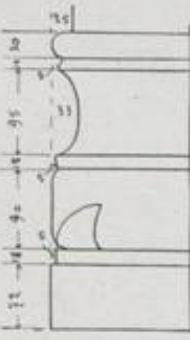

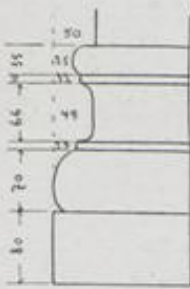

10

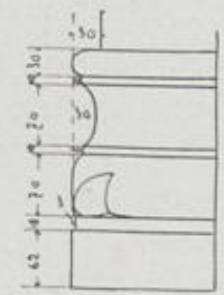

It

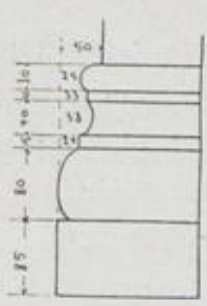

12

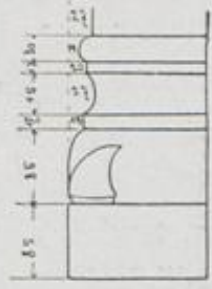

1.3

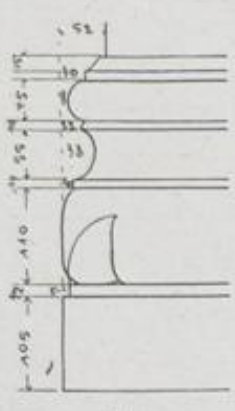

14
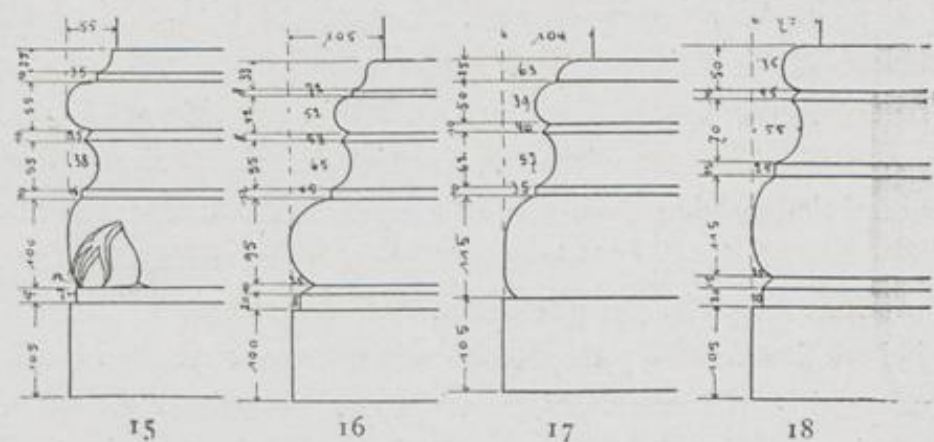

Abb. 11. Kämpfer- und Sockelprofile. 1-6 Krypta, 7 Ostchor, 8-13 Fenster des Querhauses, 14-15 Halbsäulen des Mittelschiffes, 16-18 Pfeiler des Mittelschiffes. 

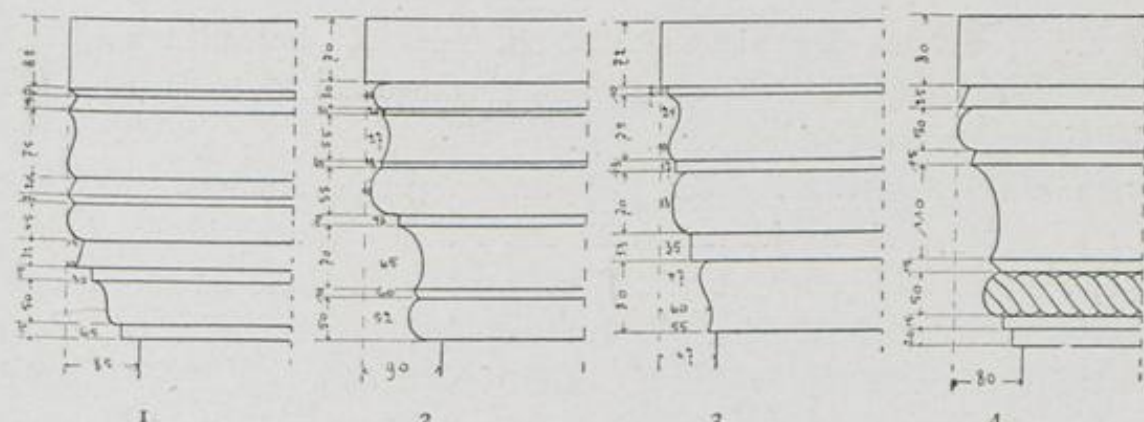

2

3
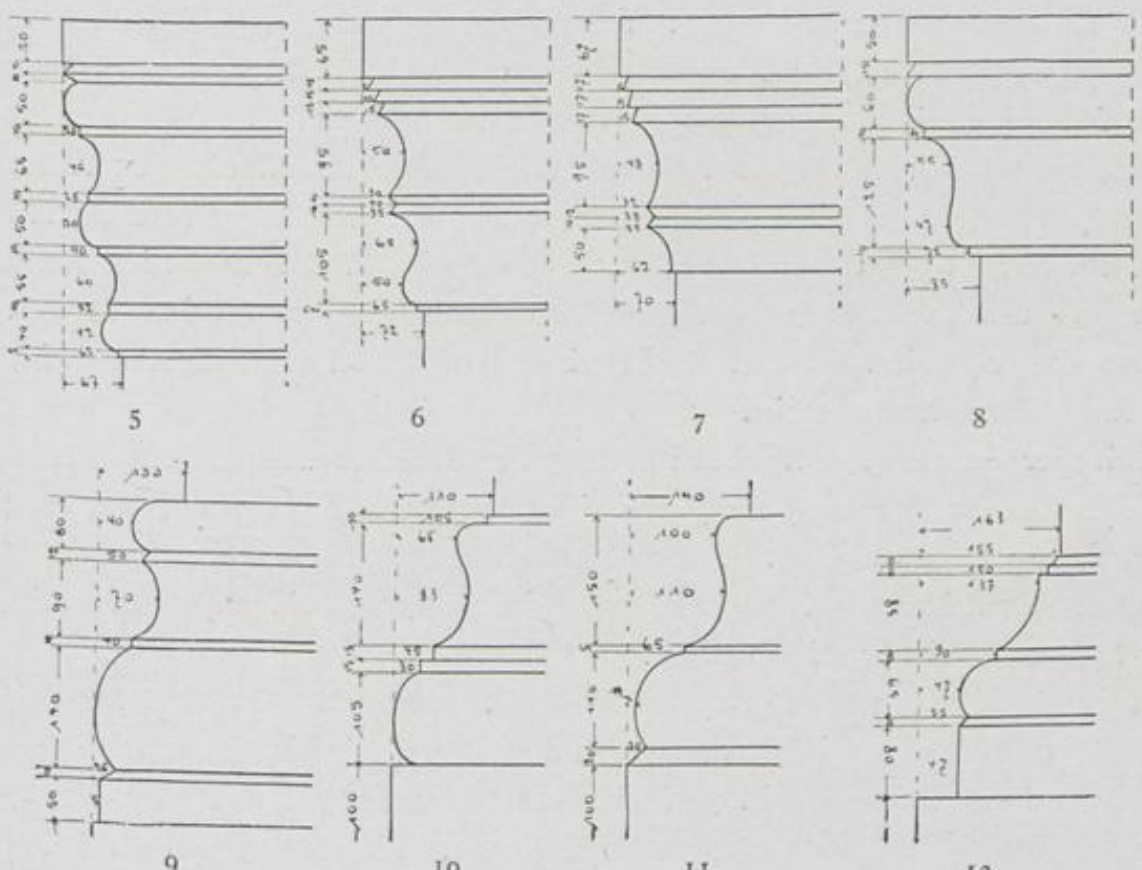

8

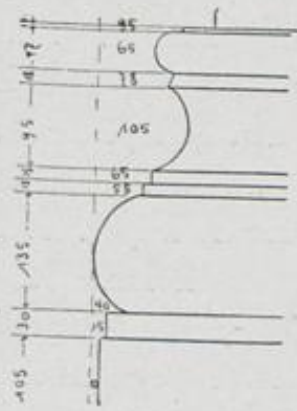

I I

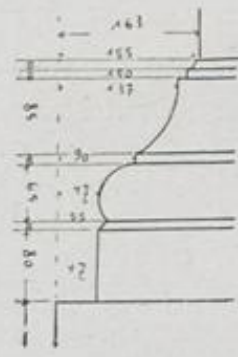

12
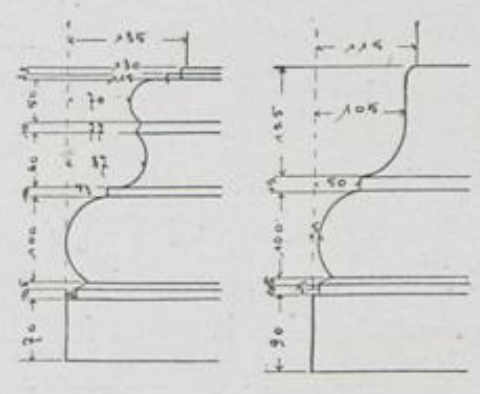

15

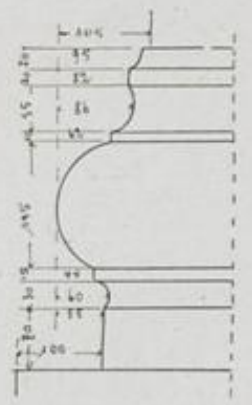

16

Abb, 12. Kämpfer- und Sockelprofile. $1-4$ Untere Kämpfer im ersten Joch vor der Vierung, 5-8 untere Kampfer am Westchor, 9 Vierung, 10-11 Abseiten vor der Vierung, 12 äuferes Profil der südlichen Nebenapsis, 13-15 Westchor, 16 Sockel des nördlichen Rundturmes. Schippers, Maria Laach. 
abschluß uns heute noch an so vielen Stellen erkennen läßt, besonders am nördlichen Kreuzarm und an dem großen Blendbogen am Eingange des Westchors, den diegelbe Tufflinie mitten durchschneidet (Abb. 34).

Wollte man dagegen zwei größere Unterbrechungen des Kirchenbaues annehmen, die erste nach 1095, die zweite nach dem Ausbau des Querschiffes zwischen 1130 und II56, so ließe sich zunächst nicht erklären, warum die letztere so plötzlich geschah, da doch damals hinreichende Mittel zur Verfügung standen. Noch schwerer aber dürfte es sein, die nötige Zeit für die Fertigstellung der Bauteile zu finden, die wir nach Ausweis der Formensprache vor der Weihe im Jahre I 156 anzusetzen haben. Es sind das nicht wenige: Vierungsturm, Langhaus, Westchor und die Einwölbung der ganzen Kirche. Auch nach Dehio deuten die Profile und der Schmuck der Würfelkapitelle im Langhause eher auf die Zeit vor als nach der Mitte des 12. Jahrhunderts $\left.{ }^{3} \mathrm{t}\right)$. Übrigens ist der letztere Abschnitt durch den Ausbau des Ostchores, der oberen Hälften der Chortürme, der drei Westtürme und der Nikolauskapelle im Garten hinreichend besetzt. Daran reiht sich bekanntlich als krönendes Schluß- und Meisterwerk der Laacher Bautätigkeit zu Beginn des I3. Jahrhunderts das Paradies. So sind die einzelnen Bauteile am besten auf die ent. sprechenden Bauzeiten verteilt.

Mit der dargelegten Zeitbestimmung der Laacher Frühbauten, der Krypta, abgesehen von der Wölbung, des Querschiffes und des Langhauses bis zur Schließung der Scheidbogen, läßt sich m. E. auch die Formensprache, soweit wir ihre Entwicklung kennen, wenigstens bis zu dem Grade in Einklang bringen, daß sie nirgendwo dieser. Datierung sicher widerspricht.

Fassen wir zunächst die Krypta ins Auge. Wie an andern Orten, so zeigt auch die Laacher Unterkirche in der Bildung ihrer Zierglieder eine bewußt gewollte Einfachheit und Gleichförmigkeit. Dieser schlichte Schmuck entspricht der Art des Raumes sowohl als seiner spärlichen Beleuchtung. Von den vierzehn Kapitellen der sechs Rundsäulen und acht Halbsäulen zeigen alle bis auf die zwei antikisierenden vor der Apsis die Würfelform mit halbrundem, einfachem Schilde. Der Abakus besteht überall aus Platte, doppeltem Plättchen, halber Hohlkehle und Stäbchen. Dieselbe Folge, der Astragal ausgenommen, begegnet an den Kämpfern der Pfeiler. Das Profil der Basis steigt meistens in überraschend feiner Linie, bei normalem Unterschied der Ausladung zwischen den beiden Pfühlen, zum Schaft empor. Nur die vier Stücke, welche mit drei Pfühlen ausgestattet sind, konnten die steile Haltung der Frühzeit nicht verleugnen. Bei zweien ist ein Pfühl in ein Schraubengewinde umgewandelt (Abb. II, 6). Sie haben ein ganz genaues älteres Gegenstück aus dem II. Jahrh. im Keller des Bischofshofes in Trier 32). An drei Säulenfüßen begegnen auch

${ }^{3 x}$ ) Handbuch der deutschen Kunstdenkmäler IV, (1911). S. 200. Bei einer anderen Gelegenheit hoffe ich mit neuen Gründen zu zeigen, daß das Ostchor mit Unterstlitzung der Gräfin Hedwig von Are höchstwahrscheinlich nach der Weihe der Kirche vollendet wurde.

32) Siehe Chr. W. Schmidt, Baudenkmale. Trier 1839 . 2, Lief., Taf. 6, Mr, Text S, 55. 
die Ecksporen. Sämtliche beschriebene Bauteile sind in weißem Kalkstein oder grauem Sandstein ausgeführt, die nur in der ersten Bauzeit verwendet wurden. (Abb. II, I-6.)

So einheitlich das Gepräge der Zierglieder in der Krypta zutage tritt, so fehlt es dennoch nicht an ganz charakteristischen Verwandtschaftszügen mit den entwickelteren Formen der Kirche, soweit diese in der Frühzeit bis nach I Ioo fertig wurde. Solche Einheitsmerkmale, wodurch die genannten Teile der Krypta durch ein neues, starkes Band in eine ununterbrochene Bauführung zusammengeschlossen werden, verdienen unsere besondere Beachtung. Hierher gehört vor allem der Einfluß der frühlombardischen Ornamentik, deren Eigentümlichkeiten an den antikisierenden Kapitellen der Krypta und am oberen Fenster in der Westwand des südlichen Querschiffes deutlich zutage treten. Weiter unten wird davon ausführlicher die Rede sein.

Die steile und hohe Basis hat besonders am Westfenster des nördlichen Kreuzarmes Vertreterinnen, die im II. Jahrhundert nicht leicht ihresgleichen finden werden (siehe Abb. II, 8-II). Der Halbsäulenfuß, der

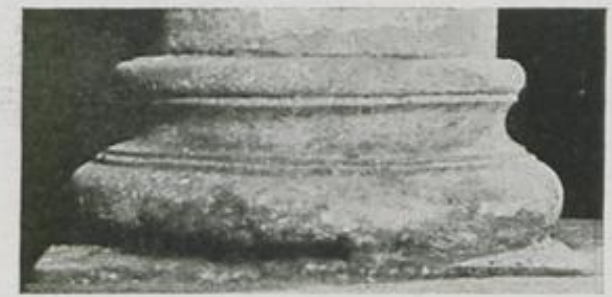

Abb, 13. Säulenfuß aus der Krypta. im Mißverhältnis von Breite und Höhe am weitesten geht und dazu keinen Unterschied der Ausladung zwischen den beiden Pfühlen einhält, erreicht eine Höhe von $38 \mathrm{~cm}$ bei nur $13 \mathrm{~cm}$ Breite 33$)$. Der untere Pfühl erscheint ebenso unschön abgeplattet wie die hohe Kehle verflacht. Auch ist die Stärke der beiden Pfühle nicht aufeinander abgewogen. Man muß jedoch zugeben, daß diese hohen Sockel in der Höhe, die sie einnehmen, infolge der optischen Verkürzung, besser wirken als diejenigen, welche das für die Augenhöhe normale Profil besitzen. Die letzteren scheinen verkümmert und zusammengedrückt. Wieweit hierbei künstlerische Berechnung mitwirkte, ist schwer zu sagen. Die Pfeiler des Langhauses weisen mit einigen Ausnahmen an den Halbsäulen das steile, sonst dagegen das normale attische Basenprofil auf (Abb. II, 14-I8). Ein Beispiel jener auch anderswo beobachteten Unbeholfenheit, die zwar ein Profil in gerader Linie tadellos, im Zusammenhange damit aber dasselbe im Halbkreis nur unvollkommen ausführen konnte. Daneben treffen wir jedoch an allen Teilen der Kirche auch Stücke an, die wie manche Basis in der Krypta und der Fuß der östlichen Säule unter der Empore vom Hauche klassischer Empfindung berührt sind (Abb, I3 u, I5). Diese Beobachtung läßt auf eine Tatsache schließen, die wiederum die Werke der Laacher Frühzeit vor den späteren deutlich kennzeichnet,

33) Daneben mißt die noch sehr steile Basis eines Säulchens der Hocheltener Triforien $35 \mathrm{~cm}$ Breite bei $28 \mathrm{~cm}$ Höhe. H, Rahtgens, Die Rekonstruktion der Stiftskirche zu Hochelten; Zeitschr. f. Geschichte d. Architektur, Jahrg. V (1912), S. 198, Abb. 29. 
nämlich daß Künstler und. Steinmetze sehr verschiedener Bildung nebeneinander tätig waren.

Die Verwendung der Ecksporen, die in der Krypta noch die Ausnahme bildete, tritt am Querschiff schon häufiger auf und wird im Langhause zur Regel. Die Ausführung der Eckzier gleicht derjenigen in Hersfeld 34). Auf der Plinthe ruht sie breit auf und übersteigt im Anschluß an den Pfühl nur wenig die Mitte. Dagegen berührt sie auf unserer Empore und in Schwarzrheindorf (vor I15I) die Hohlkehle. Etwas feinere, aber immer noch tief ansetzende Durchbildungen der Eck-

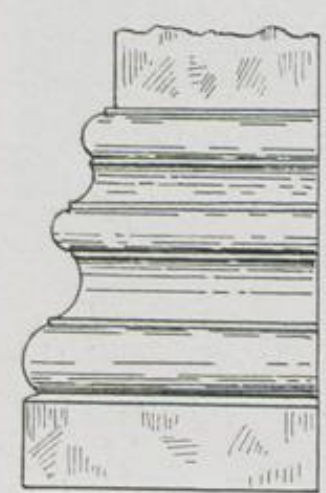

Abb, 14. Sockel aus St. Michael in Hildesheim. Vgl. hierzu Abb, $12 \mathrm{Nr}$. 2 und 5 . sporen, wie im Dome zu Konstanz 35), zeigen einige Halbșäulen des Lang. hauses vor dem Westchor und die Basis der öst. lichen Rundsäule unter der Empore,

Zwei weitere Merkmale der Frühzeit, die Krypta, Quer- und Langhaus verbinden, bilden eine ausgesprochene Vorliebe für die Verdoppelung der Plättchen und die Anwendung der halben Hohlkehle. Die doppelten Plättchen begegnen, wie an der vorhin genannten Hersfelder Basis 34), in der Krypta regelmäßig auf dem oberen Pfühl; ausnahmsweise an der Hohlkehle und am Kämpfer. In der Kirche zeigen diese Eigentümlichkeit die Sockel in der Ostapsis, in den Abseiten und am Westchor, ferner die Kämpter im nördlichen Kreuzarm des Quer-

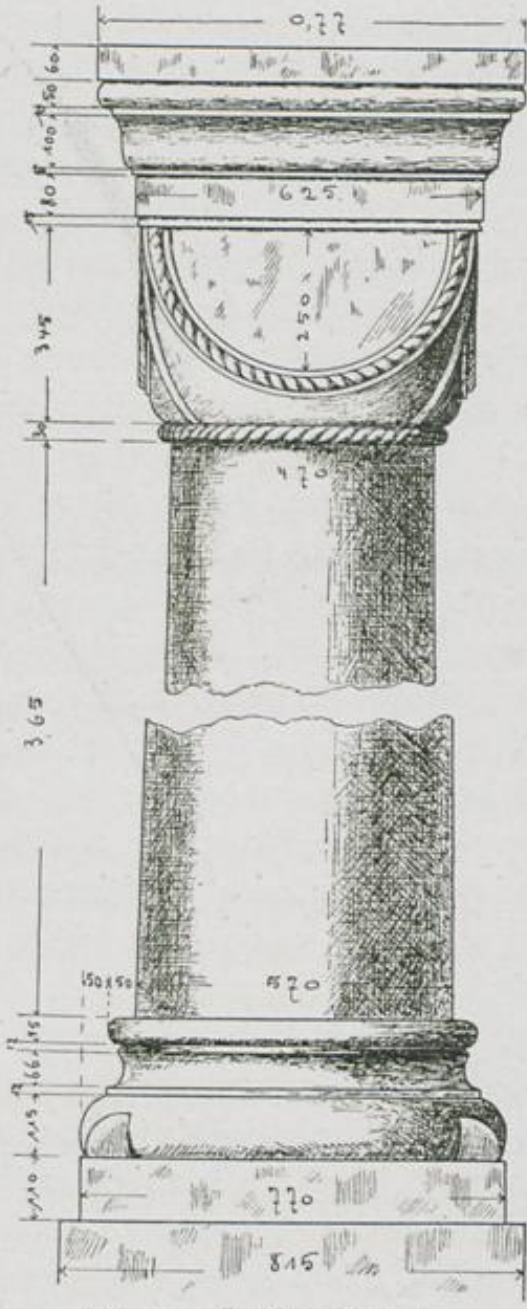

Abb. 15. Östliche Säule des Laacher Westchores. hauses, vor der Vierung und am Westbau. An den Kämpfern sind die verdoppelten Plättchen häufig in der Weise miteinander verbunden, daß sie im Profil einen spitzen Winkel bilden. An zwei Stellen

34) Dehio und v. Bezold, Atlas III., Taf. 300 , Nr. 5 .

35) Fr. X. Kraus, Die Kunstdenkm. d. Kr. Konstanz. Freiburg 1887, Taf. I. 
sind die Plättchen auch verdreifacht. Von andern frühromanischen Bauten bekennen sich zu dieser Gewohnheit Hersfeld ${ }^{3}$ ), St. Georg in Köln, Essen, St. Michael in Hildesheim, Ilsenburg, Quedlinburg (Unterkirche), der Konstanzer Dom 37) und andere.

Die halbe Hohlkehle begegnete uns schon öfters im Kreuzgange des Klosters. Die Krypta kennt an den Kämpfern überhaupt keine andere. Ferner treffen wir sie am Sockelprofil der ganzen Ostfront der Kirche und sonst an manchen Kämpfern und Sockeln der Frühzeit. Beispiele in derselben Fülle bieten die Bauten des II. Jahrhunderts in Echternach, die Ludgeridenkrypta in Werden, die ehemalige St. Martinskirche in Bonn, St. Maria im Kapitol und die Krypta von St. Severin in Köln. Das seltene Profil der Echternacher Säulen. basis hat, abgesehen von den beiden. Schaftringen, am Sockel unseres nördlichen Rundturmes Nachahmung gefunden (Abb. 12, Nr. 16).

Selbst die reicheren Formen der Kirche, zu deren Betrachtung wir jetzt übergehen, haben in der Krypta an den vier hohen Füßen, welche drei statt zwei Pfühle annehmen, ihre Vorgänger. In erster Linie sind hier zu nennen die unteren Kämpfer im Langhause vor der Vierung und am Westchor. Stellenweise bieten sie eine solche Fülle von Gliederungen, daß sie das Auge kaum übersehen kann. Solche Prunkstücke, wie Abb. 12, I - 5 sie vorführt, haben auch St. Michael in Hildesheim $3^{8}$ ) und der Konstanzer Dom aufzuweisen. Die Pfeilerbasis der ersteren Kirche kehrt sogar einmal an der Vierung ganz genau, ein anderes Mal am Westchor um zwei Plättchen bereichert als Kämpfer wieder (Abb. I4). Zwei grundverschiedene Profile an demselben

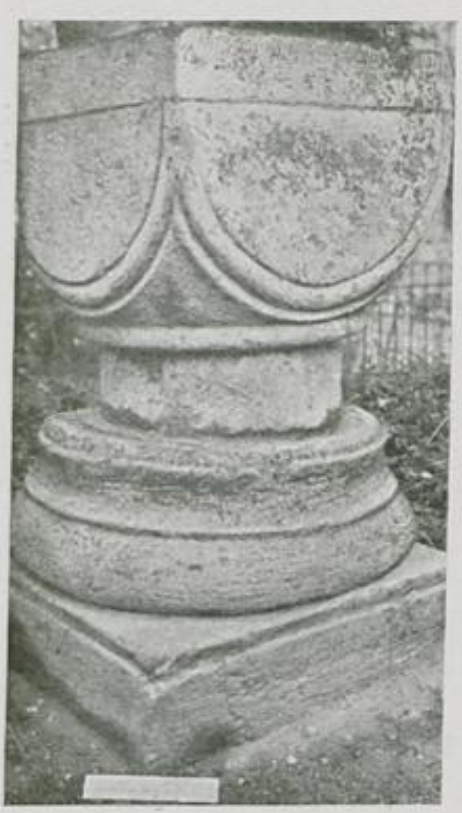

Abb. 16. Kapitell und Basis aus der ehemaligen St. Martinskirche in Bonn. Werkstück, eine hier und da im II. Jahrhundert beliebte Glanzleistung, findet sich am Gurtgesimse der Westwand des nördlichen Kreuzarmes.

An den Würfelkapitellen ist der Rand des einfachen Schildes häufig nach innen abgeschrägt, wodurch die Vorstellung eines Doppelschildes erweckt wird; vgl. z. B.

36) H. Otte, Gesch. d. deutsch. Baukunst, I874, S. 244, Abb. 113.

37) Dehio und v. Bezold, Atlas III., Taf. 311 , Nr. $1-5$ u. 10.

$\left.{ }^{38}\right)$ Dehio und v. Bezold, Atlas HI., Taf. 311,3 ; Zeller, Die roman. Denkmäler von Hildesheim, Berlin I907, Taf. 8, Abb. 3 u. 6 . 
Abb. I7. In Wirklichkeit aber kommen ganz verdoppelte, übereinander liegende Schilde nur selten und dann in sehr feiner Ausführung vor. Der einfache Schild erscheint mehrmals von einem Rundstäbchen umrahmt, das an der östlichen Säule

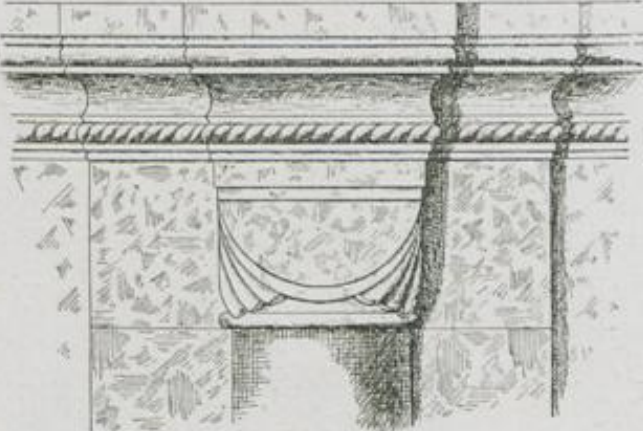

Abb. 17. Kapitell und Klimpfergesims im nördlichen Seitenschiff vor der Vierung.

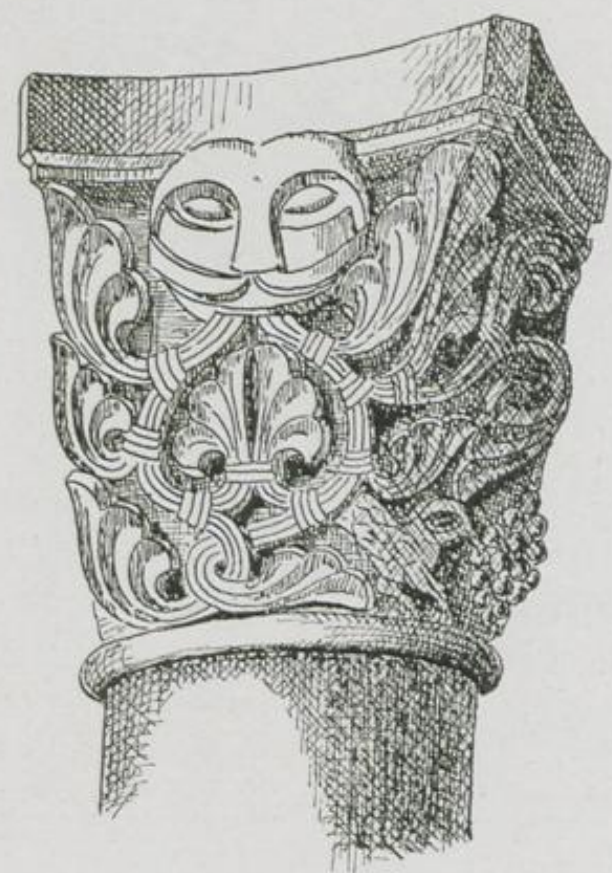

Abb. 18. Kapitell des Fensters in der Westwand des studlichen Querhausfluggels. unter der Empore in ein Seilgewinde umgewandelt ist (Abb. I5). Alle drei beschriebenen Verzierungen des Schildes gehören schon vor dem Ende des II. Jahrhunderts zum Bestande der romanischen Ornamentik. Der vom Stäbchen umrahmte Schild begegnet uns an den Überresten der ehemaligen St. Martinskirche in Bonn, die der ersten Hälfte des II. Jahrhunderts angehört (Abb. I6) 39). Die in der einen oder andern Weise verdoppelten Schilde treffen wir an den Kapitellen von St. Aurelius und St. Peter in Hirschau und amSüdostturm desSpeierer Domes $\left.4^{\circ}\right)$. Dreimal tritt an den Laacher Würfelkapitellen des Querhauses eine originelle, drei- oder fünfteilige Eckblattverzierung auf, die nur noch ein einziges Mal im nördlichen Seitenschiff wiederkehrt und sich meines Wissens sonst an keinem romanischen Bauwerk in dieser Gestalt findet (Abb. 17). Diese ungewöhnlicheEckverzierung am Kapitell läßt die verhältnismäßig früh fast zur Regel gewordene Anwendung der Sporen an der Basis leichter verstehen. Die Sockel der Langhauspfeiler vor der Vierung zeigen an Stelle der ver-

39) Dehio, Handbuch V, S. 52. Clemen, Kunstdenkm. d. Stadt u. d. Kr. Bonn (1905), S. $129-132$. Mehrere Säulen der alten Taufkirche stehen jetzt in den Anlagen des Bonner Prov,-Museums. Die beiden Abbildungen verdanke ich der Güte des Herrn J. Hagen, Assistent a. Rhein. Prov.-Museum. Weitere Beispicle, wahrscheinlich aus der annonischen Zeit, befinden sich an der nördlichen Seitenschiffmauer von St. Ursula in Köln; vgl. Rathgens, S. Maria i. Kapitol (1913), S. I12-113.

$\left.4^{\circ}\right)$ E. Paulus, Die Kunst- und Altertumsdenkmale im Königr. Württemberg, I 893 , Hirschau; MeyerSchwartau, Der Dom zu Speier (r893), S. $9 \mathrm{t} \longrightarrow 92$. 
doppelten Plättchen über der attischen Basis ein kleines Überleitungsglied zum Schaft, das als Schräge, Hohlkehle, Wulst und Karnies verschieden gestaltet wird (Abb. II, I4-I7). Die frühesten mir bekannten Beispiele hiervon besitzt die Krypta des hl. Ludgerus zu Werden ${ }^{4}$ ). Weitere Hinweise auf die Frühzeit dürfen wir im $\mathrm{Zu}$ sammenhange mit den bisher betrachteten Merkmalen in der häufigen Anwendung der Karniese und des Gewindes verschiedener Art erblicken. Vom letzteren wird weiter unten (S. 34) ausführlicher die Rede sein. Eingehendere Würdigung verdient die Pflanzen- und Tierornamentik.

Diese Zierglieder der Laacher Frühbauten lassen deutlich den Einfluß der oberitalischen Ornamentik erkennen, der seit dem Ende des II. Jahrhunderts in Quedlinburg, Mainz, Klosterrath und Hochelten vielfach und überzeugend nachgewiesen worden ist $4 z$ ). Wie in $\mathrm{S}$. Abbondio in Como und S. Ambrogio in Mailand, so finden wir an den Kapitellen des Fensters in der Westwand des südlichen Querschiffes dreisträhnige, verschlungene Bänder, die in dreiteiligen Halbblättern

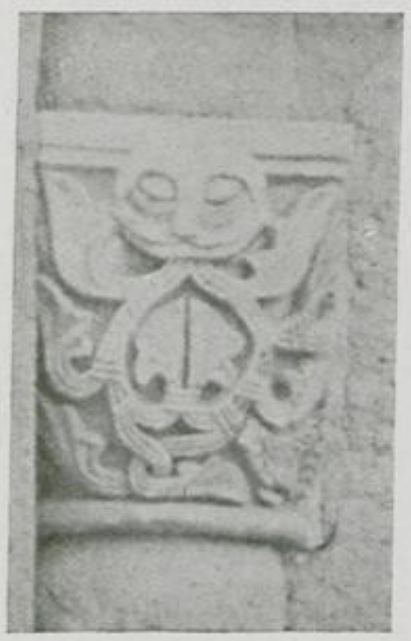

Abb. 19. Kapitell des Fensters in der Westwand des sudlichen Querhausflügels. endigen (Abb. I8 u. 19) 43). Wo der Hauptstrang Nebenzweige treibt, werden beide, wie in S. Ambrogio, durch ein dreisträhniges Querbändchen miteinander verschnürt 44). Traubenpickende Vögel und kleine Masken

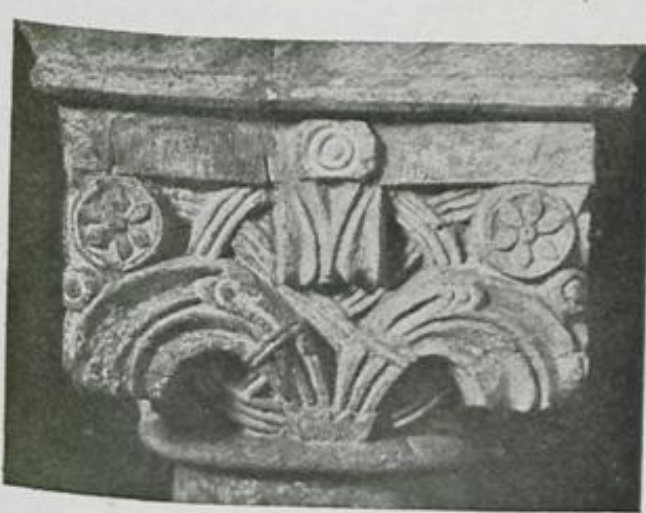

Abb, 20, Laubkapitell aus der Krypta. an den eingezogenen Auflagern der Kapitelle sind weitere Ähnlichkeiten zwischen der Laacher und der oberitalischen Ornamentik. Die Verwandtschaft erstreckt sich selbst auf die Technik. Das Laubornament tritt nicht

4t) Wilhelm Effmann, Die karolingisch-ottonischen Bauten zu Werden, StraBburg 1899, S. 85 , Abb. 59 .

42) A. Goldschmidt, Die Bauornamentik in Sachsen im 12. Jahrhundert. Monatshefte für Kunstwissenschaft 1910 , Heft 8 u. 9, S. 299-314. R. Kautzsch, Oberitalien und der Mittelrhein im 12. Jahrhundert, Bericht über den 10. Internationalen
Kunsthistorischen KongreB in Rom, 1912. H. Rathgens, Die Rekonstruktion der Stiftskirche zu Hochelten. Zeitschr. f. Gesch. d. Architektur, Jahrg. V, 1912, S. 198 ff. und: Die Kirche S. Maria im Kapitol zu Küln. Düsseldorf 1913, S. $178 \mathrm{ff}$.

43) Vgl. auch C. Martin, L'art roman en Italie. Paris 1912. S. Abbondio, II. Taf. 22-23; S. Am-

brogio, I. Taf. $58-61$.

44) Dehio und v. Bezold, Atlas III., Taf. 323, 6 u. 10. 
plastisch abgerundet hervor. Es ist vielmehr ganz flach gehalten und nur durch leichtes Vertiefen des Grundes hergestellt. Dagegen zeichnen sich die Laacher Bildwerke vor den italienischen aus durch größere Feinheit in der ganzen Haltung sowohl als in der Durchbildung der Einzelheiten.

An den höchst originellen, von reicher Erfindungsgabe und gutem Kompositionstalent zeugenden Laubkapitellen der Krypta ist der Kern von drei- und zweisträhnigen Bändern in den verschiedensten Windungen umschlungen und wie zusammengeschnürt. Breite Bänder rollen sich an den Ecken unter der eingezogenen, mit Rosetten verzierten Deckplatte spiralförmig zusammen. Ein genaues Gegenstück zu diesen Eckvoluten aus dem Ir. Jahrhundert besitzt der Kreuzgang der Cölestiner,

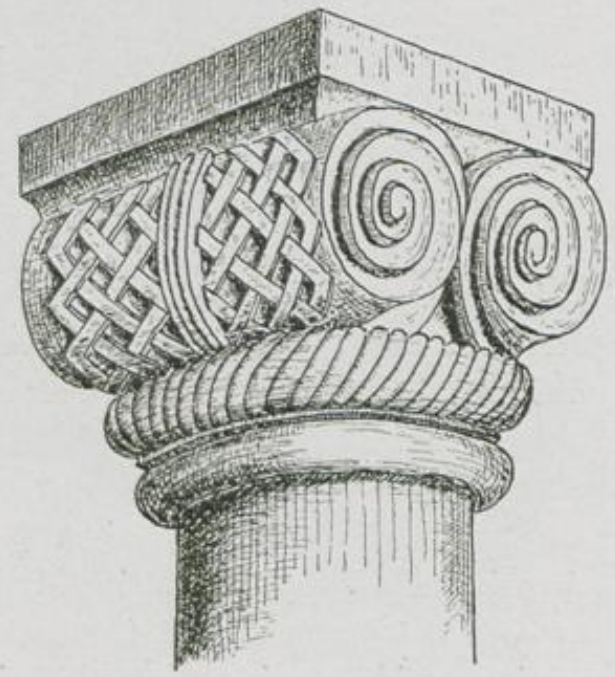

Abb, 2r. Jonisches Polsterkapitell in Maria Laach.

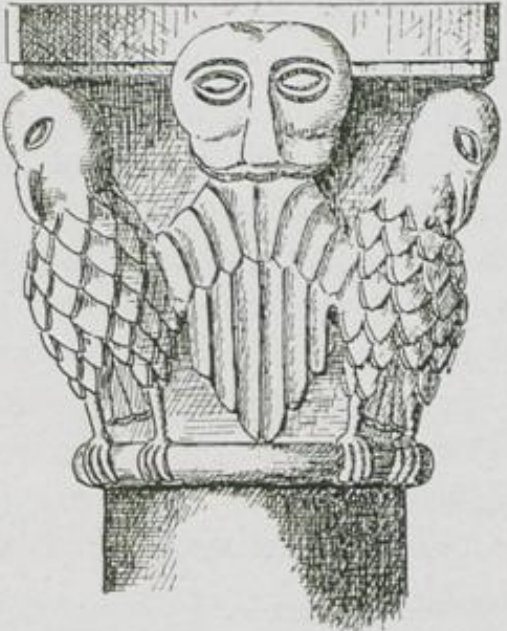

Abb. 22. Adlerkapitell in Maria Laach.

S. Stefano, in Bologna 45). Andere einheimische Vorbilder jonischer Kapitelle boten ohne Zweifel die zahlreichen, auch heute noch in den rheinischen Museen erhaltenen Reste römischer Architektur. In der Laacher Krypta sind diese Schnecken stellenweise wie in Speier zu sechsblätterigen Rosetten umgebildet. Der an den antiken Vorbildern geschulte Blick unseres Steinmetzen verrät sich auch in dem überfallenden Blatt unter der Verzierung der Deckplatte, das einmal mit einer Maske vertauscht wird. In seinem Werke über die lombardische Architektur führt De Dartein Kapitelle aus dem Baptisterium von S. Callisto in Cividale vor, deren erste Blattreihe unter dem Auflager ganz ähnlich angeordnet ist ${ }^{46}$ ). Die zweite Reihe an unseren Kapitellen bilden lanzettförmige Palmblätter, die zu zwei oder drei durch ein Band zusammengehalten werden. Sie sind vorn über dem Schaftring eingesteckt, streben

45) Martin a. a. O. II. Taf. 3 r.

46) De Dartein, Étude sur l'architecture lombarde. Atlas Taf. 9 u. 12. 
nach den Ecken und neigen sich leicht unter der Oberlast (Abb. 20; das Gegenstück aus der Krypta hierzu siehe P. Adalb. Schippers, M. Laach und die Kunst, Trier, I9II, Abb. 4).

Am meisten verwandt mit den eben beschriebenen Kapitellen der Krypta ist ein jonisches Polsterkapitell (Abb. 2I). Aus weißem Kalkstein gefertigt, stammt es mit dem gleich zu erwähnenden Adlerkapitell aus grauem Sandstein ohne Zweifel aus der Klosteranlage, vielleicht von den Doppelfenstern zu beiden Seiten des Kapitelportals. Wie oben erwähnt, wurde das Kapitel um das Jahr I700 umgebaut, und von hier mögen die beiden wertvollen Stücke als Lückenbüßer an ihren jetzigen Platz auf der Galerie des Westturmes gewandert sein.

Das eben genannte Adlerkapitell (Abb. 22) ist ein weiterer bedeutsamer Beleg für den Zusammenhang zwischen der Laacher und oberitalischen Ornamentik. Wir finden es in S. Ambrogio in Mailand und S. Abbondio in Como. Wie dort, so wird auch unser Kapitell von vier auf dem Halsring der Säule stehenden Vögeln gebildet, deren Brust

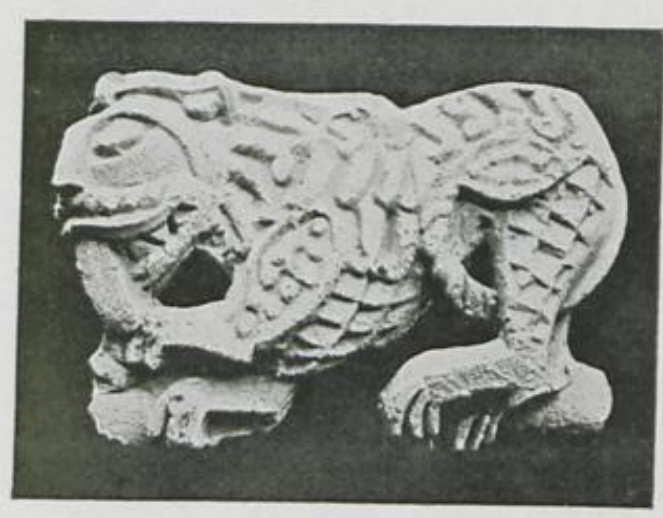

Abb. 23. Löwe als Sockeltrăger am Fenster in der Westwand des sudlichen Querhausflugels. und Kopf die Ecken und deren ausgebreitete Flügel die Seiten des Kapitells ausmachen. Noch auffallender ist die Ähnlichkeit des Gefieders, das hüben und drüben am Leibe wie die Schuppen eines Fisches dargestellt wird. Auch in der Bildung der Flügel herrscht große Verwandtschaft. In beiden Punkten weichen die Adlerkapitelle der Schloßkirche zu Quedlinburg von den italienischen Vorbildern ab. Die bei den Laacher Steinmetzen beliebten Masken am Rande des Auflagers kehren auch an der Kanzel von S. Ambrogio wieder.

Auch zwei Figurenkapitelle der Empore gehören nach Stil und Stoff hierher. Sie sind in dem weißen Kalkstein hergestellt, den nur die Laacher Frühzeit verarbeitet. Zwei Seiten der Kapitelle verwachsen mit der Mauer. Das eine zeigt mitten auf der Schildfläche einen Menschenkopf, dessen Stirne ein Perlenband schmückt. Rechts und links stehen zweibeinige geflügelte Drachen, deren lange Hälse an den Ecken durch ein Band zusammengehalten werden. Mit aufgesperrtem Rachen wenden sich die Tiere gegen den Menschen. Ihre Flügel sind am Ansatz mit gelochten Spangen verziert. Der lange Schwanz windet sich spiralförmig und endet in einem dreiteiligen Halbblatt. Das Gegenstück zu dem beschriebenen Kapitell stellt auf der einen Schildfläche einen springenden Hahn mit hohem Kamm, Bartlappen und geschwungenen Schwanzfedern dar, auf der anderen eine Henne von ihren Küchlein 
begleitet. Beide stürzen sich mit geöffneten Schnäbeln auf den die vordere Ecke einnehmenden Raubvogel, der in seinen Krallen eine Taube hält. Die Ostapsis und die Zwerggalerie des Mainzer Domes, die in ihrer Ornamentik so überraschende Verwandtschaft mit Oberitalien bekunden, weisen ähnliche, dem Beginn des I2. Jahrhunderts angehörende Kapitelle aut.

Ein von Anfang an in der italienischen Bauplastik beliebtes Motiv ist der Löwe als Säulenträger. Auch dieser fehit der Laacher Ornamentik nicht. Das Löwenpaar

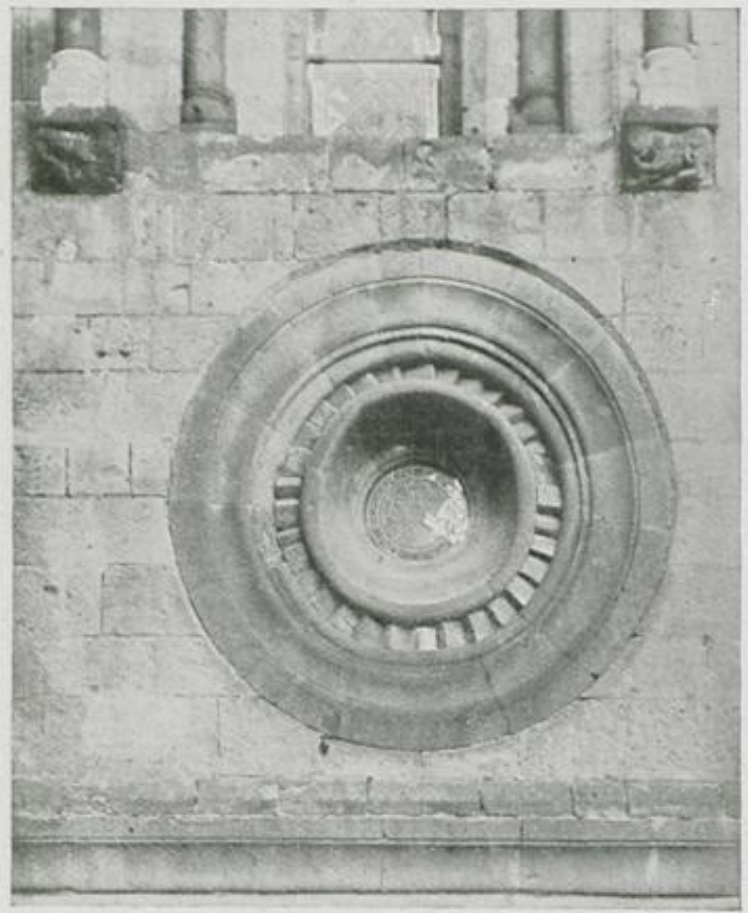

Abb, 24. Rundfenster in der Westwand des sudlichen Querhausfluggels. unter den Halbsäulen des Fensters an der Westwand des südlichen Querschiffes reiht sich durch die ganze Art seiner Stilisierung von selbst in die bisher besprochenen Formen ein 47). Wie bei den Adlern die kleinen Federn, so sind bei den Löwen die kurzen Haare tannenzapfenartig geschuppt. Die in Lappen herabhängende Mähne, die ausgestreckte Zunge, die dreieckigen, spitzen Zähne haben unsere Löwen gemeinsam mit denen an der Vorderseite des Altars des hl. Agrikola in S. Stefano zu Bologna $\left.4^{8}\right)$. Dagegen erinnern die äußerlich dem Körper angehefteten, punktierten Vorderbeine an die unter italienischem Einflusse stehenden Adlerkapitelle der Quedlinburger Schloßkapelle. Schwanz und Schnurrbart sind nach italienischer Art gedreht. Wie an der. Kanzel von $\mathrm{S}$. Ambrogio ist der Schweif an den Flanken hinaufgeschlagen und endigt in einem punktierten Büschel. Während ein Löwe auf einem Rundstabe steht, tritt der andere auf zwei Schlangen, die mit offenem Rachen den Löwen angreifen. Das Ende der gedrehten Schwänze verwickelt sich und endigt in dreiteiligen Halbblättern.

Wie in Oberitalien, so zeigt sich auch an unserer Kirche eine ausgesprochene Vorliebe für das Gewinde. Es tritt in verschiedener Durchbildung auf. Am Grabstein des Kreuzganges (Abb. 2), am Kapitell der östlichen Mittelsäule des Westchores (Abb. 15)

47) Abb. 23 u. 24; das Fenster siehe Adalb. Schippers, M. Laach und die Kunst, Trier, 1911, Abb.11.

48) De Dartein a. a. O., Atlas, Taf. 6 u. II. 
und am ersten Kämpfer des nördlichen Seitenschiffes vor der Vierung (Abb. 17) begegnet uns das Tauwerk. Das südliche Westportal ist mit ejnem gedrehten Rundstab eingefaßt, dessen Bänder leicht gekehlt sind (Abb. 36). Zwei Säulenfüße in der Krypta zeigen an einem der drei Pfühle die Nachahmung des Schraubengewindes (Abb. II, 6).

Selbst die dem oberitalienischen Backsteinbau so naheliegende Stromschicht sollte bei unserem Quaderbau wenigstens einmal am Rundfenster in der Westwand des südlichen Querschiffes den Formenschatz der Kirche bereichern (Abb. 24).

Betrachten wir nun die Fensterarchitektur des Querschiffes nach ihrer systematischen Anlage. Sie weist ebenfalls entschieden nach Oberitalien hin (Abb. 25). Die Unterschiede sind leicht als selbständige Abänderungen der Laacher Baukünstler zu erkennen. Die Gewände unserer Fenster haben einen doppelten Ausschnitt. Im Winkel des Inneren läuft, wie in S. Abbondio in Como, ein zur Säule mit attischer Basis und Würfeloder Laubkapitell ausgebildeter Rundstab. Während nun S. Abbondio hierauf einen breiten Laubfries folgen läßt, leitet unser Rahmen durch einen weichen Karnies sanft zur äußeren Wandfläche über. Das Mittelfenster der Nordwand zeigt

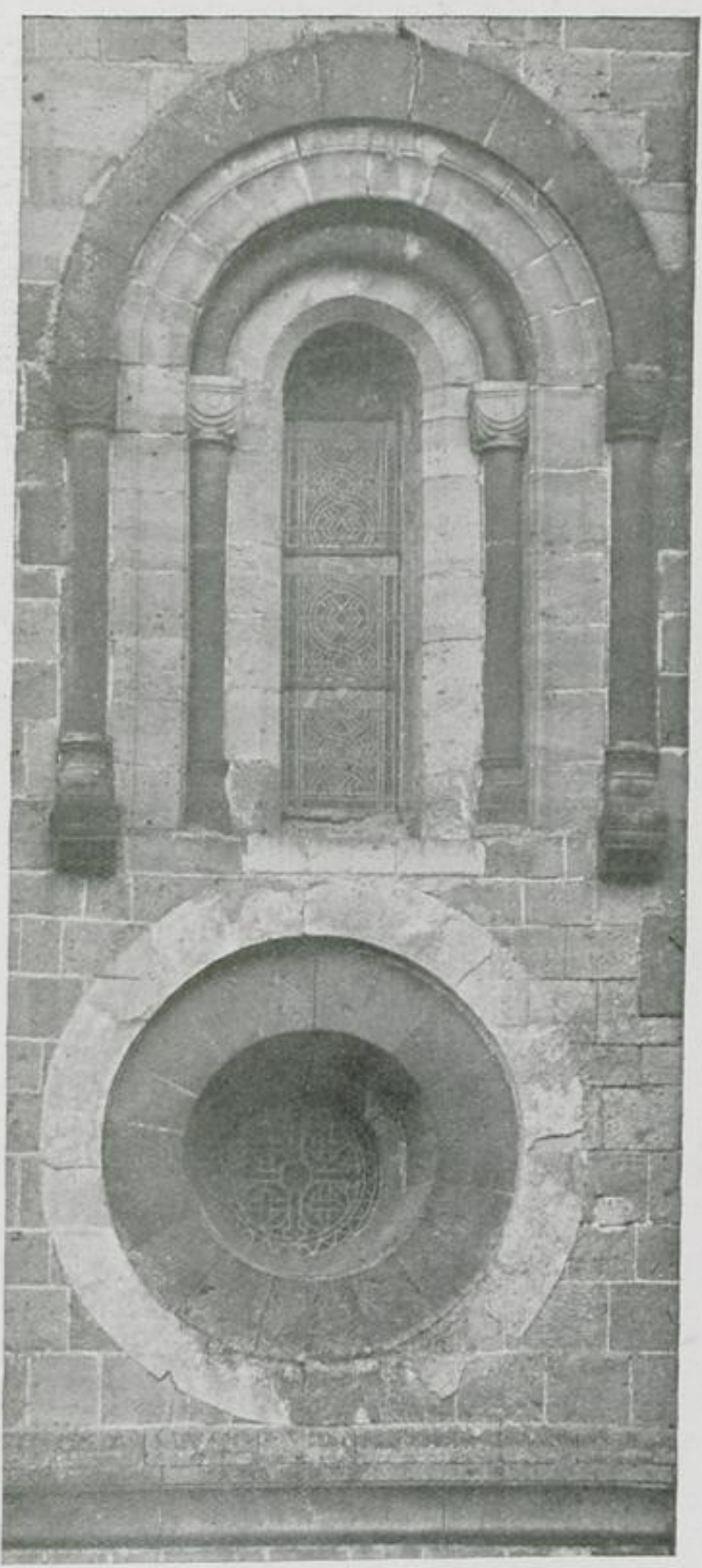

Abb. 25. Fenster in der Westwand des nördlichen Querhausflügels. die umgekehrte Reihenfolge. An der Ost- und Westwand wird der äußere Karnies in wirkungsvoller Weise nochmals von einer Bogenstellung eingefaßt. Zwei 
Halbsäulen mit attischen Basen ruhen auf Konsolen, deren Profil aus Platte, Plättchen, Wulst, Plättchen und stark überspringender Hohlkehle mit Sporen in der Mitte besteht. Am Fenster der Westwand des südlichen Flügels treten an die Stelle dieser Konsolen zwei interessante Löwengestalten, von denen schon die Rede

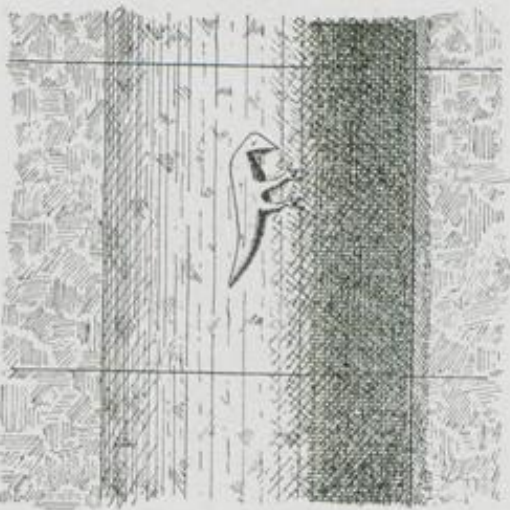

Abb, 26. Tierzeichen im Mittelschiff vor der Vierung (Größe $22 \mathrm{~cm}$ ). war. Die Würfelkapitelle der Halbsäulen sind in passender Weise von einem flachen Wandbogen bekrönt. An dem eben genannten Fenster erhält dieser eine nochmalige quadratische Einfassung, in der Weise, wie die Hirschauer Benediktiner die Arkaden des Mittelschiffes schmückten.

In ähnlicher Weise wie bei uns hat sich der italienische Einfluß an der Schloßkirche in Quedlinburg an der Fensterarchitektur geltend gemacht. Auch sonst zeigt die lombardische Ornamentik an beiden deutschen Bauten manche charakteristische Verwandtschaftszüge, die gemeinsam auf S. Abbondio in Como zurückgehen. Einige wurden schon erwähnt. Neben der Stromschicht, der Vorliebe für das Gewinde, möchte ich noch auf den ältesten Rundbogenfries unserer Kirche an den Nebenapsiden hinweisen, den ich S. 22 näher beschrieben habe (Abb. IO). Die Ähnlichkeit mit dem Rundbogenfries in S. Abbondio und Quedlinburg springt in die Augen 49).

Kein Bauteil unserer Kirche zeigt in seinen Ziergliedern eine so überraschende und charakteristische Verwandtschaft mit der frühlombardischen Formensprache Oberitaliens wie das Querschiff. So ist auch diese Tatsache wieder geeignet, meine Datierung zu rechtfertigen.

Auf der südlichen Halbsäule des Mittelschiffes vor der Vierung findet sich, 3,30 $\mathrm{m}$ über dem Bø̊den, ein Tierzeichen, dessen Sinn und Bedeutung ich nicht zu erklären vermag (Abb, 26).

Den Gegenbeweis zu meinen bisherigen Ausführungen möchte ich wenigstens durch einige Beispiele erbringen und damit die fortgeschritteneren Zierformen der Zeit zwischen II3O u. I170 veranschaulichen. Der Säulenfuß aus der

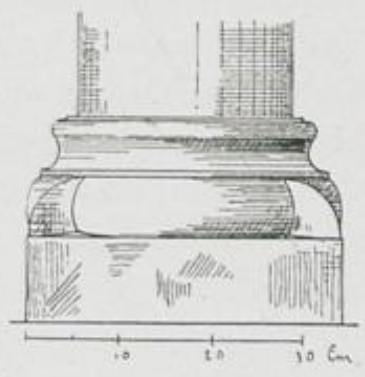

Abb. 27. SäulenfuB aus der Westapsis auf der Empore. Westapsis auf der Empore gehört zu den jüngsten nach den bisher besprochenen Basen der Krypta, des Querschiffes und des Langhauses. Die Abweichungen von diesen Stücken in der Bildung des Profils und der Ecksporen liegen zutage (Abb. 27). Am Kapitell aus dem Inneren

49) Siehe die $\mathrm{Abb}$, der beiden letzteren bei Goldschmidt a. a. O., Monatshefte 1910, 8/9, S. 307 . 
der Ostapsis ist zunächst der an unserer Kirche zum ersten Male auftretende, laubgeschmückte Abakus $\mathrm{zu}$ beachten (Abb. 28). Das siebenteilige, kreis. förmig umrahmte Blatt gibt sich bei näherer Betrachtung als die Zusammen.

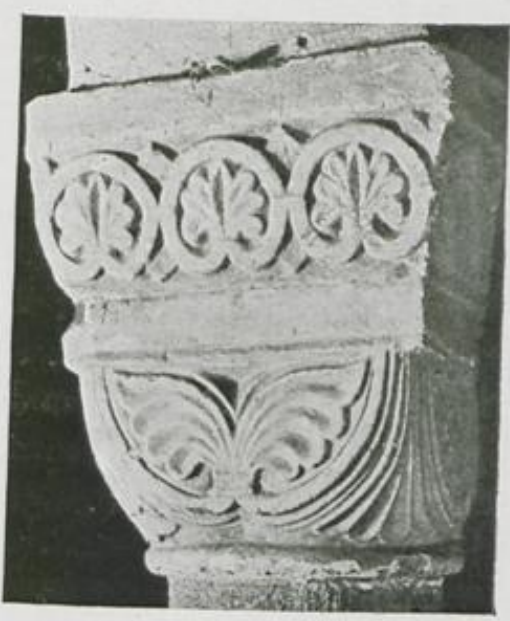

Abb. 28. Kapitell aus der Ostapsis.

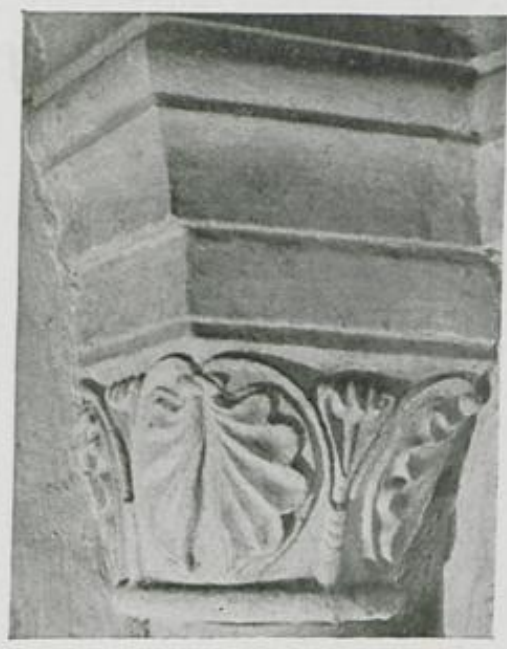

Abb, 29. Kapitell der Empore.

setzung von zwei Halbblättern zu erkennen, deren ungegliederte Stiele ein Band bilden und in sich zurücklaufen. In derselben Weise ist der dreimal abgesetzte Schild des Würfelkapitells verziert. Nur sind aus den dreiteiligen Halbblättern der Frühzeit

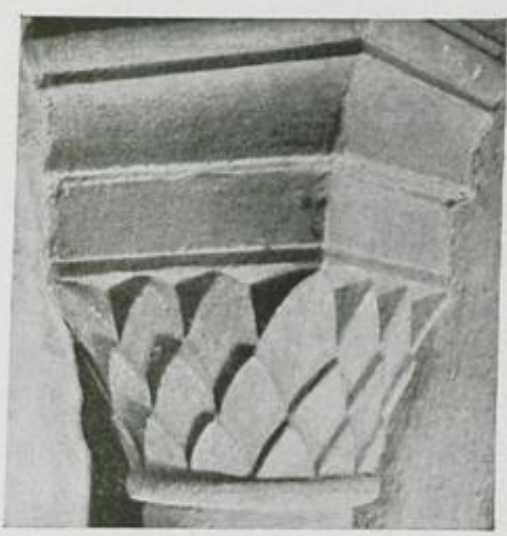

Abb. 3o. Kapitell der Empore.

vierteilige geworden. Das mittlere des siebenlappigen Blattes ergab bei der Teilung wieder zwei halbe. So nahmen die anfangs dreiteiligen Halbblätter durch Zusammenfügung und darauffolgende Teilung an Zahl immer zu, je nach Spielraum und Abwechslungsbedürfnis. 
Dieser Fortschritt in der Entwicklung des Laubes geht Hand in Hand mit einem Rückschritt, der uns klar wird, wenn wir das besprochene Kapitell mit dem der Abb. I 8 vergleichen. Hier tritt uns ein nach der Natur stilisiertes organisches Rankenlaubwerk entgegen mit Haupt- und Nebenzweigen, sogar durch Vögel belebt, die an den Früchten picken. Dagegen erscheint das Laub der späteren Stücke meistens schematisiert, das Kapitell wie ein künstlich zusammengestellter Strauß aus gleichartigen oder verschiedenen Laubzweigen. Die Eckzier am Würfelkapitell besteht nicht mehr aus Stengeln, wie auf Abb. I7, sondern aus Blättern.

Der Kreuzgang des Bonner Münsters besitzt, abgesehen von dem Abakus, ein dem beschriebenen Laacher ganz verwandtes, laubverziertes Würfelkapitell 50). Wie dieses, so bestätigen zwei andere, hier abgebildete Kapitelle der Laacher Empore (Abb. 29 u. 30) $5^{x}$, die ebenfalls fast ganz genau im Bonner Kreuzgange wiederkehren, neuerdings die von mir früher schon nachgewiesenen Beziehungen zwischen dem Laacher und dem Bonner Münster $5^{2}$ ). Gleichzeitig veranschaulichen sie durch weitere Beispiele die von der Frühzeit abweichenden Schmuckformen.

\section{DAS LANGHAUS UND SEIN GEWÖLBESYSTEM.}

Die Bedeutung der im dritten Teile dargelegten Baugeschichte gipfelt darin, daß sie zeigt, wie das Gewölbesystem des Langhauses in einheitlicher Bauführung entstanden ist. Die von Fr. J. Schmitt 53) und Huppertz 54) vertretene Ansicht, das Langhaus sei ursprünglich auf flache Holzdecke geplant gewesen, ist wohl damit widerlegt. Denn bei einheitlicher Bauleitung und ununterbrochener Fortsetzung wird doch niemand ernstlich in so kurzer Zeit einen so wichtigen und folgenschweren Planwechsel annehmen wollen. Wäre ein solcher eingetreten, dann müßte man eher erwarten, daß nach dem Tode Pfalzgraf Heinrichs ein Gewölbeplan zugunsten einer flachen Decke aufgegeben worden sei, und nicht umgekehrt. Bevor ich zur Betrachtung des Gewölbesystems selber übergehe, möchte ich einigen Einwendungen zuvorkommen.

50) Siehe Dehio und v. Bezold, Taf. 312,7 .

5r) Vgl. Abb. 29 mit Clemen, Die Kunstdenkmäler der Stadt u. d. Kr. Bonn (1905) S. 101, Abb. 49 , obere Reihe, 3. Kapitell. Das Bonner Gegenstück zu meiner Abb. 30 befindet sich im Ostflügel des Kreuzganges. Die beiden letzteren unterscheiden sich dadurch, daB das Laacher Kapitell drei, das Bonner da gegen vier Reihen kurzer, spitzer Blatter aufweist, womit das erstere sich als das ätere und wohl auch als das Vorbild zu erkennen gibt.

52) Adalb. Schippers, Die Ostchöre des Bonner Münsters und der Abteikirche zu Maria Laach, Zeitschr. f. Gesch. der Architektur, (1913) VI, S. 87-95, mit 3 Abb.

53) Uber den Urbau der Benediktinerabteikirche S. Maria und Nikolaus zu Laach, Die christl. Kunst IV, $1907 / 08$, S. $\mathrm{I}$ ff. Siehe meine Entgegnung: Adalb. Schippers, der Urbau der Abteikirche Maria Laach, mit 3 Abb. ebenda S. $266 \mathrm{ff}$.

54) A. a. O. 
Dehio und v. Bezold schrieben in ihrem Werke über die kirchliche Baukunst des Abendlandes von unserer Kirche: Das Langhaus zeigt, daß es von Grund aus auf gewölbtes Deckenwerk angelegt war 55). Im Handbuch hat ersterer seine Ansicht etwas eingeschränkt. Vielleicht, so schreibt er, war es anfangs mit Flachdecke beabsichtigt $\left.5^{6}\right)$. Eine Andeutung auf die Veränderung des ersten Entwurfs findet er, und nach ihm auch Huppertz, darin, daB das erste Joch vor der Vierung breiter ist als die übrigen. Für diese Unregelmäßigkeit habe ich den ebenso einfachen wie einleuchtenden Grund angegeben 57). Die erste Lisene des südlichen Seitenschiffes wurde auf die Breite des Kreuzganges angesetzt, weil die entsprechende Außenlisene den Gurtbogen des Kreuzganggewölbes von derOstmauer her aufnehmen sollte. Also nicht das erste Joch als Ganzes wurde breiter angelegt, sondern im ersten Joch wurde der erste Lisenenabstand aus dem angeführten Grunde breiter angesetzt: die erste Lisene steht deshalb auch nicht, wie man auf den ersten Blick erkennt, auf der Mitte der Jochbreite $5^{8}$ ).

Im übrigen enthält die Erweiterung des ersten Joches auch einen nicht zu verkennenden ästhetischen Vorteil. Sie vermittelt einen glücklichen Übergang von den Arkaden des Mittelschiffes zu den fast doppelt so breiten der Vierung und gestattet einen besseren Durchblick in die Flügel des Querhauses. Einen Beweis hierfür liefert z. B. die überraschende Tatsache, daß man von den Ecken neben den Westportalen die Mitte der Nebenapsiden im Querschiff, somit den Tabernakel und den Priester, bequem sehen kann. Gibt es eine gewölbte Pfeilerbasilika von gleichem Alter und gleicher Größe, die eine solche Durchsichtigkeit besitzt?

Diese beschriebene Unregelmäßigkeit abgerechnet, fragt es sich, nach welchem System die übrigen Lisenenabstände des Langhauses angeordnet sind. Als Gesetz für die Stützenverteilung der flachgedeckten Basilika nimmt Huppertz in nachkarolingischer Zeit die Zwei- oder Dreiteilung der Quadratseite an 59). In einem Auf-

55) A, a. O. S. 467: Kurz vorher urteilte R. Dohme in seiner „Geschichte der ceutschen Baukunste, Berlin 1887, S. 62: Daß der Bau (der Laacher Abteikirche) von Anfang an auf Wölbung berechnet gewesen, daruber lassen die reich gegliederten Pfeiler des Langhauses keinen Zweifel.

$\left.{ }^{56}\right)$ Dehio scheint seine ursprüngliche Auffassung über das Langhaus auf Grund der Abhandlung von Fr. J. Schmitt, a, a. O., geändert zu haben. Wie dieser iden stärksten Kontrast « zwischen der Außenarchitektur des Mittelschiffes und der formalen Gliederung der Außenwände der Abseiten, des östlichen Querhauses und des Ostchores konstruiert, so will auch Dehio waus der Gesimsgliederung des Hochschiffes im Vergleich mit den beiden Querhäusern erkennen, daß das Langhaus jünger ist als diesee. Handb. IV, S. 200. Nun nimmt aber Schmitt an, daB der Bogenfries des westlichen Querbaues später dem des Mittelschiffes angepaßt wurde. S. 3. In Wirklichkeit kann kein Auge einen Unterschied zwischen den beiden Bogenfriesen wahrnehmen. Wie jedes Joch des Langhauses unter dem Schachbrettfries mit drei kleinen Bogen geschmückt ist, so auch der westliche Querbau auf derselben Länge.

57) Zeitschr. f. Christl. Kunst (1912) Heft 6, Sp. 204, mit 2 Abb. Grundrib u. Querschnitt. Diese auch in Adalb. Schippers, M. Laach u. die Kunst, Abb. 3 u. 6. Dem GrundriB der Kirche ist der des Kreuzganges in Abb. 29 angeschlossen.

58) Vgl. Abb. 8 u. Huppertz a. a. O. Taf. V.

59) A. a. O. S. 1 ff. Bereits für die karolingische Zeit haben Adamy, Architektonik des muhamedanischen und romanischen Stils, Hannover 1887, S. 180 , und Effmann, Die karolingisch-ottonischen Bauten 
satz in der Literarischen Beilage der Kölnischen Volkszeitung findet er diese Regel an unserer Kirche angewendet. "Auch der ursprüngliche Plan der 1093 begonnenen Laacher Kirche war nach dem ..... System der Dreiteilung des Quadrats für Holzdecke angelegt $\left.{ }^{60}{ }^{6}\right)$. Wie aus den Ausführungen des Verfassers hervorgeht, tritt dieses System darin zutage, daß ursprünglich eine Elfteilung beabsichtigt war, wie das ja auch in Limburg a. d. Haardt der Fall sei. Eine einfache Rechnung hätte Huppertz über den Irrtum belehren können, der in der letzteren Annahme enthalten ist. Da das Einheitsmaß, aus dem der Grundriß sich entwickelt, $30 \mathrm{rh}$. Fuß und das Drittel 10 th. Fuß beträgt, so hätten elf solcher Interkolumnien im Langhaus eine Länge von II Fuß ergeben. In Wirklichkeit mißt es aber nur Ioo Fuß. Also ist eine Elfteilung nach Io Fuß unmöglich. Die Ähnlichkeit zwischen der Laacher und der Limburger Kirche besteht demnach nicht darin, daß beide im Langhause eine Elfteilung besitzen, sondern nur darin, daß sie die Dreiteilung des Quadrates befolgen.

In der Tat beträgt der Abstand der Lisenen von Mitte $\mathrm{zu}$ Mitte bei den 18 Unterabteilungen, die nach Abzug der beiden schon besprochenen übrig bleiben, durchschnittlich Io Fuß oder 3,I4 m. Zwölf dieser Interkolumnien treffen dieses Maß entweder genau oder haben etwas mehr oder etwas weniger. Die sechs andern halten sich mit einer Ausnahme ein wenig unter $3 \mathrm{~m}$. Die Länge des Langhauses beträgt von der Grundlinie der Westapsis bis zur Mitte des westlichen Vierungsbogens genau vier Quadratseiten zu 9,50 m + I, 20 m, um welches der erste Lisenenabstand vor der Vierung zu weit ist $=39,20 \mathrm{~m}$ oder $125 \mathrm{rh}$. Fuß. Ziehen wir davon zwei Interkolumnien zu 3, I4 m ab, welche die Breite des Westchores zwischen den Achsen der beiden Rundsäulen ausmachen, dann bleiben für das Langhaus 32,92 m, mit Abzug

zu Werden, Straßburg 1899, I. S. 161 ff., die Dreiteilung des Quadrates in Seligenstadt und Werden, die Zweiteilung am Plan von St. Gallen nachgewiesen.

6o) Die Anfänge der vollständigen Wölbung der romanischen Basilika in Deutschland, a. a. O. Nr. 49 S. $3^{80}$ (1912). Gleichzeitig habe ich an der Limburger Abteikirche als Interkolumniengesetz das Drittel der Quadratseite festgestellt. (Vgl. Der römische Kern des Trierer Domes, die Abteikirchen von Limburg a. d. Haardt und M. Laach in ihren MaBverhaltnissen, Zeitschr. f. Christl. Kunst (1912) Heft II, mit 5 Abb.) Die Anwendung des genannten Gesetzes auf die Lisenen unseres Langhauses führte mich zu der wichtigen Erkenntnis, daß auch diese nach dem Prinzip der Interkolumnien angeordnet seien. Hierdurch gelangte ich für die Entwicklung des Grundrisses notwendig zum Einheitsmaß von $30 \mathrm{rh}$. FuB. Daraus wird jeder erkennen, daß jch auf einem ganz andern Wege zu diesem Ergebnis gekommen bin als Huppertz in seinem Artikel: Die Abteikirche zu Laach (Zeitschr. f. Geschichte d. Architektur Jahrg. V, 1912, S. 145-148), welcher von der erwähnten Regel noch keine Ahnung verrät. Das kann dem Verfasser auch nicht entgangen sein. Meine Abhängigkeit von ihm ist ausgeschlossen durch den Umstand, daB ich das EinheitsmaB von 30 FuB vorher als verfehlt ansah. Im Gegensatze zu Huppertz tue ich das auch jetzt noch in Bezug auf die Anwendung dieses Maßes auf den Querschnitt der Kirche. Die Höhe des Mittelschiffes beträgt durchschnittlich $17,50 \mathrm{~cm}$. Das ist genau das Doppelte der lichten Breite des Mittelschiffes von Mauer zu Mauer, 8,70 m. Bestimmt man dagegen mit Huppertz die Höhe des Mittelschiffes auf $60 \mathrm{FuB}=18,83 \mathrm{~m}$, dann ergibt sich ein Überschuß von $1,33 \mathrm{~m}$, der so bedeutend ist, daB die Rechnung als verfehlt angesehen werden muf. Der Fehler wird dadurch nicht verbessert, daß der Verf. gleichzeitig auch das gleichseitige Dreieck von 60 Fuß Seitenlänge auf den Querschnitt anwendet, denn beide Maße schließen sich gegenseitig aus. 
des oben erwähnten Überschusses von $1,20 \mathrm{~m}-31,72 \mathrm{~m}$ oder $10 \mathrm{I}^{\prime} 7^{\prime \prime}$. Das ist die Summe von zehn Interkolumnien zu je $3,14 \mathrm{~m}$ oder Io rh. Fuß ${ }^{6 r}$ ).

Wie ist nun die Tatsache zu erklären, daß auf der Nordseite drei, auf der Südseite vier Interkolumnien vor dem Westchor enger stehen als die übrigen? Huppertz läßt den Bau der Kirche mit dem Westchor beginnen und die Laacher Bauleute mit einer so unglaublichen "Sorglosigkeit" arbeiten, daß sie vom vierten Feld auf der Nordseite an nicht mehr die zuerst festgesetzte Ach sen weite von $2,83 \mathrm{~m}$ beachteten, sondern gedankenlos mit einer Weite von 3,I4 m oder Io Fuß fortfuhren und am Schluß die Überraschung erlebten, daß statt der anfangs beabsichtigten Elfteilung eine Zehnteilung herauskam (S. 87). Tatsächlich wäre aber die Sorglosigkeit noch größer gewesen. Denn da gemäß der Annahme des Verfassers das Langhaus nach dem Drittel des Einheitsmaßes aufgeteilt werden sollte, hat man schon von Anfang an irrtümlicherweise 9 statt Io Fuß genommen.

Statt dessen beruht die erwähnte Tatsache auf wohlüberlegter Berechnung. Nach der Einstellung der ersten Innen- und Außenlisene vor der Vierung auf die Ostmauer des Klosterkreuzganges hätte die Achse der zehnten Lisene beinahe mit der Westkante der Pfeiler des Westchors zusammenfallen müssen. Mit Recht zog nun unser Baumeister es vor, den Platz für die $\mathrm{I}, 20 \mathrm{~m}$ breiten Pfeiler vom Langhause statt von dem ohnehin schmalen Westchor zu nehmen. Indem er die Verkürzung von I m nur auf die zunächststehenden und nicht auf alle Interkolumnien verteilte, steigerte er den schon durch das größte Joch vor der Vierung erzielten günstigen Eindruck, daß die Arkaden des Mittelschiffes nach dem Querhaus hin an Weite zunehmen.

Die Einteilung unseres Langhauses weist demnach den Gedanken an den ursprünglichen Wölbungsplan nicht nur nicht "gänzlich zurück «, wie Huppertz meint, vielmehr weist sie insofern ausdrücklich darauf hin, als die Zehnzahl, die sich dem Gewölbesystem anpaßt, von Anfang an beabsichtigt war. Diese Tatsache fällt um so schwerer ins Gewicht, je größer im übrigen die Verwandtschaft der Laacher Kirche mit der Limburger Säulenbasilika ist. Wie die Zweiteilung der Quadratseite dem quadratischen oder gebundenen Gewölbesystem, so kommt die Dreiteilung dem rechteckigen oder ungebundenen System entgegen.

Die dargestellte Einteilung des Langhauses wird in überraschender Weise selbst durch das Querschiff bestätigt. Die Süd- und Nordwand desselben ist innen und außen durch zwei Lisenen in drei Felder gegliedert, ähnlich wie in Limburg die Innenseite des Querhauses. Der Abstand der genannten Lisenen beträgt nun in unserer Kirche

6r) Dementsprechend besteht das Langhaus der Limburger Abteikirche aus elf Interkolumnien von je einem Drittel der Quadratseite, woran sich, wie in Maria Laach das Westchor, so in Limburg die Vorhalle mit zwei weiteren solchen Abmessungen anschlieBt. Was es heißen soll, dieses Langhaus sbis zur Ostseite der Westtürmee nach Quadraten abzumessen, wie Huppertz das tut (a, a. O. S. 3), ist nicht einzusehen.

Schippers, Maria Laach. 
wiederum genau Io Fuß von Mitte zu Mitte. Von hier bis zum Kern der Ost- und Westmauer bilden die drei Abstände die Länge einer Quadratseite.

In Limburg ist diese Dreiteilung mit strenger Folgerichtigkeit selbst an den Wänden des Chores durchgeführt. Wenn statt dessen im Laacher Chore die Zweiteilung vorgezogen wurde, so geschah das aus einem liturgischen Grunde, dessen Würdigung es nötig macht, die gesamte liturgische Einteilung der Kirche ins Auge zu fassen.

Wie das Mutterkloster St. Maximin, so befolgte auch sein Priorat am Laacher See die Regel des hl. Benedikt nach den Gewohnheiten von Cluny. Die beiden ersten päpstlichen Bullen, die Abt Gilbert von Innozenz II. (II 39) und Eugen III. (II 47) erwirkte, schärfen diesen Punkt nachdrücklich ein 62). Es kann daher nicht überraschen, daß die Laacher Kirche die wichtigsten liturgischen Bauvorschriften der Cluniazenser Kirchenanlage widerspiegelt ${ }^{6}$ ).

Das Münster der Cluniazenser gliederte sich in Presbyterium, Chor und Schiff (presbyterium, chorus, navis). Letzteres war der» Familia»des Klosters und dem Volke vorbehalten und bildete ungefähr die Hälfte des ganzen Gotteshauses. Diese Einteilung bestand auch in unserer Kirche, wie aus den älteren Aufnahmen des Bauwerkes noch zu ersehen ist ${ }^{64}$ ). Die Grenze zwischen dem Mönchshaus und dem Laienhaus kennzeichneten zwei Stufen, welche zwischen dem ersten Pfeilerpaar des Langhauses vor der Vierung vom Schiff in das Chor hinaufführten. In den Seitenschiffen stieg man auf der gleichen Linie zwei Stufen hinab. Somit erstreckte sich das Mönchschor über das erste Joch des Langhauses und über die Vierung bis zu den Stufen des Presbyteriums. Die zwei Halbsäulchen an der Südseite des nördlichen Freipfeilers der Vierung lassen noch den Sitz des Abtes erkennen, der nach Cluniazenser Ordnung mit dem Prior unter dem westlichen Vierungsbogen seinen Platz hatte. Nach dem Rituale des Laacher Abtes Johann Augustin (gest. 1568) war der rechte Chorflügel in unserer Kirche auf der Nordseite. Sechs Stufen über dem Sängerchor erhob sich das Presbyterium. Sein Flächeninhalt bis zur Apsis war durch eine Stufe in zwe gleiche Teile, einen niederen und einen höheren, geschieden. Der letztere, in dessen Mitte der Hochaltar stand, hieß "pavimentum altaris «. Auf diese Teilung des Presbyteriums nimmt die Gliederung der Wände durch eine Lisene und zwei Blendbogen in passender Weise Rücksicht. Die erwähnte Trennungsstufe verlief zwischen den beiden Lisenen der Wände ${ }^{64}$ ).

Wenn nun der Hochaltar die obere Hälfte des Presbyteriums einnahm, welchem

62) Imprimis siquidem statuentes ut ordo monasticus in eodem loco secundum beati Benedicti regulam et normam Cluniacensis monasterii futuris perpetuis temporibus inviolabiliter conservetur, Mittelrhein. Urkdbch. I, S. 560 u. S. 602 .

63) Vgl. hierzu Mettler, Die zweite Kirche in Cluny und die Kirchen in Hirschau nach den »Gewohnheiten des II. Jahrhunderts. Zeitschr, für Geschichte der Architektur Heft 12, Jahrg. III, S, 273-286 und Heft I, Jahrg. IV, S. I-I6, (1910),

64) Vgl, die MeBbilder aus dem Inneren. 
praktischen Zwecke diente dann die Apsis? Hinter dem Hochaltar standen in Cluny, Farfa, Hirschau und Alpirsbach drei Nebenaltäre. Während am Hauptaltar das Hochamt dargebracht wurde, feierte man in Cluny an den genannten Nebenaltären die allgemeine Frühmesse, welche zu Beginn des Tages nach dem Gesang der "Laudes * stattfand. Der Vorsprung und die Dreiteilung der Ostwand des geraden Chorabschlusses durch Lisenen in derPeterskirche zu Hirschau wurden für diese dreiNebenaltäre angelegt. Nun standen in Cluny und Hirschau außer den drei genannten noch zwei andere Altäre hinter dem Hauptaltar, nämlich in den Seitenkapellen, die das Presbyterium begleiteten. Diese fünf Altäre gehörten zu den bevorzugtesten der Kirche. Wenn nun in Hirschau in einem engen Risalit von 2,50 $\mathrm{m}$ Tiefe und $10 \mathrm{~m}$ Breite zwischen zwei Lisenen drei Altäre Platz fanden, so konnten für die $4 \mathrm{~m}$ tiefe Laacher Hauptapsis auf einer Halbkreislinie von I2,50 m ebensogut die fünf genannten Altäre geplant werden. Die drei Altäre an der Ostwand der Limburger Krypta hatten eine Länge von $1,20 \mathrm{~m}$ und eine Breite von $0,80 \mathrm{~m}$ 65). So hätte der Gesamtraum des Presbyteriums einschließlich der Apsis durch die liturgische Verwendung eine höhere Dreiteilung erhalten. Im übrigen zeigt sich dieselbe ebenso gleichmäßig wie die, welche die ganze Kirche durchherrscht. Denn die Tiefe der Apsis (4 m) ist gleich der Breite der beiden erwähnten Unterabteilungen des Altarhauses. Ob dieser von mir vermutete Plan in Bezug auf die fünf Altäre der Apsis auch noch durchgeführt wurde, nachdem das Ostchor erst nach der Einweihung der Kirche, I156, vollendet werden konnte, scheint mir zweifelhaft $\mathrm{zu}$ sein.

Eine ganz ähnliche Einteilung wie in Maria Laach dürfen wir auf Grund der Wandgliederung für das Ostchor in Limburg an der Haardt annehmen. Auffallenderweise hatte es genau dieselbe Tiefe von $12 \mathrm{~m}$ wie das Laacher Ostchor; wieder ein bemerkenswerter Ähnlichkeitszug zwischen diesen beiden, sonst schon so eng verwandten Ordenskirchen. Stand nun der Hauptaltar im mittleren Drittel des Presbyteriums, das durch die beiden Freilisenen an der Süd- und Nordwand begrenzt ist, dann blieb das östliche Drittel mit seiner fünffachen Wandgliederung für die fünf Nebenaltäre frei, welche nach Cluniazenser Gewohnheit die Begleiter des Hochaltars bildeten.

Kehren wir zum Langhause zurück. Einen ersten Hinweis auf das Gewölbesystem haben wir in der Zehnteilung der Umfassungsmauern erkannt, einen weiteren müssen wir in den Doppellisenen erblicken, womit die Mauern der Abseiten innen und außen verstärkt sind.

Ich habe schon früher hervorgehoben, daß unter vierzig deutschen flachgedeckten Basiliken keine einzige die formale Anlage der Umfassungsmauern unserer Kirche aufweist, obschon die Mehrzahl nach ihrer Gründung begonnen wurde. Diese Tatsache allein schon beweist, daß das Langhaus den Gewölbebauten ver-

65) W. Manchot, Kloster Limburg a. d. Haardt. 1892, S. 62 . 
wandter ist als den flachgedeckten Räumen. Das wird sich noch deutlicher zeigen, wenn wir die ersteren näher ins Auge fassen.

Die Gewölbebauten des I1. und I2. Jahrhunderts lassen sich in drei Gruppen scheiden. Zur ersten gehören diejenigen Kirchen, die mit Gewölben in den Abseiten glatte und ungegliederte Wände im Inneren wie im Äußeren vereinigen. Da auch die Mauerstärke durchschnittlich I $\mathrm{m}$ beträgt, so schließen sich diese Gewölbebauten aufs engste an den flachgedeckten Raum an. Hierher gehören die Seitenschiffe der Kirchen von:

Padua, S. Sofia, Langhaus nach I100, Mauerstärke und Spannweite I : $\left.6{ }^{66}\right)$.

Huyseburg in Sachsen, Kr. Oschersleben, IIOO-II2I; Mauerstärke und Spannweite $\mathrm{I}: 3$.

Köln, St. Cäcilia, nach Mitte des 12. Jahrhunderts, Mauerstärke 0,95 m, Spannweite $4,20 \mathrm{~m}=\mathrm{I}: 4,42$.

Seckau in Steiermark, beg. 1142 , Mst. u. Spw. I : 3,50, rechteckige Gewölbe in der Richtung der Längenachse.

Regensburg, St. Jakob, II52, Mst. u. Spw. I : 3,30.

Worms, St. Martin, 12. u. 13. Jahrhundert, Mst. u. Spw. I : 3 .

Diesdorf in Sachsen, Kr. Salzwedel, beg. I1 57, Mst. 0,95 m, Spw. $4 \mathrm{~m}=1: 4$.

Heiningen, Hannover, Kr. Goslar, II. Jahrhundert, Umbau Ende des 12. Jahrhunderts, Mst. u. Spw. I $: 4^{67}$ ).

St. Michael in Altenstadt bei Schongau in Bayern, 12,-13. Jahrhundert, ungebundenes, rechteckiges Gewölbesystem. Mst. I m, Spw. 3,75 m.

Niedermendig bei M.-Laach, I200, Mst. $=0,96 \mathrm{~m}$, Spw. $2,48=\mathrm{I}: 2,58$.

Die zweite Gruppe bilden diejenigen Bauten, bei denen die Umfassungsmauern an den Stützpunkten der Gewölbe durch Vorlagen verstärkt werden, entweder innen oder außen oder an beiden Stellen. Diese Vorlagen sind jedoch nicht von wesentlich konstruktiver Bedeutung. Sie verfolgen vielmehr in erster Linie den Zweck, die Gliederung der Decke dem ganzen Bau mitzuteilen. Die Beispiele sind zahlreich.

Paderborn, Bartholomäuskapelle, IOI7, flache Fensternischen zwischen den Gewölbestützen; Mst. in den Nischen 75-80 cm, sonst I m, Spw, 2,20 m. Vorlagen: schlanke Halbsäulen im Inneren.

Werden, Ludgeridenkrypta, 1059, frei über der Erde stehend, kreisförmige Fensternischen zwischen den Gewölbestützen. Mst. $0,80-\mathrm{I}$ m, Spw. $4 \mathrm{~m}$.

$\left.{ }^{66}\right) \mathrm{Zu}$ allen im Folgenden genannten Bauten, für die nicht auf besondere Bearbeitungen verwiesen ist, vgl. Dehio und v. Bezold, Die kirchl. Baukunst d. Abendlandes, Stuttgart, 1892 , Text I, S. $405-5^{16}$, mit den dazu gehörigen Tafeln; und Dehio, Handbuch.

67) Kleinere, gewölbmäßige Umbauten werden hier zum Vergleich herangezogen, weil bisher in einseitiger Weise nur die Dome in Speier und Mainz berücksichtigt wurden. 
Vorlagen: innen und außen $3 \mathrm{~cm}$ dicke Lisenen. Die sehr oblongen Gewölbe richten ihren stärksten Schub gegen die Umfassungsmauer ${ }^{68}$ ).

Hirschau, St. Aurelius, 1060-I07I, Mst. 0,90 m, Spw. 3,20 m = I : 3,55.

Vorlagen: schlanke Halbsäulen im Inneren ${ }^{69}$ ).

Köln, St. Aposteln, Einwölbung der Seitenschiffe ca. I170, Mst. ca. 90 cm, Spw. ca. 5,30 m = I :5,88. Vorlagen: schlanke Halbsäulen im Inneren.

Köln, St. Mauritius, II4I geweiht, Mst. $2^{\prime} 5^{\prime \prime} 2^{\prime \prime \prime}=0,75$ m, Spw. I2' $8^{\prime \prime}$ Io"

$=3,93 \mathrm{~m}=\mathrm{I}: 5,20$; Vorlagen: innen Wandpfeiler $\left.105 / 6^{\prime \prime} \times 19^{\prime \prime}=29 \times 49 \mathrm{~cm} 7{ }^{\circ}\right)$.

Knechtsteden, Abteikirche, beg. I138, Mst. I m, Spw. 4,60 m. Vorlagen: schlanke Halb- oder Dreiviertelsäulen im Inneren.

Brauweiler, Abteikirche, II4I gewölbmäßig umgebaut, Mst. I,20 m, Spw. $6,85 \mathrm{~m}=I: 5,70$. Vorlagen: schlanke Halb- oder Dreiviertelsäulen im Inneren; stärkster Schub der sehr oblongen Gewölbe gegen die Umfassungsmauern $7^{1}$ ).

Wissel, Pfarrkirche, beg. I. Hälfte des 12. Jahrhunderts. Mst. ca. 0,80 m, Spw, ca. $3,30 \mathrm{~m}=\mathrm{I}: 4$. Vorlagen: abwechselnd schlanke Halbsäulen mit Lisenen im Inneren $7^{2}$ ).

Caen, St. Trinité, I. Hälfte des I2. Jahrhunderts. Mst. u. Spw. = I : 5 . Vorlagen: a uBen schwache Lisenen 73).

Saint Dié, Kleinere Kirche, I2. Jahrhundert. Mst. ca. 0,90 m, Spw. $3,90=I: 4,33$. Vorlagen: innen und außen kräftige Lisenen.

Trier, St. Matthias, 1127-I148. Mst. u. Spw. vielfach I : $4 \frac{1}{2}$. Vorlagen: innen Lisenen abwechselnd ca. 7 und $20 \mathrm{~cm}$ stark 74 ).

68) Für Werden u. Paderborn, vgl. Effmann a. a. O. S. 60 ff.

69) E. Paulus, Die Kunst- und Altertumsdenkmale im Konigr. Württemberg, 1893, Hirschau.

70) Aufnahmen im Rhein. Denkmalerarchiv zu Bonn von V. Statz.

7x) Clemen, Kunstd. Landkr. Köln ( 1 S97), S. 3 .

72) Ebenda, Kr. Kleve, (1892) S. 154 .

73) Uber die normännische Bauschule, wozu St. Trinité gehört, bemerken Dehio und v. Bezold a. a. O. I, S. 279: Bald nach der Mitte des 11. Jahrh. ist sie allen ubrigen Schulen Nordfrankreichs überlegen. Sie ist entschlossen, in der Überwölbungsfrage die steinerne Decke im ganzen Gebäude zur Herrschaft zu bringen. Es sollen Kreuzgewölbe sein im Hauptschiff, wie sie in den Nebenschiffen längst in Anwendung kamen.

74) Uber das Mittelschiff von St. Matthias schreibt Architekt P. Marx: oEs ist bisher angenommen worden, daß das Mittelschiff, bevor es das spätgotische Gewölbe erhielt, mit einer geraden Holzdecke abgeschlossen war. Die Begründung dieser Annahme leitete man aus den noch vorhandenen Löchern der alten Balkenköpfe sowie aus den Putzflächen ab, die sich über dem heutigen Gewölbe befinden. Ungelöst blieb dabei, weshalb die Pfeilervorlagen nicht bis zu dieser Decke emporgefuhrt sind. Die genauere Untersuchung hat gezeigt, daß auf jeder Seite vier Putzflächen uber dem Gewölbe sichtbar sind, die sich über je zwei Joche erstrecken und von denen einige nach oben kreisförmig abgegrenzt sind (Abb.). Es ist also sicher, daB das Hauptschiff mit vier nahezu quadratisehen Kreuzgewölben uberdeckt war, deren Schildbogenfelder in diesen Putzflächen noch zu erkennen sind. Gestützt wird diese Annahme dadurch, daß die Hauptpfeiler mit Strebepfeilern versehen sind, die sich unter dem Pultdache der Seitenschiffe befinden und außen als Lisenen am oberen Mlittelschiff erscheinen. Diesen Strebepfeilern entspricht auch die stärkere Vorlage an den Pfeilern im Seitenschiff und die entsprechenden breiteren Gurten. * Trierer Jahresberichte d. Gesellschaft f. nutzl. Forschungen, 
Inichen in Tirol, ungebundenes, rechteckiges Gewölbesystem. Mst. I m, Spw. $4 \mathrm{~m}$. Vorlagen innen und außen Lisenen.

Regensburg, Templerkapelle, Anfang des I2. Jahrhunderts. Überall langgestreckte, rechteckige Gewölbe in den Seitenschiffen, die Mehrzahl fast doppelt so lang als breit; Vorlagen: im Inneren schwache Lisenen.

München-Gladbach, Abteikirche, Langhausmauern nach 1065, Einwölbung Ende des I2. Jahrhunderts. Mst. im nördl. Seitenschiff $0,60 \mathrm{~m}$, Spw. $4,50 \mathrm{~m}=\mathrm{I}: 7,50 ;$ Mst. im südl. Seitenschiff $0,60-0,80 \mathrm{~m}$. Vorlagen: schlanke Dreiviertelsäulen 75 ).

Hochelten, Stiftskirche, Rheinprovinz, Kr. Rees, II29 geweiht. Mst. ca. $0,90 \mathrm{~m}$, größte Spw. ca. $5,70 \mathrm{~m}=1: 6,33 \mathrm{~m}$, Vorlagen: innen Halbsäulen, außen schwache Lisenen. Nimmt man mit Rahtgens das gebundene System an, so richtet sich der stärkste Schub der sehr oblongen Gewölbe gegen die Umfassungsmauern.

Steinfeld, Prämonstratenserkirche, Rheinprovinz, Kr. Schleiden, II 42 beg. Mst. I m, Spw. $3,35 \mathrm{~m}$. Vorlagen: innen abwechselnd 12 und I 5 $\mathrm{cm}$ starke Lisenen.

Zur dritten Gruppe endlich zählen die Bauten, deren Gewölbestützen in den Seitenschiffen ähnlich ausgebildet sind wie die im gewölbten Mittelschiff. Die Wandpfeiler bestehen dann meistens im Innern aus einer doppelten Vorlage, wozu häufig außen noch eine Verstärkung oder ein Strebepfeiler hinzutritt. Soweit ich aus den Werken Dehios und v. Bezolds ersehe, erlangen Gewölbestützen dieser Art, abgesehen von Unterkirchen und von den wegen ihrer außergewöhnlichen Weiträumigkeit allein dastehenden Domen zu Speier und Mainz, in Deutschland erst gegen Ende des 12. Jahrhunderts größere Verbreitung $7^{6}$ ). Die II43 begonnene und 1209 geweihte

1911, IV, S. 56. Die Basilika in Echternach besitzt ähnlich wie St. Matthias in den Abseiten $8 \mathrm{I} \mathrm{cm}$ breite und 14-16 cm dicke Wandpfeiler, die mit den Mittelschiffspfeilern durch ebenso breite Gurtbogen verbunden sind. Diese tragen abgeschrägte Mauern, auf denen das Pultdach aufruht. Das Sockelprofil der Wandpfeiler und die Art und Weise, wie das frühgotische Gewölbe nachträglich dem Vorhandenen angepaßt wurde, rechtfertigen die Annahme, daß die Gurtbogen ursprünglich sind. Lotz (Kunsttopogr. (1862) I, S. 190) und Otte (Gesch. d. deutsch, Baukunst ( 1874 ) S. 212 f.) nehmen an, daß die Echternacher Abseiten schon im Urbau gewölbt waren. Rathgens (S.Maria i. Kapitol S. 176, Anm. 4) bezweifelt es, ohne jedoch seine Zweifel zu begründen. Sollte man denn bei Preisgabe der Gewölbe ein Beispiel jenes bekannten römischen Gurtbogensystems annehmen können, das auf heimatlichem Boden der römische Kern des Trierer Domes in großzügiger Weise verkörperte und während des Mittelalters der lombardischen und normännischen Bauschule vielfach noch einen Ersatz für die Steindecke bot?

75) Clemen, Kunstdenkm. Kr. Gladbach u. Krefeld, (1896) S. $14-20$.

76) Im ubrigen ergibt ein Vergleich zwischen den rheinischen Domen und unserer Kirche nicht die ggewaltigen Differenzen", die Huppertz herausgefunden hat (S. 69). Ich habe bereits früher die statischen Verhältnisse der drei Bauten verglichen. ${ }^{2}$ Die Stärke der Umfassungsmauern und die Spannweite der Seitenschiffe betragen mit Abzug der Vorlagen in Speier $1,70: 8 \mathrm{~m}$, in Mainz $1,70: 6,56 \mathrm{~m}$, in Maria Laach $0,90: 4,50 \mathrm{~m}$. Auf I m Mauerstärke kommt somit in Mainz eine Spannweite von $3,86 \mathrm{~m}$, in Speier 4,70 m, in Maria Laach 5 m. Vgl. meine Abhandlung in der $₫$ Zeitschr. f. Christl. Kunst ^ Jahrg. 1912, Sp. 209 und dic Zeichnungen bei W. Meyer-Schwartau, Der Dom zu Speier, (1893) Taf. 32. 
Stiftskirche von Klosterrath, die in den Seitenschiffen ca. $15 \mathrm{~cm}$ starke Wandpfeiler mit Halbsäulen und außen Lisenen besitzt, bildet vorläufig das erste vereinzelte Beispiel. Dann folgen bis zum Beginn des I3. Jahrhunderts der Dom zu Worms (nach II7I), Arnstein (Bez. Wiesbaden, I208 geweiht), Rosheim (Unterelsaß, Kreis Molsheim, ca. II70-II90), Gebweiler (Oberelsaß, frühestens 1182 begonnen) und St. Kastor in Koblenz (nach IIgo).

Die Laacher Seitenschiffe gehören in die zweite Gruppe der angeführten Ge wölbebauten. Ihre Mauerstärke beträgt o,90 m, die Spannweite $4,50 \mathrm{~m}$; das ergibt ein Verhältnis von I : 5. In Bezug auf die statischen Bedingungen stehen sie demnach auf gleicher Linie mit Knechtsteden und Caen, dagegen übertreffen sie Brauweiler, München-Gladbach, Hochelten, St. Aposteln, St. Mauritius und S. Sofia um ein Bedeutendes. Die statischen Verhältnisse unserer Abseiten werden aber durch verschiedene Umstände noch verbessert. Die Umfassungsmauern šnd in einer sorgfältigen Quadertechnik ausgeführt und durch neun Doppellisenen von $40 \mathrm{~cm}$ Breite und $20 \mathrm{~cm}$ Dicke aus Basaltlava verstärkt, welche in der Regel dreimal durch tief nach beiden Seiten eingreifende Quadern in die Mauer einbinden 77). Dieselbe erreicht somit an neun Stellen auf einer Breite von $40 \mathrm{~cm}$ einen Durchmesser Von I, IO m. Als Wölbstein stand ein poröser Tuff zur Verfügung, der nicht nur sehr leicht ist, sondern sich auch vorzüglich mit dem Mörtel verbindet. Infolgedessen bildet das ganze Gewölbe eine feste, zusammenhängende Masse, die sich großenteils selbst trägt und wenig seitwärts schiebt. Noch mehr, indem die rechteckigen Steindecken ihren Hauptschub in der Richtung der Längenachse ausüben, erhalten die Seitenwände dadurch eine entsprechend geringere Belastung. Wie günstig die statischen Bedingungen unserer Abseiten sind, beweisen schließlich die Gewölbe selber am handgreiflichsten, die sich 750 Jahre hindurch im besten Zustande erhalten haben.

Ebensowenig wie aus statischen läßt sich aus formalen Gründen gegen die planmäßige Wölbung der Seitenschiffe etwas vorbringen, was wirklich durchschlagend wäre. Zunächst ergibt sich aus der obigen Zusammenstellung der Gewölbebauten die vielfache Verwendung der Lisenen als Gewölbestützen. Die frühesten der acht angeführten Beispiele finden wir in der Werdener Krypta; sie haben nur eine Stärke von $3 \mathrm{~cm}$. Wie in unserer Kirche, so werden auch sonst Wandpfeiler und Halb. säulen unbedenklich gegenübergestellt, so in St. Dié, Brauweiler, Reichenhall und Inichen. In St. Trinité zu Caen und St. Cäcilia geht die flache Wand mit Halb. säulen, vielfach anderswo mit Rundsäulen, im Gewölbebau zusammen. Auch Rundsäulen und Halbsäulen stellt man gegenüber, so daß alle Abwandlungen vertreten sind.

77) Unter Doppellisene verstehe ich die zwei Lisenen von je $10 \mathrm{~cm}$ Dicke, die innen und außen einander gegenüberstehen. Nie und nimmer habe ich die Mauerstärke in den Abseiten auf $1,40 \mathrm{~m}$ angegeben, wie Huppertz (Zeitschr. t. Gesch. d. Architektur [1912] V, S, 146) ohne Angabe des Ortes von mir be-
hauptet. 
Aber die Inkonsequenz zwischen den Laacher Seitenschiffen und der Krypta, wo die $10 \mathrm{~cm}$ starken Lisenen mit Halbsäulen verbunden sind! Dieser Unterschied ist sehr gut begründet. Die Unterkirche hat eine ganz in sich abgeschlossene Raumstimmung, welche die runde Stütze beherrscht. Sie darf deshalb auch an der Wand nicht fehlen, wenn diese Stimmung zum vollen Ausklang gelangen soll. Einen ebenso entschieden ausgeprägten Charakter besitzt auch die Oberkirche. Sie ist in Bezug auf die Wandgliederung durch den Schmuck der Lisenen und Blendbogen das vollendete Vorbild. Großzügig und ebenmäßig schreitet diese Gliederung durch alle Teile hindurch. Mußte sie sich nun an den Innenwänden der Abseiten ändern und Halbsäulen annehmen, obschon sie im Chor und Querhause so vortrefflich mit dem Gewölbe zusammenging? Über die Vor- und Nachteile beider Lösungen darf man zum mindesten verschiedener Meinung sein. Wie ein großer Baukünstler um die Wende des II. Jahrhunderts darüber dachte, das dürfte nach dem bisher Gesagten ziemlich sicher sein.

Dann hätten die Gewölbestützen wenigstens kräftiger sein müssen als die Zwischenlisenen, wendet der Theoretiker weiter ein. So wenig wie im Ostchor, wo in dieser Beziehung auch kein Unterschied eingehalten wurde. In den Abseiten von St. Matthias wechseln, einmal ausgenommen, $8 \times 36 \mathrm{~cm}$ starke Lisenen mit andern von $16 \times 93 \mathrm{~cm}$ ab. Trotzdem sind alle gleichmäßig als Gewölbestützen herangezogen. Die Stärke richtet sich nach der Breite, die durchschnittlich wie in Maria Laach das Vier- bis Fünffache der Dicke beträgt. Bei uns ist somit die Aufgabe der Lisenen abwechselnd verschieden, dagegen die Stärke gleich, in St. Matthias ist die Stärke verschieden und die Aufgabe gleich. Derselbe Gegensatz besteht beiderseits zwischen der Breite der Abseiten und den gleichartigen Lisenen. In Trier ist die Schiffsbreite größer, dagegen sind die schmalen Lisenen schwächer; in Maria Laach ist die Schiffsbreite geringer, dagegen sind die Lisenen nach Stärke und Material kräftiger. Die letztere Abweichung betrifft zwar nur ganz geringe Unterschiede, verdient aber doch hervorgehoben zu werden, weil sie die Verwendung der Lisene im Gewölbebau gut beleuchtet. Die Belastung der Kämpfer in den Seitenschiffen wird unten S. 63 eingehender behandelt werden.

Die voraufgegangene Übersicht über die gewölbten Kirchen des II. und I2. Jahrhunderts macht auf Vollständigkeit keinen Anspruch. Sie genügt aber, um zu zeigen, wie verschieden die Wölbekunst ihre Aufgaben sowohl in formaler als in statischer Hinsicht löste. Wer vom Gewölbebau dieser Zeit fordert, daß die Steindecke die Gliederung der ganzen Umfassungsmauer bestimmen müsse, daß diese Gliederung nicht durch dekorative Lisenen und Wandpilaster geschehen könne, vielmehr durch starke Pfeiler mit oder ohne Halbsäulen erfolgen müsse, dem widersprechen die historischen Tatsachen aufs entschiedenste. Diese entwerfen ein so mannigfaltiges Bild, daß man fast sagen kann, jeder Gewölbebau bringt eine andere Lösung. Wer diese Entwicklung vor Augen hat, der wird bei der Entscheidung der Frage, 
ob die Laacher Umfassungsmauern auf Holz- oder auf Steindecke hinweisen, zum mindesten beide Möglichkeiten zugeben. Zieht er aber die Baugeschichte in Betracht, so wie ich sie hier dargelegt habe, erwägt er, daß die reiche innere und äußere Gliederung des Baues nirgendwo eine Disharmonie mit dem Gewölbesystem erkennen läßt, ja daß die Aufteilung des Langhauses und die Anlage des Westchors ${ }^{78}$ ) unmittelbar auf dieses Gewölbesystem hinweisen, so werden ihm alle ernsten Bedenken gegen die Einheit des Planes schwinden. Demnach bleibt die bisherige Auffassung im Recht. Der Gesamteindruck des Langhauses, der anerkanntermaßen stark zugunsten des ursprünglichen Gewölbeplanes spricht, hat sie nicht getäuscht.

Es entsteht nun die Frage nach dem Ursprung des Laacher Gewölbesystems. Italien sowohl als Frankreich haben ihre oft genannten Vertreter des ungebundenen Gewölbesystems 79). Da der Einfluß der lombardischen Architektur auf die rheinische Baukunst an nicht wenigen Beispielen seit dem Ende des II. Jahrhunderts unumstritten anerkannt wird und auch an unserer Kirche sich deutlich zeigt, so ist es möglich, daß der Laacher Baumeister die Anregung zu dem Plane seines Deckenwerkes von dorther empfing. Dehio und v. Bezold halten eine Einwirkung der Abteikirche von Vezelay für möglich, „weil beide Klöster der Cluniazenserkongregation angehörten" (S. 467). Maria Laach war aber nie der Kongregation von Cluny einverleibt $\left.{ }^{80}\right)$. Ist es aber notwendig, einen ausländischen Einfluß anzunehmen? Zwei Tatsachen waren geeignet, die Einführung des ungebundenen Gewölbesystems in die deutsche Baukunst zu begünstigen: die allgemein verbreitete praktische Anwendung der rechteckigen Kreuzgewölbe und die nicht minder übliche Dreiteilung der Quadratseite bei der Gliederung des Langhauses.

Rechteckige Kreuzgewölbe, und zwar zum Teil in sehr gestreckter Gestalt,

78) Davon wird im letzten Teil eingehender die Rede sein.

79) Ich habe schon früher darauf hingewiesen in: M. Laach und die Kunst, (1911) S. 19.

8o) Es ist streng zu unterscheiden zwischen der Reform und der Kongregation von Cluny. Die Reform verbreitete sich durch die Annahme der "Cluniazenser Gebräuche», die jedem Kloster seine volle rechtliche Selbständigkeit beließen. Die von Abt Hugo (gest. 1109) organisierte Kongregation bildete einen engeren Verband von Klöstern unter dem Vorsitze von Cluny, dem weitgehende jurisdiktionelle Rechte über die Tochterklöster zustanden. Die letzteren waren nur Priorate, nicht selbständige Abteien. Die Cluniazenser Gebräuche wurden höchstwahrscheinlich von Anfang an in Maria Laach befolgt, weil das Mutterkloster St, Maximin im 11. Jahrhundert der Herd der Reform in Deutschland war. Dem entspricht die Ausdrucksweise der Bullen Innozenz' II. und Eugens III., die verordnen, daß diese Gewohnheiten sbeibehalten werden sollen $\%$, pconservetur\%. Siehe den Wortlaut S. 42. Ostendorf irrt daher, indem er das Laacher Gewölbesystem wsicher « mit der Einfuhrung der Cluniazenser Reform in Maria Laach im Jahre ${ }_{3} 38$ zusammenbringt. (DieEntstehung der gotischen Kunst, Zeitschr. f. Bauwesen Jahrg. 63 (1913), S. 397, Anmerkung 35.) Das gilt um so mehr, als es nach Anthyme St. Paul (Annuaire de Parchéologue, 1877, S.60) und de Lasteyrie (l'architecture religieuse en France à l'époque romane, 1912, S. 426 f.) selbst in Frankreich in den von Cluny abhängigen Klöstern keine Cluniazenser Bauschule gegeben hat. Letzterer schreibt S. 426: "Par toute la France, les abbayes dépendant de Cluny ont élevé leurs églises d’après les règles admises dans le diocèse où elles étaient situées; ces églises relèvent des écoles locales au même degré que les églises cathédrales, collégiales ou paroissiales. Les églises clunisiennes de Bourgogne ont le style bourguignon, celles de Poitou ou de l'Auvergne le style poitevin ou auvergnat.e

Schippers, Maria Laach. 
sind in Deutschland während des ganzen II. Jahrhunderts vielerorts ausgeführt worden. Hier einige Beispiele. Abteikirche Limburg a. d. Haardt, Schlußweihe I045, Vorhalle mit vier rechteckigen und zwei quadratischen Gewölben. Werden, Ludgeridenkrypta, II. Jahrhundert, 9 rechteckige Gewölbe, die fast doppelt so lang als breit sind. Köln, St. Maria im Kapitol, Krypta, II. Jahrhundert, I 6 rechteckige Gewölbe. Mainz, Dom, Langhaus, Ende des II. oder Anfang des I2. Jahrhunderts. Von den fünf Mittelschiffsgewölben waren drei $=9 \times 13,80 \mathrm{~m}$, die größten ihrer Art aus romanischer Zeit. Speier, Dom, Langhaus, Ende des II. Jahrhunderts. Münstereifel, Erweiterung der Krypta der Stiftskirche, Anfang des I2. Jahrhunderts, 9 rechteckige Gewölbe, Breite und Länge beinahe I : 2. Regensburg, Templerkapelle St. Leonhard, Anfang des 12. Jahrhunderts; dreischiffiger Hallenbau, Breite und Länge der Gewölbe vielfach $I: 2$.

Verbindet sich nun das rechteckige Gewölbe im Langhause der Basilika mit der Dreiteilung der Quadratseite in der Weise, daß immer eine Zwischenstütze fortfällt oder übergangen wird, so gewinnen wir das ungebundene Gewölbesystem. Es ist eine Verbindung gleichartiger, rechteckiger Gewölbe, von denen dasjenige im Mittelschiff genau die Größe der beiden seitlichen in den Nebenschiffen zusammen erreicht. Dieses System entwickelt sich ebenso einfach und regelmäßig aus dem Kreuzmittel wie das gebundene vermittels der Zweiteilung. Keinem deutschen Baumeister des Mittelalters konnte diese Erkenntnis verborgen bleiben, und beim Entwurfe von Neubauten, die gewölbt werden sollten, mußten ihm beide Systeme vor Augen stehen.

Die Gewölbe des Laacher Langhauses sind nun ganz genau nach dem beschriebenen System angelegt. Jedes Joch des Mittelschiffes mit seinen beiden seitlichen Jochen im Nebenschiff umfaßt zwei Drittel der Quadratseite. Nach demselben Gesetz schließt sich der Westbau an das Langhaus an mit vier Gewölben unter der Empore von der Größe der Seitenschiffsgewölbe. Dieses systematisch angelegte Deckenwerk im Ernste als ein glückliches Spiel des Zufalls anzusehen, dürfte schwerer sein, als die von mir gegebene Erklärung anzunehmen.

Eine überraschende Bestätigung erhält sie durch die Anlage des Kreuzganges. Nach meinen obigen Ausführungen muß es als sicher gelten, daß der Kreuzgang mit $\mathrm{zu}$ den allerersten Bauten gehört, die in Maria Laach errichtet wurden. Ebenso unzweifelhaft steht fest, daß der Süd- und Westflügel des Kreuzganges mit fünf rechteckigen Gewölben eingedeckt waren ${ }^{8} \mathrm{x}$ ), die in der Größe von denen der Seitenschiffe wenig abwichen $\left(3 \times 4^{1 / 2}\right.$ gegen $\left.4 \times 5 \frac{1}{1 / 2}\right)$. Diese Steindecken umschlossen nach dem Lichthofe hin je zwei Arkaden, durch welche man zum Garten oder zum Waschraum hindurchging. Daraus ergeben sich mehrere beachtenswerte Übereinstimmungen zwischen drei Flügeln des Kreuzganges und den Seitenschiffen der Kirche. Die rechteckige Form, die annähernd gleiche Größe und die Fünfzahl der Gewölbe, endlich

8i) Es darf fast mit Sicherheit angenommen werden, daß der Ostflugel des Kreuzganges in der Art der Einwölbung sich dem Sud- und Westflügel anschloB. 
die Zehnzahl der Öffnungen zu Paaren durch eine Steindecke zusammengefaßt. Damit haben wir gewissermaßen die technische und formale Vorstufe für die Einwölbung der Seitenschiffe gefunden, und zwar ausgeführt vom selben Baumeister, der auch den Gewölbeplan des Langhauses entwarf. Ja, wenn wir beachten, daß der nördliche Flügel des Kreuzganges mit Rücksicht auf die Fenster des südlichen Seitenschiffes zehn quadratische Gewölbe erhalten mußte, so bewies unser Baumeister dadurch, daß er von diesem System in den übrigen Flügeln abging, eine besondere Vorliebe für die rechteckige Steindecke. Diese auffallende Bevorzugung scheint mir aber am besten darin ihre Erklärung zu finden, daß er sie auch in der Kirche anzuwenden gedachte (Abb. 3I).

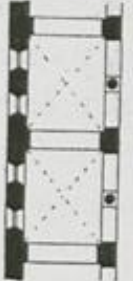

1
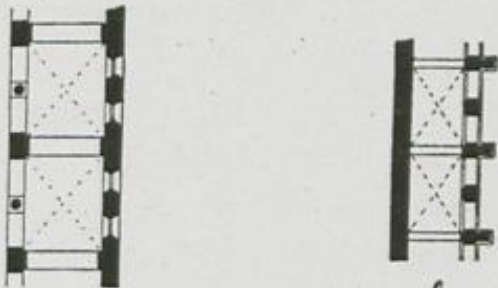

2
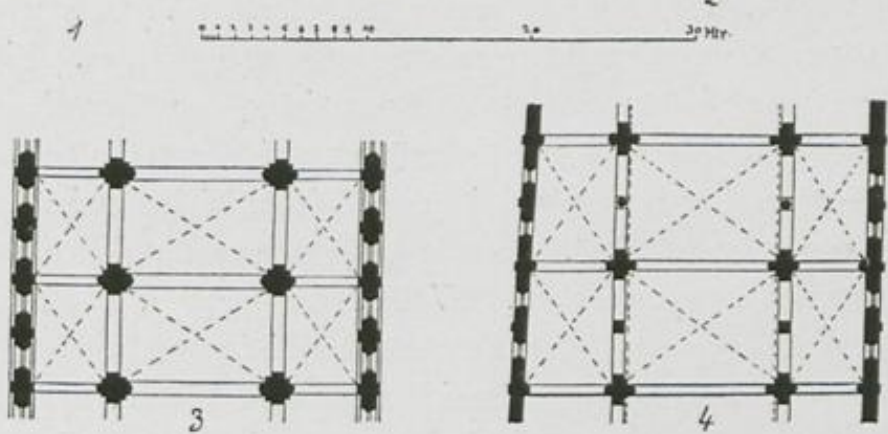

Abb. 31. Gewolbesysteme: 1 Echternach 1031; 2 Laacher Kreuzgang 1093; 3 Laacher Kirche 1095; 4 Hochelten, Stiftskirche, vermutlicher, nicht durchgefuhrter Gewölbeplan, Weihe 1129.

Vielleicht gelingt es, den Ursprung dieses Systems noch weiter hinauf zu verfolgen. Das Motiv der Umrahmung kleinerer Bogen durch einen größeren tritt in der Kirche und im Kreuzgang in so auffallender Weise hervor, daß sich die Vermutung aufdrängt, ein anderes Bauwerk habe dazu die Anregung gegeben. Eine solche konnte am ehesten von Echternach ausgehen, dessen Mittelschiff bekanntlich dieses Motiv mit dem Stützenwechsel verbindet. Beides zeigt unser Westchor in so kühner und großzügiger Durchführung, daß man besonders hier an eine ausdrücklich gewollte Nachahmung denken möchte. Diese Vermutung gewinnt an Wahrscheinlichkeit, wenn noch andere Verwandtschaftszüge zwischen Echternach und Maria Laach hinzutreten. Beide Kirchen sind im Langhause ungefähr gleich breit; die Echternacher mißt 20,79 m, die Laacher 19,47 m über dem Sockel. Die Länge beträgt hier wie dort genau zwei Breiten, in Maria Laach von der Vierung bis zur Westapsis ge- 
rechnet. Die Gliederung des Langhauses geschieht an beiden Orten nach der Dreiteilung der Quadratseite. Infolgedessen stehen beim Stützenwechsel in Echternach die Pfeiler immer auf der zweiten Dreiteilung genau wie im Laacher Mittelschiff. $\mathrm{Zu}$ dieser Sechsteilung kommt beiderseits noch je eine Unterteilung, in Echternach durch Zwischensäulen im Mittelschiff, in Maria Laach durch Wandlisenen in den Seitenschiffen. Dieser Unterschied zwischen beiden Kirchen ergab sich aber von selbst dadurch, daß die Laacher Pfeiler als Träger der Mittelschiffsgewölbe in Breite und Länge erheblich mächtiger angelegt werden mußten als die Echternacher, und die Zwischenweite unter den Stützen der Willibrordsbasilika schon die engste ist, die grundsätzlich in der romanischen Basilika vorkommt. Während sich so in Echternach die Zwölfteilung auf das Mittelschiff konzentriert, verteilt sich bei uns in glücklicher Abwechslung die große und wuchtige auf den Hauptraum, die kleinere und leichtere auf die Nebenräume. Die darin zutage tretende Verwandtschaft zwischen den beiden Langhäusern betrifft so charakteristische Punkte, daß man sagen darf, das ältere habe dem jüngeren als Vorbild gedient. Selbst in dem Falle, daß die Seitenschiffe ursprünglich nicht gewölbt waren, gab das Echternacher Langhaus zur Übertragung seines Planes auf Steindecke neben dem starken Verlangen der damaligen Zeit nach gewölbten Kirchen bestimmte Anregungen und Winke. Einerseits durch die Stellung der Pfeiler, welche sich einem Baumeister, der über die Wölbung einer Kirche nachdachte, von selber als Gewölbestützen aufdrängten, anderseits durch die breiten, übermauerten Gurtbogen, die in den Seitenschiffen zwischen Wand- und Mittelschiffspfeilern gespannt sind. So war der Rahmen für das Laacher Gewölbesystem in Echternach schon gegeben. (Vgl. hierzu auch S. 46 Anmerkung 74).

Eine gründliche Kenntnis der berühmten Willibrordsbasilika muß bei den St. Maximiner Mönchen als selbstverständlich angesehen werden. Denn die Beziehungen zwischen Echternach und St. Maximin waren die denkbar innigsten, seitdem ersteres im Jahre 974 durch die St. Maximiner aus einem Stifte wieder in ein Benediktinerkloster umgewandelt worden war. Auch der Laacher Stifter Pfalzgraf Heinrich trat als Reichsverweser von Lothringen 1090-95 der luxemburgischen Abtei nahe. Damals stand an ihrer Spitze Thiofrid (I08I-IIIO), der zu den gelehrtesten und angesehensten Männern seiner Zeit gehörte und einen weitreichenden Einfluß ausübte. Auf seine Veranlassung wurde im Jahre 1095, ppresidente domino Henrico palatino comite, cui a Domino nostro Henrico in Italiam exercitum ductante imperii commisse sunt habene" der Abtei Echternach die ihr ungerechterweise entfremdete Vogtei zurückerstattet ${ }^{82}$ ). Der Einwirkung der Echternacher Basilika auf den Laacher Neubau war demnach der Weg aufs beste geebnet.

Es ist nun freilich erstaunlich, daß der Laacher Gewölbeplan, der doch so offenbare systematische und künstlerische Vorzüge in sich barg und in seiner Weiterent-

82) Mittelrhein. Urkdbch. II, S. 22-23. 
wicklung zu den größten Hoffnungen berechtigte, in seiner Zeit und Heimat fast ganz allein dasteht. Diese Tatsache wird verständlicher, wenn wir beachten, daß die rheinischen Kirchenbauten, die nach Maria Laach bis zur Mitte des 12. Jahrhunderts von Anfang an ganz auf Wölbung angelegt wurden, auch in gewissem Sinne Einzelerscheinungen sind, insofern sie in Bezug auf die Art der Einwölbung nach drei Richtungen ihre eigenen Wege gehen. Knechtsteden, II 38 begonnen, besitzt gebundenes System mit Stützenwechsel; St. Mauritius in Köln, II4I geweiht, gebundenes System mit Pfeilern als Zwischenstützen; Steinfeld, II42 begonnen, ebenfalls; Klosterrath, nach Cuypers Langhaus II 38 begonnen, abwechselnd ein Joch nach ungebundenem System und eins nach gebundenem mit Stützenwechsel. So finden wir an fünf Gewölbebauten, Maria Laach mit eingerechnet, einmal das ungebundene System, dreimal das gebundene nach zwei Abwandlungen und einmal die Vereinigung beider Systeme.

Streng genommen muß sogar diesen vier Arten der Einwölbung noch eine fünfte hinzugefügt werden, nämlich der ursprüngliche Gewölbeplan der Stiftskirche von Hochelten am Niederrhein. Diesem hochinteressanten, II29 geweihten Baue hat H. Rahtgens an der Hand der erhaltenen Teile und der reichhaltigen Skizzen von Finkenbaum grundlegende Untersuchungen gewidmet ${ }^{8}$ ). Unter den gleichzeitigen rheinischen Kirchen erhält die Hocheltener seine besondere Bedeutung durch eine Reihe ganz merkwürdiger Eigentümlichkeiten: die flache Decke des Mittelschiffs über den Schildbögen, die kurzen, von der Vierung durch eine Arkade (eine Zwischensäule) getrennten Kreuzarme, die Pfeilerbildung mit fast vollrund vortretenden Säulen, die Fensteranordnung im Mittelschiff, die ornamentalen Schnuckformen und nicht zum wenigsten durch den höchst eigenartig ausgebildeten Westturm ${ }^{84}$ ).

Ohne Zweifel haben wir es hier mit einem hervorragenden, dem Laacher Meister verwandten Baukünstler zu tun, dessen reiche Erfahrung und selbständige Schaffenskraft uns auf Schritt und Tritt begegnet. "Am seltsamsten berührt jedenfalls die flache Decke des Mittelschiffs über den dreifachen Schildbogen bei einer fast zwingend auf gebundene Überwölbung hinweisenden Pfeilerbildung " ${ }^{4}$ ). Da die Hocheltener Kirche in die oben erwähnte Zeit der ersten, ursprünglich auf Wölbung angelegten Kirchen gehört, "so darf in der Tat vermutet werden, daß auch hier ursprünglich die Einwölbung des Mittelschiffes beabsichtigt war, was ja schon aus dem Pfeilersystem mit den Säulenvorlagen zu entnehmen ist. Den Grund für den schließ. lichen Verzicht auf das Mittelschiffgewölbe ${ }^{85}$ ) sehe ich in den schwachen Abmessungen der Pfeiler und der Arkaden, die wohl zu nachträglichen Bedenken geführt haben mochten \&.

83) Die Rekonstruktion der Stiftskirche zu Hochelten, mit 32 Abb. Zeitschr. f. Geschichte der Archi-

tektur Jahrg. V, 1912 , S. $16 \mathrm{t}-203$.

8 4) Ebenda.

85) Von mir gesperrt. 
Für die Abseiten zieht Rahtgens das gebundene System vor, obwohl, wie er sagt, manches für die ungebundene Anlage spricht, die auch die Skizzen von Finkenbaum zeigen. "Bei einer so durchaus eigenartigen Kirche, wie es die der Hocheltener Abtei ohne Frage war, schreibt er, muß allerdings mit der Möglichkeit gerechnet werden, daß den vier Jochen des Mittelschiffes vier rechteckige in den Seitenschiffen entsprachen \&. Ich möchte der letzteren Annahme den Vorzug geben. Das Fehlen von Spuren der Zwischenstützen in den Abseiten einerseits und das Vorkragen der Obermauer des Mittelschiffs über die untere Schildfläche andrerseits sind doch Tatsachen, wodurch der Bau selber unmittelbar zugunsten des ungebundenen Systems spricht. Dagegen scheinen die Gründe, die für gepaarte Steindecken in den Abseiten geltend gemacht werden können, mehr subjektiver Art zu sein und dem Bedürfnis zu entspringen, eine nicht gewöhnliche Einzelerscheinung in den Rahmen der uns geläufigen Systeme einzuspannen. Vor einer solchen Methode muß sich aber besonders eine Wissenschaft hüten, deren Aufgabe es ist, die Erzeugnisse der frei schaffenden Kunst zu würdigen. Das gilt doppelt, wenn sie einem Werke gegenübersteht, das den Stempel künstlerischer Eigenart so deutlich an der Stirn trägt wie die Eltener Stiftskirche. Übrigens erkennt auch Rahtgens an, daß das Befremdliche im ungebundenen System, die Säulen des Mittelschiffes als Gewölbestützen zu übergehen, durch das Querhaus selbst gerechtfertigt wird ${ }^{86}$ ). "Dem Grundriß nach würde ein solches Wölbsystem in den Seitenschiffen ganz dem der Kreuzarme entsprechen, wo es doch wohl zur ursprünglichen Anlage gehörte «. Und zwar ist die Verwandtschaft zwischen dem Gewölbesystem und dem Querhaus eine uneingeschränkte, die sich sowohl auf die Gestalt der Steindecke als auf die Säule zwischen den Vierungspfeilern bezieht. Es muß demnach, neben der von Rahtgens vertretenen Ansicht, als wahrscheinlich gelten, daß der Meister von Hochelten anfangs daran dachte, seine Kirche nach ungebundenem System einzuwölben. Dieser Umstand verdient aber in der Geschichte der deutschen Wölbekunst so hoch angeschlagen zu werden, daß die Eltener Gewölbeanlage in die Reihe der oben angeführten Systemabwandlungen mitaufgenommen werden sollte.

Damit haben wir zum Laacher Deckenwerk auf heimatlichem Boden ein gleichzeitiges Schwestersystem gefunden, wenn auch nicht in der Ausführung, so doch im Entwurf. Beide lassen grundsätzlich die rechteckige Steindecke an Stelle der quadratischen treten, und zwar nicht nur im Langhause, sondern auch im Westbau der Laacher und im Querhause der Hocheltener Kirche. Daraus ergibt sich nun aber auch sofort die:Verwandtschaft zwischen Hochelten und Echternach, die in gewissem Sinne noch enger ist als zwischen der Laacher und der Willibrordsbasilika. Das Hocheltener Langhaus erreicht eine lichte Breite von $20 \mathrm{~m}$ vor der Vierung und im Mittelschiff mit Einschluß der geräumigen Nonnenempore eine Länge von

86) Zwei frühere Beispiele hiervon bieten der Laacher Kreuzgang und die Echternacher Seitenschiffe. 
$40 \mathrm{~m}$. Also dieselben Raumverhältnisse wie in den Langhäusern von Echternach und Maria Laach, hier mit Ausschluß der Westapsis, dort der Vorhalle. Nur das Interkolumnium weicht ab. Der Achsenabstand von Säule zu Pfeiler beträgt in Echternach $3,40 \mathrm{~m}$ oder II Fuß; in Maria Laach von Lisene zu Lisene 3, $14 \mathrm{~m}$ oder Io Fuß; beides ein Drittel der Quadratseite. In Hochelten ist diese Zwischenweite größer und durch die untere Kämpferhöhe des Mittelschiffes auf $3,80 \mathrm{~m}=12 \mathrm{FuB}$ bestimmt. Somit zeigt sich hier wie in Maria Laach dasselbe Bestreben, das Interkolumnium zu erweitern. Der Laacher Meister ließ die Zwischensäulen im Hauptschiff fallen und ersetzte diese Unterteilung durch Verdoppelung der Lisenen an den Umfassungsmauern. In der Hocheltener Nonnenkirche, wo der weichere Rhythmus des Stützenwechsels sich einer solchen Beliebtheit erfreute, daß er selbst im Querhause nicht fehlen durfte, erweiterte man den Abstand der Pfeiler um zwei Fuß. Ohne Zweifel wäre man hierin noch weiter gegangen, wenn, wie Rahtgens annimmt, in den Abseiten das gebundene Gewölbesystem geplant gewesen wäre. Die ziemlich gestreckten Steindecken hätten dann auch nicht ihren stärksten Seitenschub auf die verhältnismäßig schwachen Umfassungsmauern ausgeübt. Die Tatsache aber, daß man sich in der Erweiterung der Interkolumnien so große Einschränkung auferlegte, scheint mir wieder auf das auch in Echternach befolgte ungebundene Gewölbesystem hinzuweisen.

Meine Vermutung, daß der Hocheltener Meister die vielbesuchte Wallfahrtskirche des hl. Willibrord kannte, erhält eine beachtenswerte Bestätigung dadurch, daß wir hier auch die ersten, bis jetzt im ehemaligen Lothringen bekannt gewordenen Triforien antreffen, wovon Hochelten ein .zweites, originelles Beispiel bietet ${ }^{87}$ ). Die Echternacher Triforien sind zweiteilige, durch ein Säulchen getrennte und im Rundbogen geschlossene Fensteröffnungen, wie das Mittelschiff von St. Kastor in Koblenz sie am Ende des 12. Jahrhunderts erhielt ${ }^{88}$ ). Dieselben stehen auf der Achse der Rundsäulen ungefähr in der Mitte zwischen den Blendbogen und den Fenstern des Hauptschiffes ${ }^{89}$ ). Wie in der Form, so schließen sie sich auch in den Maßen den großen Doppelbogen an. Die Breite der Zwillingsöffnungen beträgt ein Viertel des lichten Abstandes von Pfeiler zu Pfeiler und die Höhe etwas mehr als ein Viertel der Höhe der Blendbogen. Damit scheint mir die Ursprünglichkeit dieser Triforien hinreichend gesichert, und es ist kaum daran zu zweifeln, daß der Eltener Meister sie gesehen und daraus die Anregung zu seinen interessanten Neubildungen dieser Art geschöpft hat.

Auf Grund der vorstehenden Ausführungen möchte ich, solange keine bessere Erklärung gefunden wird, das Laacher Gewölbesystem als eine selbständige Schöpfung

87) Abb. bei Rahtgens, Zeitschr. f. Gesch. d. Arch. V (1912), S. $18_{3}$.

$\left.{ }^{88}\right)$ Heute sind sie vermauert und die Zwischensăulchen mit Basis und Kapitell ausgebrochen. Abb. im Organ f. christl. Kunst, Luxemburg, Jahrg. $1862-1863$.

${ }^{89)}$ Die Anbringung solcher Öfnungen auf den Achsen der Pfeiler ging nicht an, wegen der Strebemauern, welche diese unter dem Dache der Abseiten tragen. 
des Laacher Architekten ansprechen, wozu er durch das Echternacher Langhaus angeregt wurde. Diese Annahme bestätigen die gleichzeitigen Bauten des Kreuzganges am See und der Stiftskirche zu Hochelten, wo wir ähnliches finden. Daß der Meister einer solchen Schöpfung fähig war, wird niemand bezweifeln, der die andern hohen Vorzüge seines Werkes zu würdigen versteht.

\section{WELCHE DECKE WAR FÜR DAS QUERSCHIFF UND DAS OSTCHOR GEPLANT?}

Die Art des Deckenwerkes, Holz- oder Steindecke, die ursprünglich für das Querschiff und das Ostchor geplant war, ist erst in jüngster Zeit in Frage gezogen worden. Bis dahin wurde allgemein angenommen, daß beide von Anfang an als Gewölbebau gedacht waren. Dagegen hat Huppertz zuerst den Versuch unternommen, eine Holzdecke als den ursprünglichen Plan nachzuweisen $\left.9^{\circ}\right)$. Seinen Ausfüh-

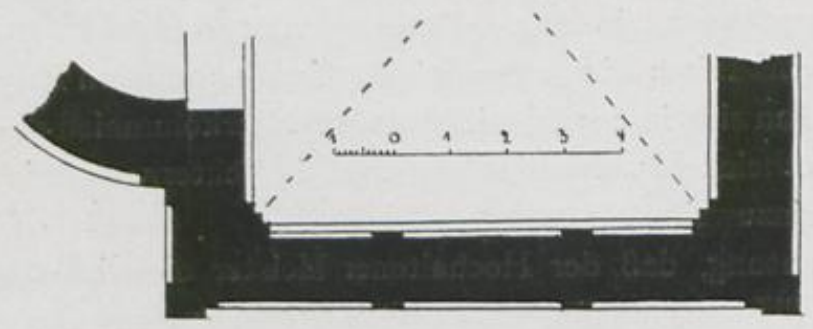

Abb, 32. Eckverstärkungen im Querhause.

rungen gegenüber möchte ich die bisherige Auffassung durch folgende Gründe als die richtige in Schutz nehmen.

Ich verweise zunächst auf die Darlegungen des vorigen Teiles. War das Langhaus von Anfang an auf Gewölbe berechnet, so ist das noch viel mehr vom Querschiff und vom Chor zu erwarten. Und umgekehrt. Lassen diese Bauteile ihrerseits unzweifelhafte Hinweise auf die Steindecke erkennen, so erhöhen sie dadurch auch wiederum das Gewicht der für das Gewölbesystem vorgebrachten Gründe.

Die Mauern des Querhauses erreichen eine Stärke von $\mathrm{I}, 20 \mathrm{~m}$ und sind in sorgfältiger Quadertechnik ausgeführt. In den Ecken erhalten sie innen und außen eine Verstärkung durch kräftige Lisenen aus Basaltquadern, so daß dadurch für den Gewölbeschub ein Widerlager von $2,20 \mathrm{~m}$ in der Diagonale gewonnen wird. Man vergleiche in diesem Punkte unsere Kirche mit den frühesten rheinischen Gewölbebasiliken des I2. Jahrhunderts, mit Knechtsteden, Klosterrath, Steinfeld, Wissel, die auch in den Ecken des Querhauses Lisenenverstärkungen anwenden. Keine übertrifft die Laacher in der sorgfältigen Behandlung der Eckwiderlager (Abb. 32).

5o) A. a. O. S. $65-74$. 
Dazu kommt Folgendes. Die Lisenen sind im Innern nicht gleich stark. Die vier Ecklisenen der Nord- und Südwand bilden eine Ausnahme. Sie sind mehr als doppelt so stark wie die nebenstehenden Ecklisenen der West- und Ostwand und die freistehenden Wandlisenen. Der Grund leuchtet sofort ein, wenn man zu den Gewölbekämpfern emporschaut. Während die anderen Lisenen nur einen Bogen tragen, nehmen die genannten vier Ecklisenen der Nord- und Südwand je zwei Bogen auf, den dekorativen Wandbogen und dazu den großen, breiten Schildbogen der Gewölbe. Diese Verwendung entspricht offenbar der ursprünglichen Absicht des Architekten. Siehe Abb. 32.

Den beschriebenen Unterschied der Lisenenstärke in unserem Querhause hat Huppertz übersehen. Darum ist der Vergleich, den er zwischen diesen und den Ecklisenen in Limburg a. d. Haardt, St. Ursula in Köln, St. Castor in Koblenz und in unserer Kirche außerhalb des Querhauses zieht, hinfällis. Nirgendwo an den genannteı Denkmälern findet sich ein solcher Unterschied der Lisenenstärke wie in unserem Querschiff.

Zwischen den Ecklisenen im Innern des Querhauses treffen wir noch ein drittes Glied an, nämlich eine Eckvorlage für den Diagonalgrat (Abb. 32). Mehr noch als die Verschiedenheit der Lisenenstärke, bereitet dieses Bauglied dem Verfechter der Balkendecke Schwierigkeiten. Der Umstand, daß es über dem Sockel nicht weitergeführt wurde, kommt erst in zweiter Linie in Betracht und kann von der Notwendigkeit, das Vorhandene zu erklären, nicht entbinden. Wer nicht behaupten will, daß dieses Bauglied gedanken- und zwecklos entstanden ist, der muß zugeben, daß3 es nur mit Rücksicht auf ein Gratgewölbe angelegt werden konnte. Wenn Huppertz meint, daß es vor der Entstehung der eigentlichen Dienste für Rippengewölbe keine ähnlichen Bauglieder gab (S. 68), so täuscht er sich. Die noch vorhandenen Überreste des Laacher Kreuzganges, die gleichzeitig mit dem südlichen Querhaus entstanden, enthalten allein schon zwei Beispiele. Siehe z. B. Abb. 3. Das östliche Querhaus des Mainzer Domes, das um 1100 aufgeführt wurde, besitzt sowohl im Unter- wie im Obergeschoß fur seine Gratgewölbe überall drei Dienste, zwei für die Schildbogen und eine Eckvorlage für den Diagonalgrat 9r).

Betrachten wir jetzt die Anlage der Süd- und Westwand des südlichen Querhauses. Ich habe im zweiten Teile gezeigt, daß sie gleichzeitig mit dem Ostflügel und dem Kreuzgang des Klosters errichtet wurden. Trotz dieses Anbaues sollte die Südwand Fenster erhalten. Infolgedessen wurde das Dach des Ostflügels äußerst riedrig gehalten, um über demselben drei kleine Fenster anbringen zu können, von denen das nittlere, mit Rücksicht auf den Dachgiebel, etwas über der Mitte der seitlichen Fenster ansetzte. Alle drei genannten Fenster sind noch erhalten. (Vgl. Abb. 8 und Titelbild.) Das Rund- und Sechseckfenster haben, ähnlich

91) Vgl. Fr. Schneider, Der Dom zu Mainz, 1886, Folio-Ausgabe, Taf. 5. 
wie die anderen Öffnungen, Abb. 24 und 25, sogar noch den aus Lava hergestellten Innenrand, in dessen Falz die Verglasung eingefügt wurde.

Warum legte man sich diesen Zwang auf, wenn eine Balkendecke geplant war? Diese hätte erst in der Höhe von $17 \mathrm{~m}$ ihren Platz gefunden. Der Dachgiebel des Klosters konnte dann so hoch hinaufsteigen wie das Dach der Seitenschiffe, bis zur Höhe der Mittelschiffsfenster. In diesem Falle hätte man, wie es die Anlage der flachgedeckten Basilika verlangt, auf der Linie der Mittelschiffsfenster in die Südwand des Querhauses drei große Fenster anbringen können, ähnlich wie die Nordwand sie im unteren Gaden zeigt.

Statt dessen war genau das geplant, was wir heute im Querschiff noch sehen. Der Platz der drei kleinen, in Rede stehenden Fenster der Südwand war begrenzt von außen durch das Dach des Klosters, von innen durch die drei Wandarkaden. Darüber folgte der Schildbogen des Gewölbes der wiederum nur einen kleinen Raum für ein viertes Fenster gestattete.

Die Anlage auf die ursprünglich geplante Wölbung lassen aber auch die anderen Wände des Querschiffes deutlich erkennen. In Limburg a. d. Haardt geht die Sohlbank der oberen Fenster in einer geraden Linie durch Chor, Quer- und Langhaus. Im unteren Lichtgaden sitzen die Fenster des Chores und des Querhauses um $90 \mathrm{~cm}$ höher als die des Langhauses. An unserer Kirche bilden die unteren Fenster des Westchores und des Langhauses eine gerade durchgehende Linie, und es ist nicht zu bezweifeln, daß die unteren Fenster des Ostchores sich dieser Reihe anschlossen. Das Querschiff macht hiervon eine auffallende Ausnahme, die ihre genügende Erklärung nur im Gewölbeplan findet. Hätte man dem Querschiff ursprünglich eine flache Decke zugedacht, dann wären seine unteren Fenster in der Höhe der Langhausfenster angebracht worden. Die Richtigkeit dieser Annahme beweist die Tatsache, daß selbst im Gewölbebau die Fensterlinie des Langhauses an der Außenwand des nördlichen Querhausflügels durch eine Lavaschicht fortgesetzt wurde. Eine andere Bedeutung kann dieses schwarze Band zwischen den gelben Tuffquadern meines Erachtens nicht haben als die Wandfläche zu teilen, und zwar an der Stelle, wo dies sonst die Fenster getan hätten. An der Südwand des Querschiffes fehlt diese Lavaschicht. Wieder eine Bestätigung für den gleichzeitigen Anbau des Klosters an dieser Stelle, wie ich dies vorhin und im zweiten Teile dargelegt habe. Auch die Durchführung des Gurtgesimses am Querhause unter den Fenstern als Dachgesimse der Nebenapsiden spricht für einen einheitlichen, wohl überlegten Plan. Siehe Adalb. Schippers, M. Laach u. die Kunst, Abb. I2.

Gemäß der beschriebenen Fensteranordnung wäre auch die Westwand unter der Holzdecke mit drei Fenstern versehen worden wie in Limburg a. d. Haardt, und zwar um so mehr, als sie in unserer Kirche die Nord- und Südwand an Ausdehnung übertrifft. Diese Absicht lag aber ganz sicher nicht vor. Das beweisen die beiden Lisenen, welche die Westwand des südlichen und nördlichen Querhausflügels außen 
von unten auf in der Mitte teilen. (Vergl. das Titelbild.) Da nun die unteren Teile des südlichen Querschiffes mit zum Allerersten gehören, was überhaupt gebaut wurde, so zeigt auch diese Tatsache, daß man vom ersten Augenblicke an das Querschiff so eindecken wollte wie es jetzt dasteht.

Zum gleichen Ergebnis gelangen wir, wenn wir die Mauerstärke und die Spannweite in unserem Querhause mit den statischen Bedingungen in den Querschiffen der rheinischen Gewölbebasiliken des I2. Jahrhunderts vergleichen, die der Laacher Kirche sowohl in Bezug auf die Zeit als auf die Raumverhältnisse am nächsten stehen.

Maria Laach, Mauerstärke $1,20 \mathrm{~m}$, größte Spannweite 9,20 m = I : 7,66. Knechtsteden 92), beg. II 38 , Mauerstärke I,05 m, größte Spannweite $8,30 \mathrm{~m}$ $=\mathrm{I}: 7,90$.

Klosterrath 93), beg. vermutlich I143, Mauerstärke I,O0 m, größte Spannweite $8,50 \mathrm{~m}: 1=\mathrm{r}: 7,73$.

Wisse194), Pfarrkirche, beg. I. Hälfte d. 12. Jahrhunderts, Mauerstärke $\mathrm{I}, \mathrm{IO} \mathrm{m}$, größte Spannweite $7,80 \mathrm{~m}=1: 7,09$.

Steinfeld95), beg. II42, Mauerstärke und größte Spannweite = I : 7 .

Eberbach ${ }^{6}$ ) im Rheingau, II 86 geweiht, Mauerstärke I,30 m, größte Spannweite $I \mathrm{I}, 20 \mathrm{~m}=\mathrm{I}: 8,62$.

Unter den fünf angeführten Bauten beansprucht somit Maria Laach allein schon in bezug auf die Mauerstärke den dritten Platz. Nehmen wir hinzu, daß der tiefere Ansatz der Gewölbe die Standfestigkeit derselben durch die Oberlast einer $3 \mathrm{~m}$ hohen Mauer noch vermehrt, so übertrifft das Laacher Querschiff die anderen erwähnten Gewölbebauten um ein Bedeutendes. Die ursprünglich geplante Einwölbung der LaacherQuerhausflügel, und zwar in der Weise wie sie heute noch vor uns steht, kann demnach nicht mehr bezweifelt werden 97).

92) Clemen, Die Kunstdenkm. der Rheinprovinz. Kr. NeuB, (1895) S. 2 I.

93) Dehio u. v. Bezold, Taf. 165,4 .

94) Clemen, a. a. O., Kr. Kleve, (1892) S. 154.

95) Die Aufnahmen im Rhein. Denkmälerarchiv zu Bonn sind leider unvollständig. Den vier zuletzt genannten Kirchen widmet Huppertz im 2. Teile seiner Schrift eine besondere Untersuchung (S. $\mathrm{rO}_{3}$ bis 106, Taf. XIII, Abb. 4 und 5), unterläBt aber den von mir gezogenen Vergleich mit unserer Kirche. Unter den Gewölbebauten weist er nur auf die Dome von Speier und Mainz hin und findet zwischen diesen und unserer Kirche sgewaltige Differenzene (S, 69) in statischer Beziehung. Das Mainzer Querschiff gehört bekanntlich dem Anfang des 13. Jahrhunderts an. Wenn man in der Datierung des Speierer Querschiffes einig wäre, käme es hier nicht in erster Linie in Betracht, sowohl wegen der viel gröBeren Spannweite seiner Gewölbe $(14,70)$ als wegen der eigentümlichen Anlage der Nord- und Südwand, in welche Kapellen eingebaut sind, die eine außergewöhnliche Verstärkung der ubrigen Mauerteile $(3,70)$ mit sich brachten.

96) Geier und Görz, Denkmale romanischer Baukunst a. Rh., 1846, Liefrg. 1 und 2.

97) Die Art und Weise, wie der Laacher Architekt die mächtigsten Steindecken seines Baues durch Oberlast sicherte, finden wir in der einige Jahrzehnte spăter, 1123, gegründeten Prämonstratenserkirche zu Ilbenstadt in Oberhessen wieder. (Vgl. R. Adamy, Kunstdenk. im Großherzogt. Hessen, Kr. Friedberg, S. $136 \mathrm{ff}$. Dehio u. v. Bezold, Taf. 52 und 54 . Dehio, Handbuch, IV. S. 162.) Die Höhe der Mauer 
Waren demnach die Querhausflügel von Anfang an auf Wölbung geplant, so schwinden auch die Bedenken, die gegen das Vierungsgewölbe geltend gemacht werden könnten. Solche erblickt Huppertz vor allem in der einfachen Kreuzform der östlichen Vierungspfeiler, die durch den Mangel der Eckdienste auf flache Decke hinweisen sollen. Nun dürfte es allgemein bekannt sein, daß im romanischen Gewölbebau nur selten alle Bauglieder ihre eigenen Dienste besitzen. Als Beispiel führe ich nur St. Mauritius in Köln an, das der Verfasser im zweiten Teile seines Buches behandelt $\left.9^{8}\right)$. Die Hauptpfeiler dieses Gewölbebaues zeigen überall die einfache Kreuzform ohne Eckdienste.

Wenn nun dieselben östlichen Vierungspfeiler später über den Kämpfern feine Dienste erhielten, so lassen sich dafür mehrere Gründe anführen. Zunächst ist zu beachten, daß in unserer Kirche die in Lavaquadern ausgeführten Bogen gewöhnlich ohne Schildbogen sind99). Nach dieser Regel hätte der östliche Vierungsbogen keine Schildbogen erhalten sollen; der betreffende Pfeiler brauchte also auch keine Dienste. Später wurde der erwähnte Bogen nicht nur unter der Vierung, sondern auch im Chor, und hier mit einem besonders starken Schildbogen versehen, meines Erachtens aus dem Grunde, weil nach Schluß des östlichen und westlichen Vierungsbogens, der Bau längere Zeit unterbrochen werden mußte. So erklärt sich einer der über den östlichen Vierungskämpfern ansetzenden Dienste aus dem später hinzugefügten Schildbogen. Dagegen waren an den Hochwänden unter der Vierung von Anfang an Schildbogen geplant, ähnlich wie im ganzen Langhause. Daraus folgt aber nicht, daß ihre Dienste wie an den westlichen, so auch an den östlichen Pfeilern unten am Fuße derselben beginnen mußten. Vielmehr ließ man sie gemäß einer auch anderswo befolgten Bauregel aus einem triftigen, gleich zu erwähnenden Grunde, an den östlichen Pfeilern erst über den Kämpfern anfangen. Bekanntlich stehen in der romanischen Baukunst nicht alle Dienste mit oder ohne Sockel auf dem Boden. So beginnen sämtliche Wandlisenen im Mittelschiff von St. Ursula in Köln auf den Kämpfergesimsen ${ }^{100}$ ). In Eberbach werden die beträchtlichen Schildbogen des Mittelschiffes von kleinen, neben den Kämpfern angebrachten Konsolen getragen ${ }^{101}$ ). In der Maria Laach benachbarten romanischen

über den ursprünglich unzweifelhaft geplanten Gewölben des Querschiffes beträgt ebenfalls $3 \mathrm{~m}$. Auch hier wurden Querhaus und Chor vor dem Langhaus fertiggestellt. Nur der Unterschied waltet zwischen beiden Kirchen ob, daß in der Laacher das Vierungsgewölbe die Höhe des Mittelschiffes erreicht und so dessen Innenraum bis zur Hauptapsis zur vollen Entfaltung gelangen läßt, während in Ilbenstadt die Vierungsbogen die Einheit des Mittelschiffsraumes zerschneiden. Ebenso in der spătromanischen St. Andreaskirche in Koln.

95) S. 103 und Taf. XIII, 1. Vgl. auch Otte, Geschichte der deutschen Baukunst, S. 297, Abb. 146.

99) In dem von Huppertz gegebenen Grundriß der Kirche, Taf. 3, sind dem Gesagten zufolge die Schildbogen an der Vierung im Querhause und am Westchor zwischen den östlichen Pfeilern unter der Empore irrtümlich eingetragen. Dagegen fehlen sie hier in der Apsis zwischen den Rundsäulen.

${ }^{100}$ ) Dehio u. v. Bezold, Atlas I, Tafel 63, und Huppertz, a. a. O., Taf. XV.

10.) Geier u, Görz, Denkm. rom. Baukunst a. Rh. I. Liefrg. Taf. III. Dehio u. v. Bezold, Atlas Taf. $198,1-2$. 
Kirche in Niedermendig stehen die Dienste ebenfalls auf den Kämpfergesimsen ${ }^{102}$ ). Wären statt dessen die Dienste der östlichen Pfeiler so wie die der westlichen angelegt worden, dann hätten die Eckpfeiler eine nicht unbedeutend gròßere, aber überflüssige Stärke erlangt. Als Mauerpfeiler, die mit den Flankierungstürmen ganz verwachsen sind, entsprechen sie in ihrer jetzigen Anlage vollkommen der ihnen zugedachten Aufgabe.

So ergibt sich die Form der östlichen Eckpfeiler folgerichtig aus der Stellung, die sie einnehmen. Ganz dasselbe ist bei den westlichen Vierungspfeilern der Fall. Nach Osten hin einerseits, nach Süden und Norden hin andererseits müssen sie sich ganz verschiedenen Eckpfeilern anpassen. Infolgedessen betragen ihre Vorlagen in axialer Richtung $0,86 \mathrm{~m}$, in queraxialer Richtung aber $1,20 \mathrm{~m}$ Breite. Diese Stärke wird nun dadurch noch vermehrt, daß sie sich in bezug auf die Form den Langhauspfeilern anschließen. Hier finden wir, wie in Speier am Bau Heinrichs IV. im Hauptschiff, Kreuzpfeiler mit Halbsäulenvorlagen nach dem Mittelschiff und den Abseiten hin. Dadurch wird das Profil dieser Pfeiler an den Ecken dreiteilig. Die westlichen Vierungspfeiler erhielten diese Gliederung durch Einfügung von starken Eckdiensten.

Aus der Anpassung der westlichen Vierungspfeilern an die Eckpfeiler der Abseiten oder mit anderen Worten an die Mauern des Querhauses ergibt sich weiterhin mit Notwendigkeit die größere Breite des westlichen Vierungsbogens gegenüber dem östlichen. Dieser Unterschied kann demnach nicht, wie Huppertz S. 67 behauptet, auf den später geplanten Vierungsturm zurückgeführt werden.

Die vorhin beschriebene Anpassung der Pfeilerform an die jeweiligen Bedingungen ihrer Aufgabe und Stellung finden wir fast noch konsequenter am Westchor durchgeführt. Hier erreichen die Vorlagen der Eckpfeiler an einer Seite nur $0,60 \mathrm{~m}$, an der anderen dagegen I $\mathrm{m}$ Breite. Die Freipfeiler sind nach dem Langhause hin mit Rücksicht auf die Mittelschiffspfeiler mit Eckdiensten ausgestattet, während sie nach Westen hin fehlen.

Können somit weder der Unterschied zwischen den östlichen und westlichen Vierungspfeilern noch der Ansatz der Dienste über den Kämpfern auf eine Planveränderung zurückgeführt werden, so ist es noch unzulässiger, mit Huppertz zu behaupten, der Baumeister habe durch die Schildbogen erst nachträglich den notwendigen Unterbau für den jetzigen Vierungsturm gewinnen wollen (S. 67). Diesen Zweck konnte er durch diese ganz dünnen Vierungsschildbogen unmöglich erreichen. Folglich wollte er es auch nicht. Zudem ließen sich gerade die schwächsten Vierungsbogen, der südliche und der nördliche $(0,86 \mathrm{~m}$ breit), an der Hochwand nur durch einen Schildbogen verstärken, und auch dieser fiel ganz schwach aus. Dagegen erhielt der östliche, o,91 m starke Vierungsbogen zwei Schildbogen, von

102) Die Kämpfergesimse sind in den erwähnten Fällen als Konsolen benützt. Diese waren aber der romanischen Baukunst jederzeit geläufig, wie allein schon die Rundbogenfriese beweisen. 
denen der im Chore überdies noch stärker angelegt wurde, und zwar aus demoben angeführten Grunde, nicht um den Vierungsturm aufführen zu können.

Sind damit die formalen Einwände gegen das Vierungsgewölbe entkräftet, so treten nun auch seine wohl überlegten statischen Bedingangen klarer zutage.

Wie der Seitenschub der Gewölbe in den Querhausflügeln nach der Vierung hin nur durch die Hochmauer völlig ausgeglichen werden kann, so beruht auch die Standfestigkeit des Vierungsgewölbes wiederum großenteils auf der Oberlast des Vierungsturmes. Diese Vorliebe unseres Baumeisters, mit Oberlast zu rechnen, zeigt sich besonders anschaulich am Westchor. Hier muß die östliche Rundsäule dem Seitenschub von zwei großen rechteckigen Gewölben und deren Gurtbogen standhalten. Ohne Zweifel die kühnste Anlage in der ganzen Kirche! Die Säule ist denn auch, trotz der $4,30 \mathrm{~m}$ hohen Obermauer, so weit ausgewichen, daß die Ostseite jetzt senkrecht steht, obgleich der $3,65 \mathrm{~m}$ hohe Schaft sich um $10 \mathrm{~cm}$ verjüngt (Abb, 8 u. 15).

Wenden wir jetzt unsere Betrachtung dem Chore zu. Für die ursprünglich geplante Wölbung desselben spricht meines Erachtens zunächst die Tatsache, daf die Chormauern zwischen den Türmen und den Strebepfeilern erheblich stärker sind als an den Turmwänden. Während sie hier nur $67 \mathrm{~cm}$ dick sind, erreichen sie dort einen Durchmesser von $97 \mathrm{~cm}$. Dieser beträchtliche Unterschied findet seine hinreichende Begründung nur in dem geplanten Gewölbebau.

Hierauf weisen aber vor allem die Strebepfeiler zu beiden Seiten der Apsis hin, und zwar zunächst durch die Mächtigkeit ihrer Anlage. Wie die Widerlager in den Ecken der Querhausflügel, so erreichen auch sie mit der Chormauer einen Durchmesser von über $2 \mathrm{~m}$. Zudem sind sie außen auf beiden Seiten durch $50 \mathrm{~cm}$ breite Lisenen und innen durch den Apsispfeiler verstärkt. Die Ausführung ist vorzüglich und zeigt überall schwere Basaltquadern (Abb. 5). Da die Diagonalspannung der Gewölbe im Querhause größer ist, sind die statischen Bedingungen im Chore günstiger, wenn man von der Oberlast im Querhause absieht. Überdies wird der Druck des Gewölbes auf die Chormauern fast zur Hälfte von den Flankentürmen aufgenommen.

Ebenso deutlich wie aus der Stärke erhellt die den Strebepfeilern in erster Linie zugedachte Aufgabe aus der Stellung, die sie einnehmen. Wären sie, wie Huppertz annimmt, nur zur Sicherung des Apsisbogens da, dann müßte die Achse des Apsispfeilers mit derjenigen der Strebepfeiler zusammenfallen. Das ist aber nicht der Fall, wie Abb. 33 zeigt. Vielmehr teilt die Achse des Apsispfeilers die Strebepfeiler auf der Grundlinie nahezu in zwei und drei Fünftel, wovon der größere Teil auf der Ostseite liegt. Ergibt sich schon daraus, daß die Strebepfeiler den Apsisbogen nach Osten hin merklich überschreiten, so wurde das noch mehr dadurch erreicht, daß dieselben überdies eine Drehung in derselben Richtung erhielten. Von den vier Freiseiten sind nämlich die beiden nach Osten gerichteten verkürzt. 
Während diese 33 und $71 \mathrm{~cm}$ breit sind, messen die anderen 42 und $74 \mathrm{~cm}$. Am südlichen Strebepfeiler beträgt der Unterschied zwischen den kleineren, der Mauer zugewandten Seiten sogar $16 \mathrm{~cm}$. Beide Umstände nun, die Drehung der Strebepfeiler sowohl als ihr Überschreiten des Apsispfeilers nach Osten, können in befriedigender Weise gar nicht anders erklärt werden, als dadurch, daß damit noch ein Zweck verfolgt wurde, der über die Absicht, den Apsisbogen zu sichern, hinausgeht. Die Drehung läuft dieser Absicht geradezu zuwider. Hier an Nachlässigkeit oder an einen Zufall zu denken, ist ausgeschlossen. Vielmehr mußten die Basaltquadern auf die erwähnte Verkürzung genau hergerichtet werden. Es bleibt somit nichts anderes übrig, als anzunehmen, daß die beiden Strebepfeiler deshalb nach Osten vorgeschoben und gedreht wurden, um dem Diagonalschub des Chorgewölbes noch

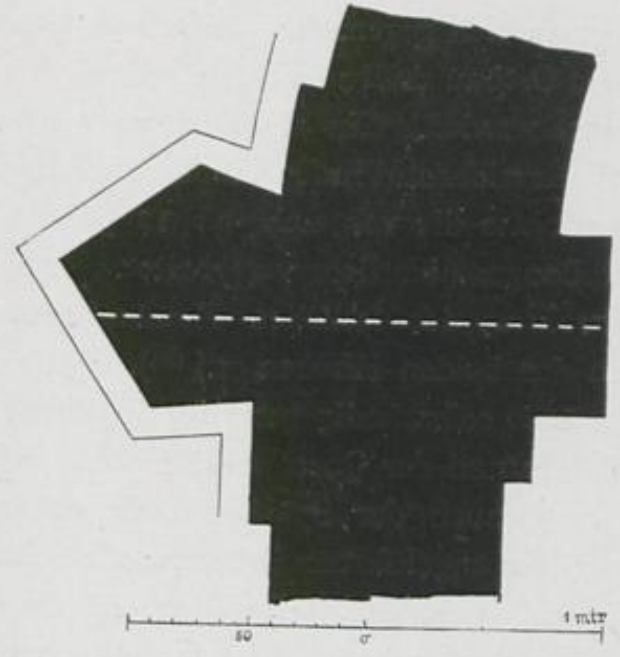

Abb. 33. Schnitt durch die Strebepfeiler des Ostchores. besser begegnen zu können. Da dieser Aufgabe auch ihre außergewöhnliche Stärke entspricht, so enthalten diese Stützen einen unleugbaren Hinweis auf die ursprünglich beabsichtigte Wölbung des Chores.

Infolge der Bauunterbrechung die nach Schluß der Vierungsbogen entstand, wurde, wie ich früher S. 60 angenommen habe, der Schildbogen im Chore an der Vierung stärker angelegt, als ursprünglich beabsichtigt war. Hieraus ergab sich weiterhin eine vermehrte Belastung der entsprechenden Ecklisenen. Im übrigen begegnen neben der normalen Belastung der Kämpfer die weitgehendsten Ausnahmen. Die Wandbogen im ersten Joch der Seitenschiffe vor dem Querhause, die nach meinen obigen Ausführungen der Wende des II. Jahrhunderts angehören, stehen fingerspitz auf den $50 \mathrm{~cm}$ breiten Kämpfern, während sie nach der Mitte um das vierfache anschwellen. Das trifft nicht nur bei dekorativen, sondern auch konstruktiven Bogen zu. So verjüngen sich die mächtigen Schildbogen des Querschiffes über den Kämpfern bis auf die Hälfte der größten Breite. An der West- und Ostwand kommt es sogar vor, daß die Schildbogen an einem Fuße dreimal so breit sind als am anderen. Ähnliches wiederholt sich in den Seitenschiffen. Am weitesten geht hierin die Krypta, wo an einignen Stellen der Schildbogen rechts 18 oder $20 \mathrm{~cm}$ breit auf dem Kämpfer aufruht und links entweder verschwindet oder nur $5 \mathrm{~cm}$ Breite mißt. Solche Unregelmäßigkeiten, wovon jeder romanische Gewölbebau Beispiele bietet, können, auch wenn sie sich öfters wiederholen, nicht als Beweise für Änderungen des ursprünglichen Planes 
angeführt werden, wie Huppertz das durch die Abb. $\mathrm{I}-4$ auf Taf. Io zu tun sich bemüht $\left.{ }^{103}\right)$.

Was der genannte Verfasser S. 72 über die Verkürzung des Chorquadrates zugunsten des Gewölbes vorbringt, steht im Widerspruch zu seinen früheren Aufstellungen. Er nimmt an, daß die ganze Kirche einschließlich des Ostchores bis zur Höhe von $5 \mathrm{~m}$ zuerst auf flache Decke angelegt wurde. Hierin ist aber auch schon die Verkürzung des Chorquadrates enthalten, die ja nur darin besteht, daß der $55 \mathrm{~cm}$ breite Apsisbogen auf die Chorfläche übergreift. Also kann von einer späteren Anpassung an das Gewölbe keine Rede sein.

Die ursprünglich beabsichtigte Einwölbung des Chores kann nach dem Gesagten nicht mehr ernstlich in Zweifel gezogen werden. Wie das Querhaus, so enthält auch der Chorraum Bauglieder, die formal und statisch unmittelbar auf die Steindecke hinweisen. Darin stützen und ergänzen sich gegenseitig beide Bauteile.

Im Anschluß an die Ausführungen über den Ostbau muß wenigstens mit einem Worte das Verhältnis zum Speierer Dome berührt werden. Ein abschließendes Urteil wird man sich erst bilden können nach der in Aussicht stehenden Veröffentlichung der bayerischen Akademie der Wissenschaften, welche die vor mehr als I2 Jahren in der Kaisergruft gemachten Entdeckungen baugeschichtlich verarbeitet. Am meisten fällt bekanntlich die gleichartige Stellung der östlichen Flankentürme in den Ecken zwischen Chor und Querschiff an den beiden Kirchen auf ${ }^{104}$ ). Abgesehen davon hat der Laacher Meister seine Ostteile selbständig gestaltet in Bezug auf die Stärke der Türme, den Umfang des Chores und der Querhausflügel und die Nebenapsiden. Auf den Vierungsturm, den wohl auch der Speierer Dom unter Heinrich IV. erhielt, weist außer den schon S. 62 angeführten Gründen, die sehr schlanke Anlage der Laacher Flankentürme hin, die allein den drei mächtigen Westtürmen kein Gegengewicht zu bilden vermögen. Die nach W. M. Schmid ${ }^{105}$ ) seit 1085 im Speierer Langhause auftretenden Pilaster mit Halbsäulen und Ecksporen finden wir im Laacher Mittelschiff wieder. In unserer Krypta fielen die Ecksporen an den Halbsäulen vermutlich deshalb fort, weil die letzteren nicht auf dem Fußboden, sondern auf einer $0,35 \mathrm{~m}$ hohen Bank stehen und daher dieser Eckverstärkung nicht bedurften. An beiden Orten begegnet uns endlich gleichzeitig der Einfluß Oberitaliens. Da wir unter den "ausländischen Künstlern «106), die Heinrich IV.

103) Die Wandbogen des Ostchores werden an den Ecklisenen von kragsteinähnlichen Konsolen aufgenommen, wie meine Abb. 8, nicht. wie Abb. I, Taf. 1o bei Huppertz zeigt. Die Abb. 3 und 4 derselben Tafel besitzen so auffallende charakteristische Ähnlichkeiten mit den von mir veröffentlichten Zeichnungen in der Zeitschrift: Die christl. Kunst, IV. (1907-08) S. 270 , selbst in dem, was sie Fehlerhaftes an sich haben, daß die Übernahme nicht bezweifelt werden kann. Die Angabe der Quelle fehlt jedoch.

ro4). Dehio u. v. Bezold, Atlas, III. Taf. 220.

to5) Huppertz, a. a. O. S. 6, Anmerkg. 1 .

106) Imperator omnes sapientes ac industrios architectos, fabros et cementarios aliosque opifices regni sui vel etiam de aliis regnis in opere ipso habens. Mon. Germ. SS. XII, S. 750. 
an seinem Baue beschäftigte, am ehesten an die Lombarden denken müssen, so liegt es nahe, anzunehmen, daß die oberitalienischen Zierformen, die ich an unserer Kirche nachgewiesen habe, durch Speier vermittelt wurden. Diese Verwandtschaftszüge zwischen dem Kaiserdome und dem Pfalzgrafenmünster am See reichen allein schon hin, um die beiderseitigen Beziehungen deutlich erkennen $\mathrm{zu}$ lassen.

\section{DER WESTBAU,}

Kein Teil der frühromanischen Basilika hat bekanntlich unter den Händen der fränkischen Baumeister so verschiedene Lösungen gefunden wie der Westbau. Das erste große, um 800 vollendete Münster der Karolingerzeit, die Klosterkirche St. Richarius von Centula bei Abbeville in der Picardie, besaß ein Westwerk, d. h. einen Westbau mit Emporen und dem Hauptportal auf der Achse des Mittelschiffes. Der Neubau der Abteikirche zu Fulda wurde nach 802 zu Ehren des hl. Bonifatius gegenüber dem Ostchor mit Westchor und Querschiff ausgestattet. Beide Kirchen wichen dadurch entschieden von dem altchristlichen Ideal ab, wonach der Westbau weder Emporen noch Chor erhielt, sondern als Stirnseite des Gotteshauses lediglich die Eingänge vermittelte. Diese Anlage wählte der Minister Karls des Großen, Einhart, für die Basiliken, die er zu Steinbach und Seligenstadt erbauen ließ. Bis zum Ende des II. Jahrhunderts gestaltete sich der Westbau in Deutschland wesentlich in dieser dreifachen Art, natürlich mit größter Mannigfaltigkeit im einzelnen. Gerade als man anfing, die Westwerke und Westchöre entschieden aufzugeben, da verschmolz unsere Kirche beide Anlagen noch einmal in einer Weise miteinander, wie es vor- und nachher keine zweite getan hat. Nimmt man die später angeschlossene Vorhalle mit dem großen Mittelportal hinzu, so kann man sagen, daß das Laacher Münster selbst den altchristlichen Eingangsbau mit den fränkischen Westanlagen soweit vereinigt, als dies überhaupt möglich ist ${ }^{107}$ ).

Um die verschiedenen Verwandtschaftszüge, die unser Westbau mit anderen aufweist, besser zu überblicken, müssen wir zwischen Grundriß und Aufbau unterscheiden. Unsere Westanlage umfaßt im Grundriß die Apsis, den rechteckigen Vorchor, die Seitenräume und zwei auf der Achse der letzteren stehende runde Treppentürme. Dieselben Bauteile sowohl der Zahl als der Bestimmung nach finden wir im Westen des Trierer und im Osten des Mainzer Domes. Die reichste Ausbildung, die diesen Räumen am Westbau je zuteil wurde, zeigt St. Michael in Hildesheim. Um einen Grad entfernter verwandt von unserem Westbau ist derjenige der alten Paulinuskirche bei Trier ${ }^{108}$ ), der Abteikirche in Limburg a. d. Haardt und der Mi.

107) Siehe Maria Laach und die Kunst, Abb, 21, Paradies mit der Westfront der Kirche.

$\left.{ }^{108}\right)$ E. Renard, die Zerstörung der Kirchen St. Maximin und St. Paulin bei Trier durch die Franzosen im Jahre 1674 , in: Mitteilungen des Rheinischen Vereins für Denkmalpflege und Heimatschutz, Jahrg. 8, Heft 3 , S. $230-40$. 
chaelskirche auf dem Heiligenberg bei Heidelberg ${ }^{109}$ ). Hier ist an die Stelle des Westchores eine diesem Raume entsprechende Vorhalle getreten. Es ließe sich demnach in Bezug auf die Grundrißanordnung unseres Westbaues folgende Verwandtschaftsreihe in zwei Graden aufstellen: Trierer Dom, Mainzer Dom, St. Michael in Hildesheim: erster Grad; St. Paulin in Trier, Limburg a. d. Haardt, St. Michael auf dem Heiligenberg: zweiter Grad.

Anders gestalten sich diese beiden Gruppen, wenn wir den Aufbau in Betracht ziehen. Im Äußeren zeigt unsere Kirche eine dreitürmige Westfront, einen Hauptturm von der Breite des Mittelschiffes über dem Querbau zwischen den Treppentürmen. Mit dieser Anordnung gingen ihr der Mainzer Dom und St. Michael in Hildesheim voraus $\left.{ }^{10}\right)$. Dagegen sind der Trierer Dom, St. Paulin und Limburg mit vier Westtürmen versehen. An die Stelle des einen Hauptturmes über dem Mittelschiff treten zwei andere über den Seitenräumen.

Mit der Verschmelzung von Westchor und Westwerk im Innern aber steht unser Münster in diesem Denkmälerkreise ganz allein. Überhaupt ist diese Verbindung leicht begreiflich selten. Vor der Laacher Gründung begegnet sie meines Wissens nur einmal an dem sehr originellen Westbau der Abteikirche von Hersfeld $\left.{ }^{\mathrm{II}}\right)$. Hier haben die Westanlagen, Vorhalle, Chor und Empore, den kürzesten architektonischen Ausdruck gefunden ${ }^{112}$ ). Ein späteres Beispiel bietet St. Godehard in Hildesheim, 1172 vollendet ${ }^{113}$ ). Über den Zweck unseres Westchores und der geräumigen, $19 \mathrm{~m}$ langen, in der Apsis $10 \mathrm{~m}$ und sonst $5 \mathrm{~m}$ breiten Empore besitzen wir leider keine historischen Nachrichten. Hundert Jahre nach der Gründung stand im Westchor der Altar des hl. Martin ${ }^{114}$ ). Das schöne Grabdenkmal des Stifters mit dem Baldachin wurde erst im Jahre 1695 aus der Mitte des Langhauses hierhin versetzt 115).

Bei der Rekonstruktion der vermeintlich geplanten Laacher Säulenbasilika hat Huppertz auch dem Westchore eine gründliche Verbesserung zuteil werden lassen, so daß von dem wirklich ausgeführten Deckenwerk der Kirche nur die zwei rechteckigen Gewölbe vor den Westportalen übrig bleiben.

rog) Meyer-Schwartau, Der Dom zu Speier, S. 2 ff. und Taf. 31 ; Huppertz, a. a. O. S. 49 ff. Die von letzterem gegebene Rekonstruktion des Mainzer Ostbaues, Taf. 11, dürfte in Bezug auf den Raum vor der Apsis schwerlich bei jemand Zustimmung finden. Wo ist denn in der deutschen Architekturgeschichte ein Ostchor bekannt, das mit sechs Saulen bepflanzt war?

1ro) Die im Jahre 1674 von den Franzosen zerstörte große Abteikirche von St. Maximin hatte nach den Stichen des P. Claudius Anthoni ebenfalls einen mächtigen Westturm von der Breite des Mittelschiffes, der auf der Empore mit einem Altare zu Ehren des hl. Michael versehen war. S. Renard, a. a. O., und die dort angeführten weiteren Quellen.

iii) Nach Meyer-Schwartau sind die Westteile zeitlich im unmittelbaren Anschluß an den Ostbau 1038 anzusetzen, A. a. O. S, 10.

ix) Dehio u. v. Bezold, Atlas, Taf. 48 und 55 .

ri3) Dehio u. v. Bezold, Atlas, Taf. 52 .

114) Dedicationes monasterii Lacencis, Mon. Germ. SS. $15^{2}$, S. $970-71$.

1x5) Siehe Maria Laach und die Kunst, S. $3^{8}-39$ und Abb. 35 . 

gewesen. Diese Anlage ist aber nur möglich, wenn der Mittelraum von den Seitenräumen durch Mauern getrennt wird. Auch diese nimmt Huppertz an, setzt sich aber dadurch in Widerspruch mit unumstößlichen, auch von ihm ausdrücklich verteidigten Tatsachen $\left.{ }^{116}\right)$. Die Westapsis schließt an den Ecken mit mächtigen Pfeilern $a b$, die in weißem Kalkstein ausgeführt sind und ganz sicher wie der ersten Bauzeit so auch dem ersten Bauplane angehören. Sie fordern unabweislich die gegenüberstehenden Freipfeiler, denen ihrerseits in den Seitenschiffen wieder Wandpfeiler entsprechen. Diese zeigen ebenfalls fast bis zum Kämpfer den weißen Kalkstein. Darin ist schon die ganze heutige Anlage des Westchores vorgebildet. Demgemäß waren von Anfang an zwischen dem Mittelraum und den Seitenräumen des Westchores die großen Bogen geplant, die wir auch jetzt da finden. Damit stürzen aber die Mauern, die Huppertz an ihre Stelle im ersten Plane setzen möchte, zusammen, und mit ihnen fällt die ganze oben beschriebene Konstruktion.

Ihr Urheber gesteht selbst ein, warum er sie unternommen, obschon ihm die Aussichtslosigkeit auf Erfolg nicht verborgen sein konnte. Die Mehrteilung des Westchores paßt sich besser, so schreibt er S. 90, den kleinen Arkaden einer Säulenbasilika an, während die zweiteilige Gliederung den jetzigen großen Mittelschiffsbogen entspricht. Das ist unzweifelhaft richtig. Da nun die Teile, die wir vom ursprünglichen Plan kennen, nur mit der heutigen Anlage des Westchores vereinbar sind, so muß Huppertz selbst zugeben, daß darin ein deutlicher Hinweis auf das Gewölbesystem des Langhauses enthalten ist. Derselbe fällt um so schwerer ins Gewicht, als seinerseits auch das Langhaus, wie wir früher gesehen haben, in der Zehnteilung durch Doppellisenen die Anpassung an das System der Laacher Steindecke unleugbar erkennen läßt.

Um die unbegreifliche, spätere Verleugnung der früher angenommenen Ergebnisse im Westchore zu vermeiden, hätte der erwähnte Verfasser besser getan, seinem Vorgänger in der Verteidigung des Laacher Langhauses als ursprünglich geplanten Säulenbaues, Fr. J. Schmitt, auch in Bezug auf das Westchor zu folgen. Derselbe vereinigt die heutige Anlage des Westchores mit flacher Decke im Langhause ${ }^{117}$ ). Daran hinderte aber Huppertz unter anderem das verlockende Unternehmen, den wieder entdeckt geglaubten Urplan unserer Kirche in wichtigen Punkten auf die Abteikirche von Limburg a. d. Haardt zurückzuführen. Wie diese im Langhause die Elfteilung und in der westlichen Vorhalle die Dreiteilung aufweist, so sei auch anfangs der Laacher Grundriß gedacht gewesen. Nun habe ich aber im vierten Kapitel den Beweis erbracht, daß die Übertragung der Limburger Elfteilung auf unsere Kirche unzulässig ist.

Erwägen wir zudem noch folgende Gründe. Die großzügige, dreifache Bogenstellung am Eingang zum Westchor bringt den Rhythmus des Mittelschiffes in

166) Vgl. Huppertz, a. a. O. Taf. XI, 6 mit Taf. III u. V, Text S. 43-44.

117) Vgl. die Zeitschrift: Die Christl. Kunst, 1907-8, S. 2. 
einem gewaltigen Schlußakkord zum Ausklang. Sie ist künstlerisch sozusagen unzertrennlich von den großen Bogen des Langhauses. Selbst die ursprünglich gedachte Bekrönung dieser Bogenstellung scheint mir einen Hinweis auf den Gewölbeplan des Langhauses zu enthalten. Der jetzige Abschluß mit der Emporenbrüstung wirkt unbefriedigend, weil die untere Partie so reich gegliedert ist, die obere dagegen jeder Gliederung entbehrt und infolgedessen wie eine große Leere empfunden wird. So war die Lösung ursprünglich nicht gedacht. Das können wir aus dem jetzigen Zustande noch deutlich ersehen. Auf der Brüstung der Enpore stehen an den Eckpfeilern zwei Bauglieder. Das eine dient dem großen Scheidbogen als Stütze, das andere davorstehende entbehrt jeder architektonischen Aufgabe. Der Zweck des letzteren kann unmöglich ein ästhetischer sein, weil unter den jetzigen Bedingungen das Gegenteil erreicht wird. Wer sich auf der Empore befindet, sieht unter einem $1,20 \mathrm{~m}$ breiten Bogen einen $75 \mathrm{~cm}$ breiten Dienst. Erst nach längerem Überlegen erkennt man die dem großen Bogen entsprechende Stütze hinter dem vorgelagerten, funktionslosen Dienst. Aber auch nach dieser Erkenntnis bleibt der Anblick dieses Eckpfeilers verwirrend. Abb. 34.

Betrachten wir die Emporenanlagen der Grabkapelle des hl. Lutwin in Mettlach, der Kirchen in Limburg a. d. Haardt, St. Maria im Kapitol und St. Ursula in Köln, Gernrode, in der Frankenberger Kirche bei Goslar, so wird uns bald klar, daß, wie an den genannten Bauten, so auch auf der Brüstung unserer Empore eine dreifache Arkade geplant war. Sie sollte an den Eckpfeilern auf den jetzt funktionslosen Diensten und in der Mitte auf zwei Säulchen stehen. Fassen wir nun den Querschnitt der Kirche vor dem Westchor ins Auge, so ergibt sich mit dieser Ergänzung eine wirkungsvolle, doppelte Steigerung von Bogen und Linien (Abb. 35). Die Abseiten und die Durchgänge zum Chor bilden vier gleich große Arkaden, die nit dem mittleren kräftigen Blendbogen einen ersten Aufschwung nehmen. Nun folgt in bester Proportion ein zweiter. Die untere Partie bildet den Maior der nach dem Goldenen Schnitt geteilten Gesamthöhe. Unten zwei große, oben drei kleinere Bogen je in der Umrahmung eines größeren von der Spannung der Mittelschiffsbreite. Fürwahr ein Aufbau voll Größe und Schönheit! Wer wollte nicht bedauern, daß die Ausführung in der Blüte erstickte? - Stellen wir jetzt die Frage, auf welches Deckenwerk der obere Abschluß dieses Aufbaues am ehesten hinweist, so muß die Entscheidung wieder zugunsten der Gewölbe ausfallen.

$\mathrm{Zu}$ den kleineren Arkaden des Langhauses und des Westchores, wie Huppertz sie sich im ursprünglichen Plane denkt, waren nach seiner Annahme auch kleinere Fenster in der Westapsis vorgesehen. "Die Sohlbänke der jetzigen Fenster, so schreibt er S. 9I, sind nicht als solche eigens gehauen und eingemauert, sondern in die fertige Mauerschicht eingemeißelt worden. ...... Es waren demnach anfangs höher gelegene Sohlbänke, mithin auch wohl kleinere Öffnungen geplant «. Die ganze Ausführung gründet sich auf die Abschrägung der Sohlbank. Wie ist denn die Sohl- 
bank der ältesten, im ursprünglichen Zustand erhaltenen Fenster angelegt worden? Dieser Vergleich, den der erwähnte Verfasser unterlassen hat, gibt die beste Antwort auf die aufgeworfene Frage. Die Sohlbank der Fenster in der Ostwand des Querschiffes zeigt überhaupt keine Abschrägung; ebensowenig die des Fensters in der Westwand des nördlichen Querhausflügels. (S. Abb. 25.) Bei den anderen

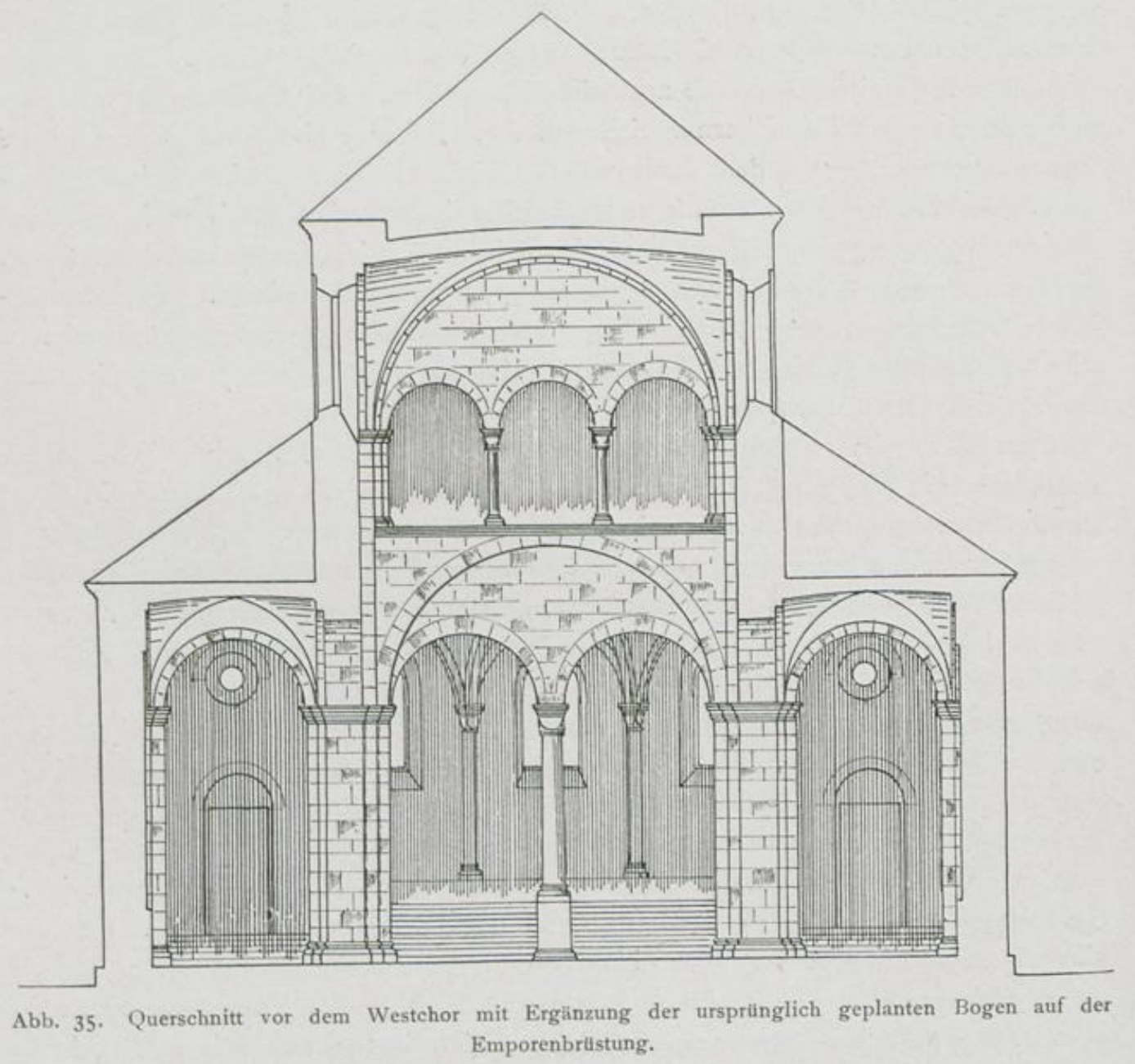

Fenstern ist nur die Kante der äußersten Quaderschicht ein wenig abgeschrägt ${ }^{118}$ ). Demnach ist anzunehmen, daß auch die unteren Fenster der Westapsis ursprünglich keine Abschrägung erhalten sollten. Wenn man später eine solche anbrachte, so läßt sich daraus nichts gegen die ursprünglich geplante Höhe der jetzigen Sohlbank ableiten. Vielmehr weist hierauf überzeugend die Tatsache hin, daß man gerade an dieser Stelle bei der Aufführung des Westbaues eine Pause eintreten lieB,

${ }^{n 18}$ ) S. Maria Laach und die Kunst, Abb. 11. 
wie die verschiedenen Baustoffe dartun. Zudem stimmt die Fensterhöhe der West. apsis genau mit derjenigen der Seitenschiffe überein.

Und warum soll man in der Westapsis zugunsten der jetzigen Fenster nicht dreikappige Gewölbe geplant haben? Die Einwölbung einer Krypta mit drei Fenstern in der Apsis hatte bekanntlich schon lange vorher und sehr oft dieselben Anforderungen an die Wölbekunst gestellt. Rechts und links vom mittleren, vierkappigen Gewölbe mußten in der Apsis zwei dreikappige Steindecken konstruiert werden. So auch in unserer Krypta. In der Westapsis brauchte somit der Laacher Baumeister nur dreimal das in etwas größerem Maßstabe zu wiederholen, was er in der Krypta zweimal geplant hatte.

Und wie hätte er denn sonst die Einwölbung vornehmen sollen? Entweder wie auf der Empore oder wie in der Ostapsis. Das Kugelgewölbe mit Stichkappen auf der Empore muß aber Huppertz folgerichtig für das Erdgeschoß noch mehr ablehnen als die dreikappigen Steindecken, weil es diese an Vollkommenheit übertrifft. Auch der Laacher Meister hat es aus guten Gründen nicht gewählt. Die großen Bogen, von der Spannung der Mittelschiffsbreite, die sich aus dem Kugelgewölbe ergeben, wie die Empore zeigt, gehen garnicht mit den Arkaden des Langhauses zusammen, während die gegenwärtigen Doppelbogen auf einer Mittelsäule vorzüg. lich zum Rhythmus des Langhauses stimmen.

Es bleibt also noch das Kugelgewölbe ohne Stichkappen, wie die Hauptapsis es zeigt. Konstruiert man aber ein solches in die Mitte der Gesamthöhe des Westchores hinein, so reicht die Koncha bis auf die Sohlbank der jetzigen Fenster herunter. Wäre diese Einwölbung beabsichtigt gewesen, dann hätten die Lichtöffnungen der Apsis bedeutend tiefer als jetzt, und nicht höher, wie Huppertz schreibt, angesetzt werden müssen. Überhaupt wäre in diesem Falle das Westchor ganz anders angelegt worden. Statt den Boden zehn Stufen über die Bodenhöhe des Langhauses zu erheben, hätte man denselben, wie in St. Godehard in Hildesheim, fünf Stufen tiefer als das Schiff legen müssen ${ }^{119}$ ). Diese letztere Lösung würde aber noch viel ungünstiger wirken als die erstere. Das Westchor erhielte dadurch das Gepräge einer Art Krypta, während es sich jetzt wie das Ostchor zehn Stufen erheben und überdies von seiner Lichtfülle den dunkleren Seitenräumen mitteilen kann. Wie in der ganzen Kirche, so gelangt auch hier eine gründliche Untersuchung dazu die Einheit des Planes festzustellen. Vor anderen Westchoranlagen besitzt die Laacher hohe Vorzüge in der gehobenen Bodenfläche, der reichlichen Beleuchtung des Chores und vor allem in der vorzüglichen Anpassung an das Langhaus.

Nach dem Grundriß, Taf. III, nimmt Huppertz an, daß die Türgewände der beiden westlichen Portale gleichzeitig mit dem Paradies erneuert wurden. In der Baubeschreibung sagt er, S. 44: von den Seitenräumen des Westbaues» führen kleine Türen, deren Wände und Sturz wie der Wandsockel aus rötlicher Lavaschlacke

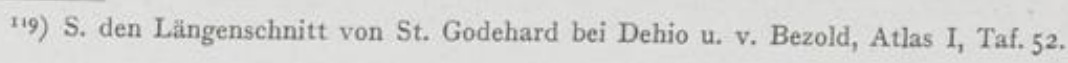


bestehen in die runden Türme; größere Portale, Wände und Sturz ebenfalls aus Lavaschlacke, in die Gänge des anstoßenden Paradieses ". Von dem, was hier über die Kirchenportale behauptet wird, ist weder das erstere noch das letztere richtig. Ebensowenig stimmt die Beschreibung der Türen, welche in die Treppentürme führen. Die Wände dieser Türen bestehen wie der Sockel des Westbaues aus der grobkörnigen Augitlava des Laacher Veitskopfes. Dagegen sind die Gewände der

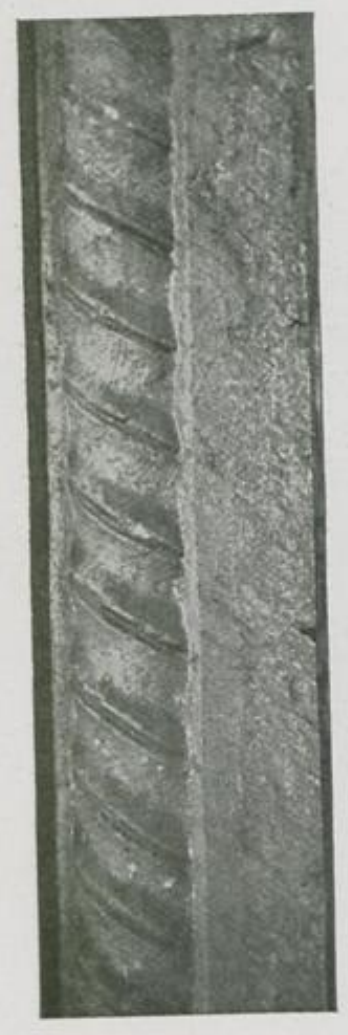

Abb. 36 . Gewinde an der Einfassung des südlichen Kirchenportales. Kirchenportale bis zum Sturz in dem weißen Kalkstein ausgeführt, der auch sonst am Westbau und am Querschiff auftritt. Durch dieses Material sowie durch den an demselben auftretenden Randschlag ist die Datierung des bemerkenswerten Gewindes an der südlichen Türeinfassung für das Ende des II. Jahrhunderts gesichert. (Siehe Abb. $36^{120}$ ).

Das Nordportal zeigt über dem geraden, aus einer Augitlavaquader bestehenden Sturze im Bogenfeld ein kleines, mosaikartiges Buntmauerwerk. Es sind 26 quadratische Steinchen von $12 \mathrm{~cm}$ Seitenlänge, die abwechselnd aus weißem Kalkstein und rotem Sandstein bestehen und drei horizontale Schichten bilden. (Abb. 37). Wie weit dieses interessante Stück beim Anbau des Paradieses verkleinert wurde, ließ sich nicht feststellen. Ähnliches Buntmauerwerk in weißen und roten Steinen schmückt bekanntlich die Felder der großen Blendbogen über den Türen des Westchores des Trierer Domes und die ganze Fassade der fränkischen Torhalle in Lorsch ${ }^{\mathrm{r} 2 \mathrm{r}}$ ). Nur sind in Trier die Steine ziegelförmig und in Stufenreihen übereinander geordnet; die LorscheVorhalle bringt verschiedene Zusammensetzungen in Ans wendung. Weitere Beispiele dieser Mauermosaik sind meiner Wissens in Deutschland nicht bekannt geworden.

Die ersten Jahrzehnte der Laacher Klostergeschichte sind in den vorstehenden Ausführungen klargelegt worden. Die Bautätigkeit am Kloster und an der Kirche, die damit zusammenhängt, vollzog sich unter der einheitlichen Leitung der Mönche von St. Maximin bei Trier, welche die Gründung besiedelten. Nach dem Tode der beiden Stifter, Heinrichs (1095) und Adelheids (I IOO), stand das Querschiff, abgesehen von den Gewölben, kurz vor der Vollendung. Das Langhaus war mit dem Westchor bis zur Schließung der Scheidbogen des Mittelschiffes angelangt.

120) Eine ähnliche Einfassung aus sgewundenen Rundstäben, findet sich am Portal des Westturmes der um das Jahr tooo gegründeten Klosterkirche zu Zyfflich am Niederrhein. Clemen, Kunstd. d. Rhprvz. Kr. Kleve, S. 158, Abb. 84 .

las ,II Taf. 278,1 u. 213,1 ; u. Adamy, Die fränkische Torhalle, Darm. stadt, 1891 . 
Da der Erbe der Stifter, Pfalzgraf Siegfried, sich um die Fortsetzung nicht kümmerte, ruhte der Bau, bis die Mönche in der Lage waren, aus eigenen Mitteln die Weiterführung zu betreiben. Die Einheit des Kirchenplanes, die bis vor zehn Jahren allgemein angenommen wurde und sich auch in allen Teilen dem vorurteilsfreien Forscher aufdrängt, ist durch diese Feststellungen endgültig gesichert.

Freilich erhebt das Gewölbesystem des Langhauses die Kirche für Deutschland in die Reihe der Schöpfungsbauten. Dieser Vorzug wird verständlicher, wenn wir die Zeitumstände in Betracht ziehen. Die rheinische Baukunst hatte am Ende des II. Jahrhunderts unseres Wissens noch keine Erfahrungen in der Überwölbung des Mittelschiffes aufzuweisen. Man war daher im Entwerfen freier und kühner.

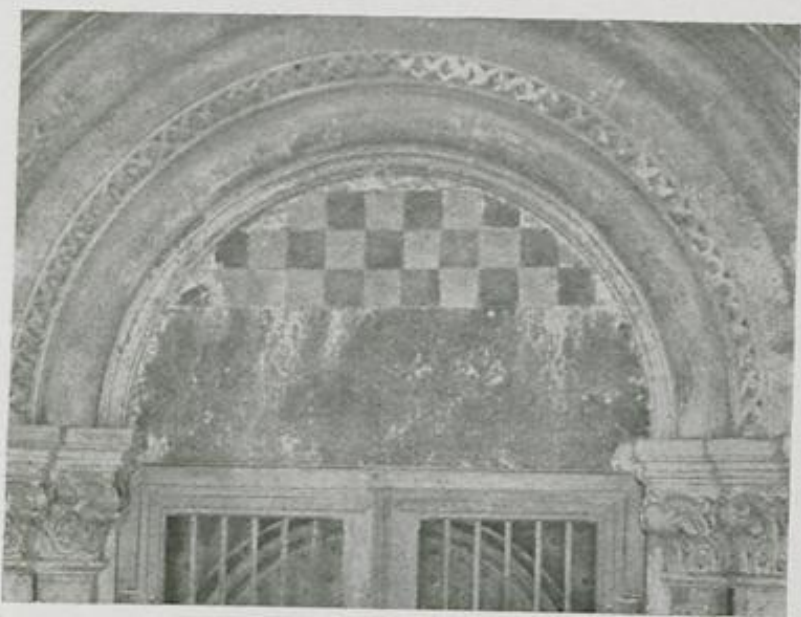

Abb. 37. Mosaikartiges Buntmauerwerk im Bogenfeld des nördlichen Kirchenportales.

Das zeigt die baukünstlerische Tat, die sich seit 1085 am Speierer Dom vollzog. Sie konnte einen so hervorragenden Meister, wie der Laacher sich sowohl in der Gesamtanlage seines Werkes als in der Beherrschung der Technik zu erkennen gibt, wohl zu seiner Schöpfung veranlassen. Zudem beweist das gleichzeitig oder wenig später begonnene Langhaus des Mainzer Domes, daß man sich bei der Eindeckung des Mittelschiffes mit rechteckigen Gewölben viel mehr zutraute, als in unserem Falle erfordert war. Es ist daher vergebliche Mühe, dem Laacher Münster den vornehmsten Platz neben den Erstlingen des deutschromanischen Gewölbebaues, den Domen in Speier und Mainz, und der rheinischen Baukunst eine ihrer originellsten Schöpfungen streitig machen zu wollen ${ }^{122}$ ).

122) Dem Leser meiner Darlegungen möchte ich empfehlen, sich zur Ergötzung die von Irrtïmern wimmelnden Ausführungen E. Male's uber unsere Kirche anzusehen. (Monatshefte fur Kunstwissenschaft, Heft 12 (1916), S. 441-42). Er wird dann an einem sprechenden Beispiele erkennen, wie es um das Wissen und die Unparteilichkeit dieses französischen Gelehrten steht, dem es vorbehalten blieb, allen Ernstes den Beweis zu versuchen, da $B$ dem germanischen Geiste jede künstlerische Erfindungsgabe und der deutschen Kunstforschung alle Ehrlichkeit abgehe. Studien uber die deutsche Kunst, a. a. O. Heft 11 u. 12 (1916), Heft 2 u. 3 (1917). 
INHALT.

1. Gründung . . . . . . . . . . . . . . . . . . . . 1-9

2. Bau des Klosters und der Kirche bis zum Tode Pfalzgraf Heinrichs (1095) $9^{-15}$

3. Ausbau des Querschiffes .................... . . . ${ }_{15}{ }^{-} 3^{8}$

4. Das Langhaus und sein Gewölbesystem . . . . . . . . . . . . . . $3^{8}-56$

5. Welche Decke war für das Querschiff und das Ostchor geplant? . . . . 56-65

6. Der Westbau . . . . . . . . . . . . . . . . . . 65-73 



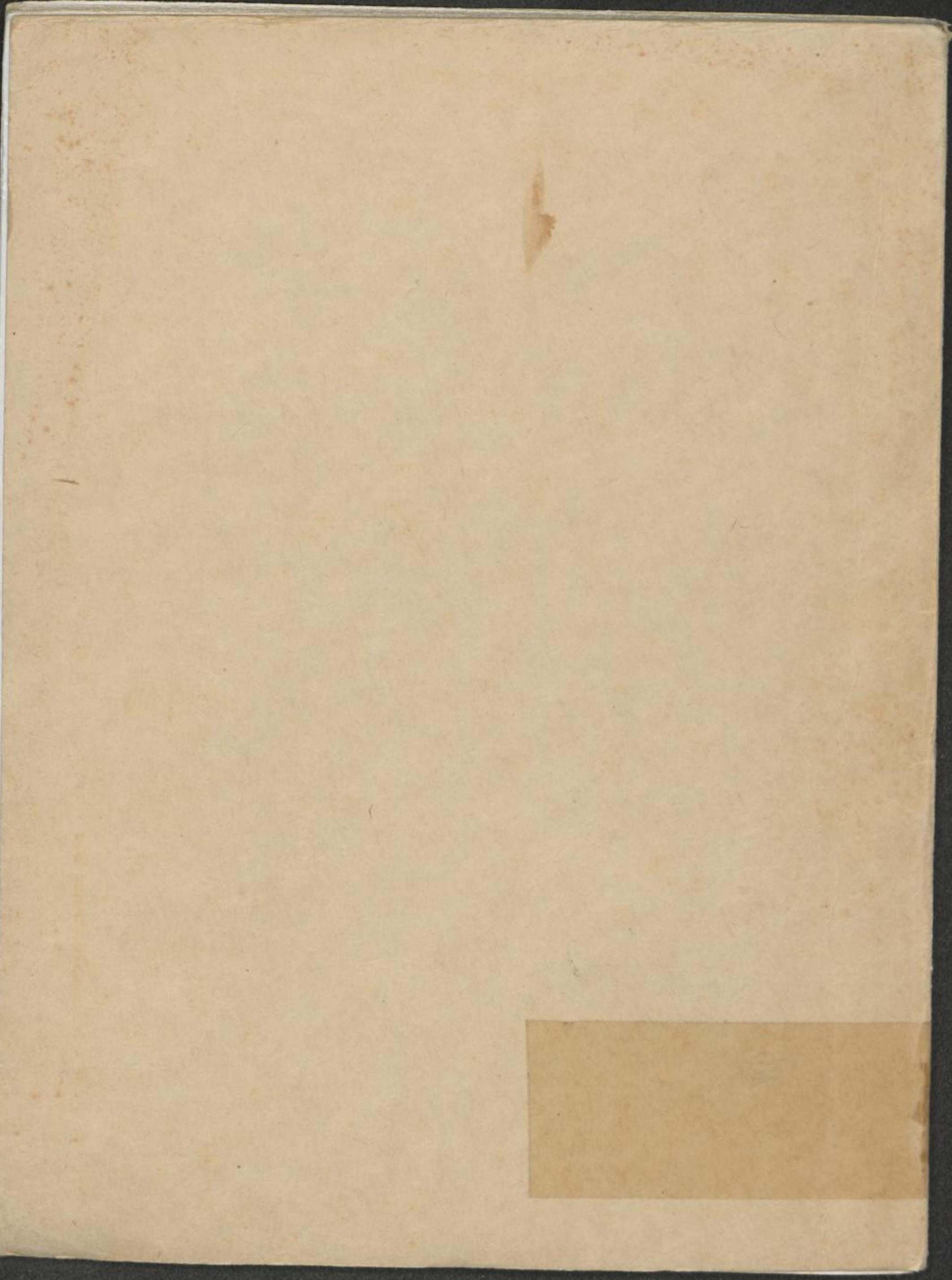

